\title{
Children's memory: treasure or teachery of the mind?
}

Citation for published version (APA):

Otgaar, H. P. (2009). Children's memory: treasure or teachery of the mind? [Doctoral Thesis, Maastricht University]. Datawyse / Universitaire Pers Maastricht. https://doi.org/10.26481/dis.20090913ho

Document status and date:

Published: 01/01/2009

DOI:

10.26481/dis.20090913ho

Document Version:

Publisher's PDF, also known as Version of record

\section{Please check the document version of this publication:}

- A submitted manuscript is the version of the article upon submission and before peer-review. There can be important differences between the submitted version and the official published version of record.

People interested in the research are advised to contact the author for the final version of the publication, or visit the DOI to the publisher's website.

- The final author version and the galley proof are versions of the publication after peer review.

- The final published version features the final layout of the paper including the volume, issue and page numbers.

Link to publication

\footnotetext{
General rights rights.

- You may freely distribute the URL identifying the publication in the public portal. please follow below link for the End User Agreement:

www.umlib.nl/taverne-license

Take down policy

If you believe that this document breaches copyright please contact us at:

repository@maastrichtuniversity.nl

providing details and we will investigate your claim.
}

Copyright and moral rights for the publications made accessible in the public portal are retained by the authors and/or other copyright owners and it is a condition of accessing publications that users recognise and abide by the legal requirements associated with these

- Users may download and print one copy of any publication from the public portal for the purpose of private study or research.

- You may not further distribute the material or use it for any profit-making activity or commercial gain

If the publication is distributed under the terms of Article $25 \mathrm{fa}$ of the Dutch Copyright Act, indicated by the "Taverne" license above, 


\section{Children's memory: Treasure or treachery of the mind?}

Precursors of children's false memories

PROEFSCHRIFT

ter verkrijging van de graad van doctor aan de Universiteit Maastricht, op gezag van de Rector Magnificus, Prof. mr. G.P.M.F. Mols volgens het besluit van het College van Decanen, in het openbaar te verdedigen op vrijdag 13 november 2009 om 14.00 uur

door

Henry Philippe Otgaar

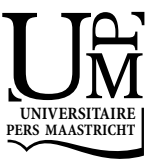




\section{Promotor:}

Prof. dr. H.L.G.J. Merckelbach

\section{Copromotor:}

Dr. I. Candel

\section{Beoordelingscommissie:}

Prof. dr. C. de Ruiter (voorzitter)

Prof. dr. P. van Koppen

Prof. dr. M. Peters

Prof. dr. A. Postma (Universiteit Utrecht)

Prof. mr. E. Rassin (Erasmus Universiteit Rotterdam)

The research presented in this dissertation was supported by the Netherlands Organization for Scientific Research (NWO, The Hague) grant number 400-05-015 awarded to Dr. I. Candel.

(C) Copyright H. Otgaar, Maastricht 2009

ISBN 9789052788739

Universitaire Pers Maastricht 


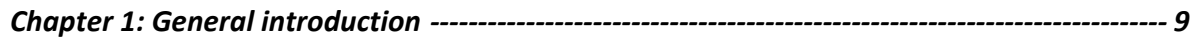

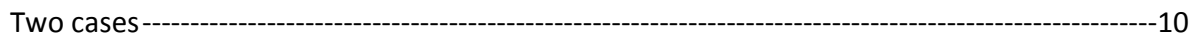

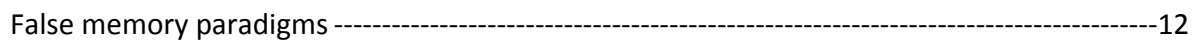

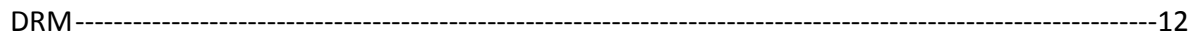

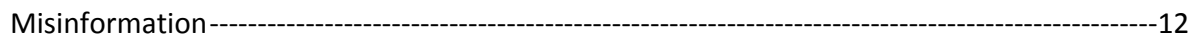

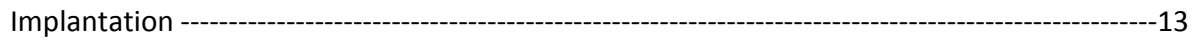

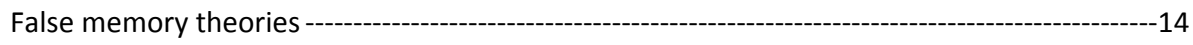

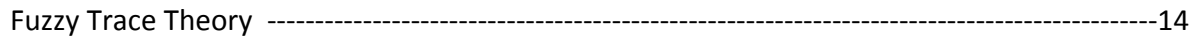

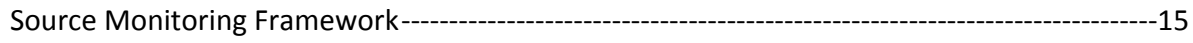

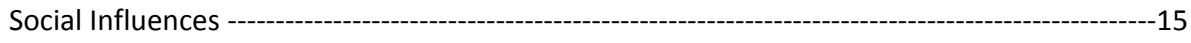

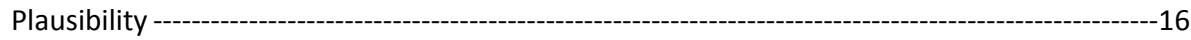

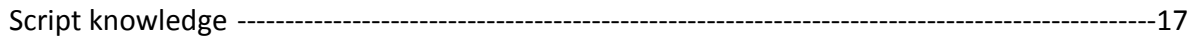

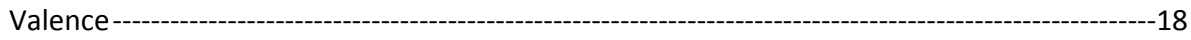

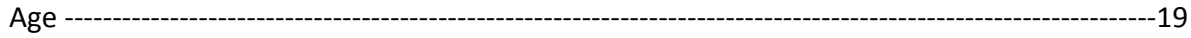

Outline of this dissertation ---on

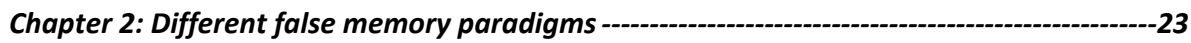

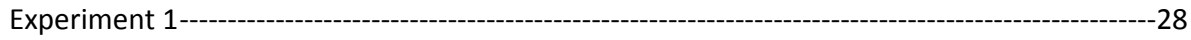

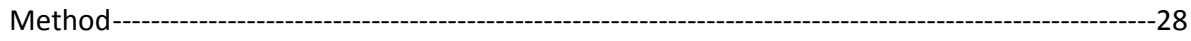

Results-----

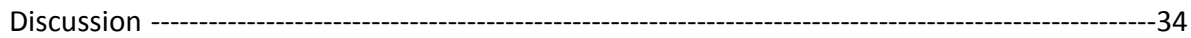

Experiment 2----------------------------------------------------------------------------------------------------35

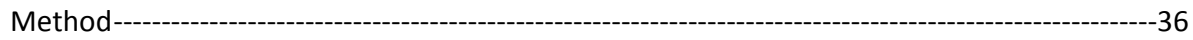

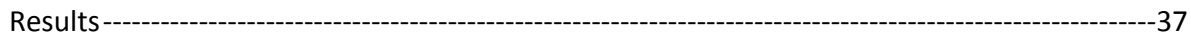

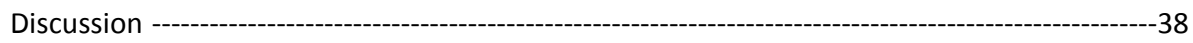

General Discussion ---

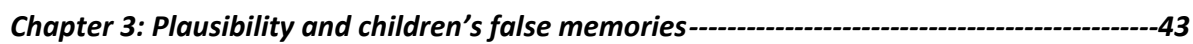

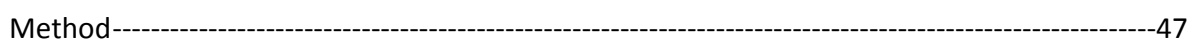

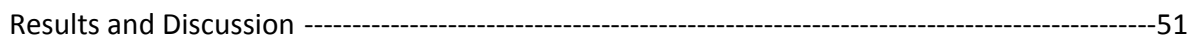

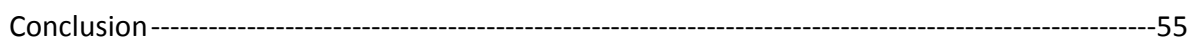

Chapter 4: Script knowledge and children's false memories ---

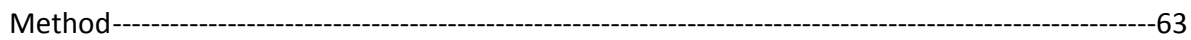




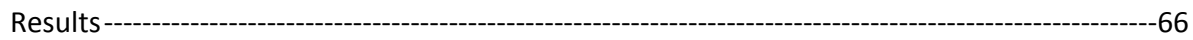

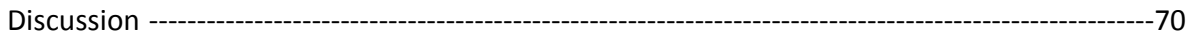

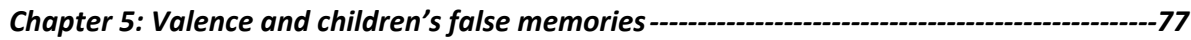

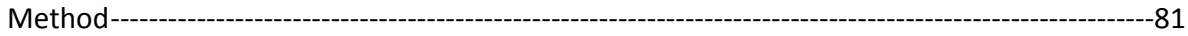

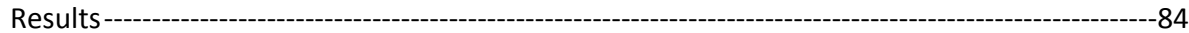

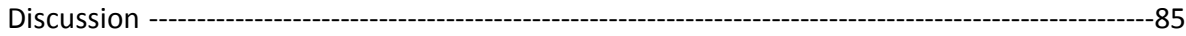

Chapter 6: Differentiating between children's true and false memories----------------------89

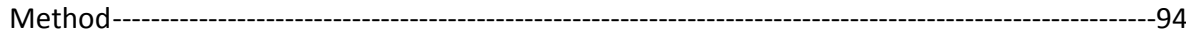

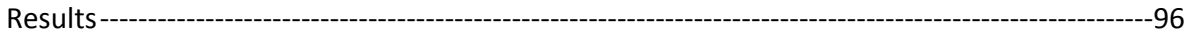

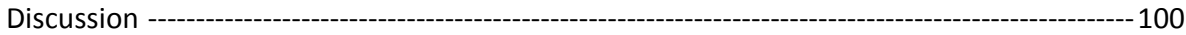

Chapter 7: Children's omission and commission errors -- 105

Method--------------------------------------------------------------------------------------------------------------- 110

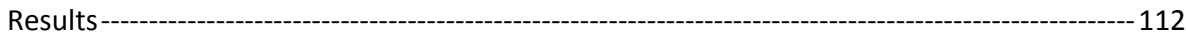

Discussion ---------115

Chapter 8: General discussion ---119

Different false memory paradigms ----_- 120

Event characteristics --- 122

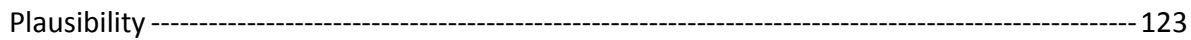

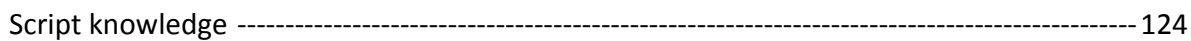

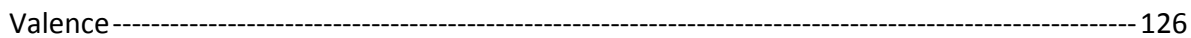

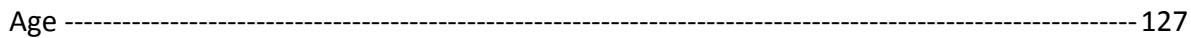

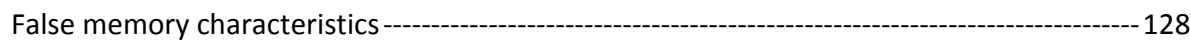

Compliance or memory distortion? -- 129

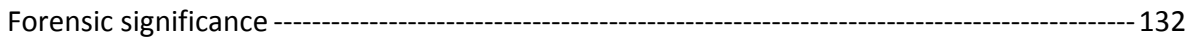

Future research avenues---- 135

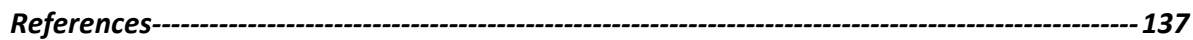

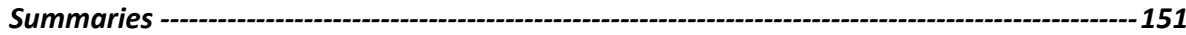

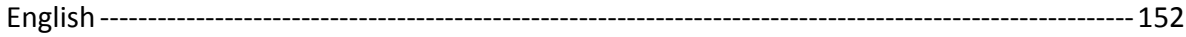

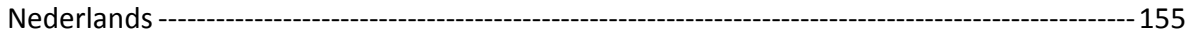

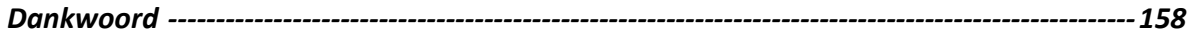


Curriculum vitae ---_-

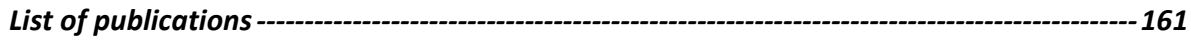



General introduction 


\section{Two cases}

"Heerle"

In April 2007, 20 children of an elementary school in Heerle, a village in the Netherlands, said to have been sexually abused by a 6- and 7-year-old boy. Presumably, these children had been forced to participate in sexual games. They stated that they had to put sticks and leaves into their own genital organs and that they had to perform oral sex. Yet, no (physical) evidence existed for the children's claims. The children's parents indicated that they had discussed these events with their children and that the children themselves spoke with other children about what supposedly had happened. Is it possible that these conversations had led children reporting a non-experienced event?

$H C^{2}$

On January $24^{\text {th }} 2007$, Mrs $\mathrm{N}$ reported to the police that her 14 -year-old mentally handicapped son $\mathrm{HC}$ had told her that he had been sexually abused by his father 7 years ago. For some years now, Mrs N. had been divorced from the father of HC. HC, for example, remembered that his father had handcuffed him during the abuse and that the father had videotaped the abuse. He also remembered that a boy from the neighborhood fired an iron pin from a crossbow which inflicted his mother's back. However, no evidence corroborated his accounts. Although HC had never spontaneously talked about the alleged abuse, his mother suspected nevertheless that he had been sexually abused by his father. Because of her suspicion, $\mathrm{HC}$ received therapy in which he first denied the traumatic events. His initial reports concerning the sexual abuse started during conversations with his mother and therapists which were predominantly characterized by suggestive questions (e.g., "Did your father videotape you during the abuse?"). Is it possible that the boy HC "remembered" an event he did not experience?

\footnotetext{
${ }^{1}$ See Otgaar, H., \& Candel, I. (2007). Herinneringen kleuters Heerle wellicht vals. Dagblad De Limburger.

${ }^{2}$ This is a Dutch court case that came to the attention of the author when he was consulted by the court-appointed expert witness in this case.
} 
With these cases in mind, the question arises whether children can be led to remember non-experienced events as the result of suggestive information. Among memory scholars, such erroneous recollections have also been dubbed false memories (Loftus, 1997). Although research (see Bidrose \& Goodman, 2000; Orbach \& Lamb, 1999) shows that children are highly accurate when they describe a traumatic event that they in fact experienced, a myriad of studies also shows that children are easily led into developing false memories (e.g., Pezdek \& Hodge, 1999; Strange, Sutherland, \& Garry, 2006). This research has traditionally been inspired by contentious legal proceedings in which children reported to have experienced traumatic events for which no corroborative evidence existed. For example, in the "Wee Care Nursery School" trial in New Jersey, 20 children reported being ritually abused by their teacher during a 7-month period. These children remembered some extremely unusual, implausible events such as being assaulted with Lego blocks or being forced to drink urine. Obviously, experts who interviewed these children about the alleged sexual abuse had to explore whether these memories referred to a fabricated or authentic experience. Transcripts of interviews with the children, however, revealed that they were suggestively interrogated, which potentially could have caused children falsely recollecting these events (see Ceci \& Bruck, 1993; 1995).

However, some clinicians (e.g., Faller, 1996; Summit, 1992) claim that children do not fabricate accounts of horrible events. These authors argue that when children describe a traumatic event, it must refer to an authentic experience even if the event is extremely bizarre and unusual (for a more detailed discussion see also Laney \& Loftus, 2005; Lindsay \& Read, 1995). For example, Summit (1988) asserts that the bizarre features of ritual sexual abuse argue for the credibility of children's statements. Furthermore, he argues that no scientific evidence exists showing that children make up stories to please interviewers. The Dutch physicians Jonker and Jonker-Bakker (1991, p. 194) even opined that "children are not more suggestible than adults" and that therefore "[i]t is important for child abuse professionals to be aware that the most bizarre stories may indicate the possibility of satanic rituals" (p. 196). It would be naïve to believe that cases such as the "Wee Care Nursery School" trial are confined to American or Canadian societies in the nineties. Two prominent cases in point are the "Outreau" case in France in 2001 and the "Rignano Flaminio" case in Italy in 2007 in which many children came to remember that they were sexually abused. Also, in these two cases, no evidence could support their statements. 
Clearly, children's false memories of sexual abuse can have dramatic consequences in legal settings. For example, in the "Wee Care Nursery School" trial, the alleged perpetrator was convicted due to children's inculpatory statements (Ceci \& Bruck, 1993). Therefore, legal cases motivated researchers to investigate to what extent and under what conditions children develop memories of non-existing events. To this end, researchers have invented different paradigms that intend to experimentally elicit these false memories. This chapter will present a short overview of these false memory paradigms, of false memory theories, and of antecedents that are likely to be involved in children's false memory formation.

\section{False memory paradigms}

DRM

One of the most well-known false memory paradigms is the Deese/RoedigerMcDermott (DRM) paradigm which was originally developed by Deese (1959) and revived by Roediger and McDermott (1995). In experiments using this paradigm, participants study word lists consisting of semantically related words (e.g., tiger, jungle, Africa, cage) that are thematically linked to a non-presented word, the critical lure (i.e., lion). Participants are instructed to memorize the words. Next, they are asked to recall and/or recognize these words. A robust finding is that participants have the tendency to falsely recall and recognize the critical lures. The false recall and recognition of critical lures is considered to be indicative for the development of a false memory.

The DRM paradigm is a meaning-based procedure in which false memories arise because the studied words share the same underlying theme, also called "gist" (Brainerd, Reyna, \& Ceci, 2008). That is, when people study these words, they repeatedly activate their joint semantic associative networks resulting in the false recall/recognition of the critical lure. Since children have less well-developed semantic networks than adults (Bjorklund, 2004), a reduced probability exists that critical lures will be activated and therefore children are less likely to erroneously report the critical lure than adults.

\section{Misinformation}

While false memories induced by the DRM paradigm typically develop spontaneously -i.e., due to internal associations-, false memories evoked by the 
misinformation paradigm evolve due to the acquiescence of suggestive information. A classical misinformation experiment involves three stages. First, participants are exposed to a certain scene (e.g., a man drinking a Coke). Then, they are given suggestive information (i.e., misinformation) about this event (e.g., a man drinking a Pepsi). Finally, participants are instructed to recall what they have seen. Studies have shown that about one-third of the participants is completely convinced having perceived the misinformation. This phenomenon is labeled the misinformation effect (Loftus, 2005).

In contrast to adult studies, children often participate in a live staged event during a misinformation experiment. In Pezdek and Roe's (1997) study, for instance, children were touched in a particular way or not touched at all. Then, they received misinformation about the incident. Results showed that children were easily led by this misinformation.

Implantation

The DRM- and misinformation paradigm are focused on false memories for details of experienced events (e.g., lion, a Coke). However, the crux of the implantation paradigm is to suggestively manipulate people into falsely recollecting entire events. More precisely, participants are confronted with false narratives and/or photographs suggesting that certain events happened to them in their childhood. Then, during multiple interviews, they are encouraged to report as much as they can remember about these events. Studies have shown that approximately $30 \%$ of the participants is absolutely confident having experienced the false event (see Lindsay, Hagen, Read, Wade, \& Garry, 2004). To give a classical example of such a study, Loftus and Pickrell (1995) presented adult participants with a false narrative describing that they had been lost in a shopping mall in their childhood. Across two interviews, participants had to report everything they could remember about the events. Results showed that a quarter $(n=6)$ of the participants falsely remembered being lost in a shopping center in their childhood. They reported additional details of the non-experienced event. Besides adult participants, also children have been subjected to these experimental manipulations (e.g., Pezdek, Finger, \& Hodge, 1997). Although this research is relatively sparse, results demonstrate that a non-trivial percentage of children concur to the suggestive manipulations and develop "memories" of entire fictitious events.

Since Loftus and Pickrell's work (1995), studies using the implantation paradigm have grown gradually and false memory researchers have succeeded to implant a wide variety of events including negative (i.e., receiving a rectal enema; Pezdek \& Hodge, 1999), 
implausible (i.e., drinking a cup of tea with Prince Charles; Strange et al., 2006), and bizarre (i.e., sitting on a dice; Thomas \& Loftus, 2002) events. Although these studies compellingly demonstrate that implanted false memories are fairly easy to engender, a more fundamental question arises. How it is possible that both adults and children can come to remember events that they did not experience? The next section describes three influential theories which explain how false memories arise.

\section{False memory theories}

\section{Fuzzy Trace Theory}

Fuzzy Trace Theory (FTT; Brainerd \& Reyna, 1998) assumes that people store two opponent representations of their experiences in their memory (Brainerd, Reyna, \& Forrest, 2002; Brainerd, Forrest, Karibian, \& Reyna, 2006). Specifically, one of these representations is called the verbatim trace, which captures the exact surface components of experiences (e.g., "seeing the movie "Cinderella", "ate popcorn"). The other representation, the gist trace, is involved in understanding the meaning of experiences (e.g., "going to the cinema"). When these two types of traces are retrieved, they work in opposite directions regarding the development of false memories. Retrieval of verbatim traces of true experiences results in suppressing false memories due to a phenomenon called recollection rejection (Brainerd, Reyna, Wright, \& Mojardin, 2003). This happens, for example, when people state they did not ate M\&M's because they vividly remember eating popcorn. Gist retrieval, however, supports the recollection of false events that share the same meaning with the original event. Then, people falsely remember seeing the movie "Snow White" and eating M\&M's (Brainerd et al., 2008).

Note that FTT predicts that the potential for false memory occurrence becomes greater when children become older since gist-memory abilities, which are involved in false memory responses, show a developmental increase with age. Research indicated indeed that connecting meaning across information is more restricted in younger children than in older children and adults (Bjorklund, 2004; Esposito, 1975). According to Brainerd and associates (2008), false memories are therefore less prevalent among younger than older children and adults. 
Source Monitoring Framework

The rationale behind the Source Monitoring Framework (SMF; Johnson, Hashtroudi, \& Lindsay, 1993) is that people make attributions concerning the sources of their memories, knowledge, and beliefs. Specifically, SMF holds that images, thought, and feelings of experienced events are assigned to particular sources of past experience. For instance, when you recollect a past experience about going with your friend to a museum, this recollection might contain information regarding the perceptual aspects of the event, your feelings at that time, and thoughts that you had about the museum. These aspects can be used as parameters to determine the sources of that recollection (Lindsay \& Johnson, 2000). The whole issue of source identification becomes important when, for example, a person remembers a certain detail about the museum, but starts to wonder whether he/she read it in the newspaper or saw it with his/her own eyes during the visit to the museum.

People can apply different strategies for discriminating between sources. For example, when people try to distinguish between memories of imaginations and memories of perceived events, internal-external source monitoring discriminations are required. SMF postulates that false memories emerge when people erroneously attribute internally generated sources to external sources (e.g., attributing recollections of imagining that you are going to the cinema to an authentic event; Lindsay, Johnson, \& Kwon, 1991; Lindsay \& Johnson, 2000).

As to age differences, studies show that mistaken internal-external source judgments are more likely to occur with younger children than with older children and adults (Foley, Santini, \& Sopasakis, 1989; Lindsay et al., 1991). Consequently, according to SMF, younger children are more prone to false memories than older children and adults.

\section{Social Influences}

According to this view, false memory occurrence is due to the social context in which events are recalled. Specifically, social processes as compliance may affect the way memories are altered (see Reysen, 2007; Wessel \& Moulds, 2008). Multiple studies have shown that when suggestive information is presented by a confederate (i.e., social contagion; Meade \& Roediger, 2002) or other participants (i.e., memory conformity; Gabbert, Memon, \& Wright, 2003), this information is extremely likely to be misremembered. As younger children are more likely to show compliant behavior towards other persons (e.g., parents, teachers, researchers) than older children and adults (Ceci \& Bruck, 1993; Gudjonsson, 1989; Richardson \& Kelly, 2004), younger children are more likely 
to accept erroneous information from others than older children and adults. While the above-stated theories provide an account of how false memories arise, specific antecedents have been linked to false memories. The following paragraphs describe potential antecedents that are involved in the development of false memories.

\section{Plausibility}

According to Pezdek and colleagues (1997; 2006b), three conditions need to be fulfilled before a non-existing event can be implanted into memory. First, a false event has to be perceived as plausible. Then, knowledge about the typical sequences of an event (i.e., script knowledge; Hudson, Fivush, \& Kuebli, 1992) will be triggered which supports constructing an image about the event. Finally, when this image is wrongfully ascribed to an authentic experience, a false memory develops. An assumption of this line of reasoning is that the level of plausibility of an event is associated with the amount of knowledge one possesses about the event. That is to say, people have more script knowledge about plausible than implausible events.

False memory studies concentrating on the role of event plausibility generally examined whether false memories are more readily implanted for a plausible than for an implausible event. Pezdek and colleagues (1997; 1999), for instance, showed that both children and adults were more likely to falsely recollect that they had been lost in a shopping mall (i.e., plausible event) than that they had received a rectal enema (i.e., implausible event). Although Pezdek et al.'s studies suggest that event plausibility boosts false memory development, Strange et al. (2006) recently found that event plausibility does not affect the development of children's false memories. In their study, children were as likely to develop a false memory for a plausible event (i.e., taking a ride on a hot air balloon ride) as they were for an implausible event (i.e., drinking a cup of tea with Prince Charles). However, the authors presented children with doctored photographs of the false events. Specifically, they exposed children with researcher-fabricated photographs depicting the children on a hot air balloon ride or drinking tea with Prince Charles. This powerful evidence could have elevated the perceived plausibility of the false events, thereby making them equally plausible. 


\section{Script knowledge}

Although Pezdek and colleagues' $(1997 ; 2006)$ idea about the preconditions and successive stages of false memories suggest that script knowledge plays a role in these stages, the evidence for this is limited. Studies (Hart \& Schooler, 2006; Pezdek et al., 2006; Scoboria, Mazzoni, Kirsch, \& Jiminez, 2006) have examined whether script knowledge would impact false beliefs (i.e., believing that a particular event occurred), yet these results are not encouraging. Only one study has found that script knowledge enhances the belief in a fictitious event (see Pezdek et al., 2006). In this study, adult participants were instructed to rate the likelihood that certain events happened to them before and after they received script knowledge about these events. Script knowledge only increased belief ratings when the event was situated in a familiar context (i.e., situated at home).

Although studies have examined whether script knowledge affects false beliefs, studies examining the impact of script knowledge on false memory formation are extremely rare. Researchers have recently stressed the importance in distinguishing beliefs from memory (Scoboria, Mazzoni, Kirsch, \& Relyea, 2004; Smeets, Merckelbach, Horselenberg, \& Jelicic, 2005). Beliefs, then, refer to when person come to believe that a certain event has been experienced. However, when someone believes in the occurrence of an event, but also has a vivid phenomenal episodic recollection of it, then this can be denoted as a memory.

To the best of our knowledge, only Pezdek and colleagues (1997; 1999) demonstrated that adults and children are more likely to develop false memories for events of which they have knowledge (i.e., lost in shopping mall) than for events with which they are not familiar (i.e., receiving a rectal enema). The authors assumed that plausibility and script knowledge were highly interrelated constructs. However, given the fact that Scoboria and colleagues (2004) did not find any relation between script knowledge and plausibility, it remains to be seen if and how script knowledge affects false memory development for entire events ${ }^{3}$.

\footnotetext{
${ }^{3}$ In Scoboria et al's (2004) study, students had to rate the plausibility, belief, and memory of ten possible childhood events. Furthermore, for each of these events, they were instructed to write down the way these events typically proceed for a person before the age of 6 (i.e., script knowledge).
} 


\section{Valence}

Altogether, research concentrating on possible antecedents (i.e., plausibility, script knowledge) of implanted false memories has revealed varied results. One potential confounding factor that may have contributed to these mixed results is valence (i.e., emotional aspect of an event). Since legal cases are mainly about negative events, studying the role of valence in the development of false memories has practical relevance.

False memory research has employed a wide variety of valenced events ranging from emotional positive to emotional negative events. To give some examples, Ceci, Loftus, Leichtman, and Bruck (1994) provided their child participants with false descriptions suggesting that they fell off a tricycle (emotional negative) or that they took a hot air balloon ride (emotional positive). Children more easily accepted the fictitious positive event as a genuine experience than the negative event. Hyman, Husband, and Billings (1995) encouraged their adult participants to come up with information that they had been hospitalized (emotional negative) or had had as a child a birthday party with pizza and a clown (emotional positive). In contrast with Ceci et al's findings, false memory rates for both classes of events were similar. Furthermore, in a study by Porter, Spencer, and Birt (2003), adult participants viewed highly positive, neutral, or negative scenes and were asked misleading questions about them. They found that participants more likely endorsed the misleading questions when they were confronted with the negative scene than with the neutral or positive scene.

Besides studies relying on the implantation method, DRM studies have examined whether valence affects false memory formation. Recently, Howe (2007) and Howe, Candel, Otgaar, Malone, and Wimmer (2008) found that children and adults falsely recognized more negative than neutral lures. Furthermore, Brainerd, Stein, Silveira, Rohenkohl, and Reyna (2008) showed that valence and memory falsification interact such that false memories are more prevalent for negative material, intermediate for neutral material, and less for positive material.

Interestingly, these DRM findings are well driven by the FTT (Brainerd \& Reyna, 2005). The FTT postulates that gist representations are often implicated in processing negative valence (see for an overview Rivers, Reyna, \& Mills, 2008). From this perspective, one would expect to find emotional negative material to be more susceptible for memory distortion than either neutral or positive material. Recent false memory studies have 
confirmed this prediction indicating that emotional negative material is more likely to be erroneously recollected than positive and neutral material (Porter, Bellhouse, McDougall, ten Brinke, \& Wilson, under review; Porter, Taylor, \& ten Brinke, 2008).

\section{Age}

Not only event characteristics like event plausibility and valence seem to have an effect on false memory creation, also individual characteristics such as age have a robust impact on false memory development. Over the past decades, age has been regarded as one of the most important predictors for the occurrence of false memories. Typically, findings illustrate that younger children more easily accept and internalize suggestive manipulations (e.g., fictitious narratives) and are therefore more likely to develop false memories than older children and adults (e.g., Ceci \& Bruck, 1993; Ceci, Ross, \& Toglia, 1987; Pezdek \& Hodge, 1999; Saywitz, 1990; Strange et al., 2006; Sutherland \& Hayne, 2001).

At least three explanations may account for the age-related decline in the acceptance of suggestive information. To begin with, maturing source monitoring abilities appear to be related to the developmental decline of false memories (Lindsay et al., 1991; for an overview see Roberts \& Blades, 2000). As younger children experience more difficulties in discriminating between genuine and fabricated events than older children and adults, they are also more at risk for the development of false memories (see Johnson, Hashtroudi, \& Lindsay, 1993).

Second, the age-related decrease in suggestibility may reflect developmental changes in cognitive and social abilities (Ceci \& Bruck, 1993). Numerous studies show that younger children are more likely to yield to suggestive information provided by authoritative figures than older children and adults (e.g., Ceci et al., 1987; Lampinen \& Smith, 1995). Third, the developmental decline in suggestibility may also be related to developmental differences in memory trace integrity (e.g., Brainerd \& Reyna, 1988; Ceci, Toglia, \& Ross, 1988; Pezdek \& Roe, 1995. According to this view, younger children have weak memory traces of events which would make them more vulnerable for suggestive information than older children and adults (Brainerd \& Reyna, 1988; Ceci et al., 1987; but see Reyna \& Kiernan, 1994; Rovee-Collier, 1995). 
Of note, the finding that younger children more readily develop false memories than older children and adults stands in stark contrast with what DRM research shows (see Brainerd et al., 2008). Generally, DRM studies show an age-related increase in false memory rates (Brainerd \& Reyna, 2002; Sugrue \& Hayne, 2006; but see Ghetti, Qin, \& Goodman, 2002). This finding is consistent with FTT predictions regarding the developmental trajectory of false memories (Brainerd et al., 2008). According to FTT, younger children are less likely to extract gist-related information resulting in reduced susceptibility to develop false memories compared to older children and adults, at least within the context of the DRM paradigm..

Summing up, some potential key determinants (i.e., plausibility, script knowledge, valence, age) have emerged out of false memory research that may play a vital role in false memory development. Gaining more insight in these factors would deepen our knowledge about children's susceptibility for developing false memories. However, as already described, it remains to be seen how these factors individually might strengthen or decline false memory effects. The outline of this thesis will be centered against this backdrop.

\section{Outline of this dissertation}

The present dissertation will examine potential antecedents of children's false memories. To address this issue, several more specific research questions serve as the starting point for the chapters that follow.

\section{Do different false memory paradigms reveal different results?}

As findings from false memory research have been used to explain children's questionable accounts of sexual abuse, one wonders whether different types of false memories may equally well serve as a model of such accounts. Recently, there has been discussion as to whether findings from false memory research can be generalized to real life situations (Pezdek, 2007; Pezdek \& Lam, 2007; Wade et al., 2007). Hence, Chapter 2 focuses on different false memory paradigms and the type of false memories they elicit. Specifically, the purpose is to investigate whether the different false memory paradigms reveal similar results. 
2. What is the role of event plausibility in the development of children's false memories?

Research focusing on the role of event plausibility in children's false memory development has revealed mixed results. Whereas Pezdek and Hodge (1999) found that children were more likely to falsely remember plausible than implausible events, Strange and colleagues (2006) showed that children were equally likely to come up with false reports of plausible and implausible events. The aim of Chapter 3 is to examine whether manipulating event plausibility by exposing children to prevalence information (i.e., information regarding the frequency of a false event) affects false memory rates for a plausible (i.e., almost choking on a candy) and implausible (i.e., being abducted by a UFO) false event.

\section{What is the role of script knowledge in the development of children's false memories?}

Chapter 4 describes the role of script knowledge in the development of children's false memories. More specifically, the study described in this chapter will concentrate on whether knowledge about an event has implications for children's false memory formation. To test this, 7- and 11-year-olds are presented with a script-present (i.e., being caught with your finger in a mousetrap) and script-absent (i.e., receiving a rectal enema) false event. Moreover, this study examined whether the provision of additional knowledge about these events impacts children's false memory formation.

\section{What is the role of valence in the development of children's false memories?}

Legal cases in which children have to testify as a witness are primarily about negative episodes. Therefore, the question arises whether children's false memories are more easily provoked by a negative (i.e., being accused for copying off your neighbor) or neutral (i.e., moving to another classroom) false event. This issue will be the point of interest in Chapter 5.

\section{Can children's true and false memories be differentiated?}

False memory research shows that false memories can be relatively easily elicited in children. Moreover, legal cases show that these false memories can even appear dramatically authentic. Hence, a significant issue resides whether these false memories can be discriminated from children's true memories. The aim of Chapter 6 is to test the efficacy of a verbal deception technique, called Reality Monitoring (RM), in differentiating between children's true and fabricated reports of events. 
6. What is the effect of misleading information on omissions and commissions in children's memory reports?

Whereas a bulk of studies has concentrated on the effect misleading information (e.g., false narratives) has on inducing memories for details that were not present (i.e., false memories), little is known about the effect misleading information has on omission errors (i.e., leaving out details). Therefore, Chapter 7 compares the effect of misleading information on omission and commission errors in 4- and 10-year old children's memory reports. This issue is important in legal cases in which perpetrators frequently told the victim that certain aspects did not happen. 


\section{Different false memory paradigms}

Otgaar, H., \& Candel, I. (in press). Children's false memories: Different false memory paradigms reveal different results. Psychology, Crime \& Law. 


\begin{abstract}
The aim of the present study was to examine whether two different false memory paradigms (DRM vs. suggestion) produce similar results. In Experiment 1, hundred children from four age groups (5/6-year-olds, 7/8-year-olds, 9/10-year-olds, and 11/12-year-olds) were instructed to remember lists of semantically related words (DRM paradigm) and to complete a children's suggestibility measure (i.e., BTSS-NL). Results showed that children's false memories for non-presented words increased with age while accepting suggestive information decreased with age. Moreover, no significant relation was found between children's susceptibility to the DRM illusion and concurring to suggestive information. In Experiment 2, DRM false recall and recognition was compared between children with $(n=20)$ and without $(n=20)$ false memories for entire events. Children with implanted false memories did not falsely recall and recognize more critical lures than children without implanted false memories. This study shows that children's DRM intrusions are not related to their acceptance of suggestive information.
\end{abstract}


Examining under what conditions human memory can be inaccurate has sparked researchers' interest for several decades (see for an overview Loftus, 2004). Moreover, this interest has boosted tremendous public attention since it led to new insights valuable for the legal domain, such as new findings concerning the authenticity of memories of childhood sexual abuse (Ceci \& Bruck, 1993; Loftus, 1997). Researchers have used different paradigms to study erroneous memories, also labeled false memories. The aim of this study was to examine whether two different false memory paradigms produce similar results. Later in the introduction, we will explain the relevance of this issue.

A well-known and often used false memory paradigm is the Deese-RoedigerMcDermott (DRM; Deese, 1959; Roediger \& McDermott, 1995) paradigm in which participants have to study lists of words, like wet, tears, laugh, and sorrow which are semantically related to a non-presented critical lure cry. A robust finding is that participants tend to falsely recall and recognize the critical lures with rates not reliably different from the recall and recognition of presented words (Roediger \& McDermott, 1995; Roediger \& Gallo, 2005). While the development of false memories using DRM word lists is rather spontaneously (see Brainerd, Reyna, \& Ceci, 2008), other paradigms focus on the development of false memories by providing participants with suggestive information. In some studies, the suggestive information is presented in the form of false narratives or doctored photographs suggesting that participants took part in a fictitious event (Loftus \& Pickrell, 1995; Otgaar, Candel, \& Merckelbach, 2008; Otgaar, Candel, Merckelbach, \& Wade, 2009; Pezdek \& Hodge, 1999; Strange, Sutherland, \& Garry, 2006, Wade, Garry, Read, \& Lindsay, 2002). These studies have shown that a wide range of events can be falsely implanted (e.g., being abducted by a UFO, being lost in a shopping mall). In other studies, suggestive information is presented in the form of misleading questions (e.g., Candel, Merckelbach, Jelicic, Limpens, \& Widdershoven, 2004; Garven, Wood, Malpass, \& Shaw, 1998). These studies show that participants have the tendency to yield to suggestive information.

Theoretical accounts for false memories are provided by the Fuzzy-Trace Theory (FTT; Brainerd \& Reyna, 2005) and by the source-monitoring framework (Johnson, Hastroudi, \& Lindsay, 1993). From a fuzzy-trace perspective, memories are stored along parallel, dissociated traces called verbatim and gist traces (Brainerd \& Reyna, 2002; for an overview see Brainerd et al., 2008). While verbatim traces are involved in storing details and surface components of memory and fade quite fast, gist traces store meaning and persist 
much longer in memory. According to the FTT, false memories are mainly supported by gist memories. So, false memories arise because series of words or events repeatedly activate their underlying general meaning and when people are asked to report what they saw or heard, they memorize gist-related information that may include incorrect information (e.g., critical lure).

Source monitoring, however, capitalizes on people's ability to correctly ascribe the sources of their memories (Johnson et al., 1993). Specifically, this framework posits that people can use different source monitoring strategies to make attributions about the origins of their memories. According to this framework, a false memory occurs, when people wrongfully attribute internally generated information (e.g., critical lure) to an external source (e.g., a presented word).

A critical important, yet unresolved theoretical issue is whether the false memories produced by different paradigms (i.e., DRM, paradigms using suggestion) are akin or unrelated to each other. Recently, it has been questioned whether these false memory paradigms generate the same type of memory illusion (see Pezdek \& Lam, 2007; Pezdek, 2007, Wade et al., 2007). Specifically, Pezdek and Lam (2007) argued that there are constraints on generalizing findings from false memory research directly to real world settings since it could well be the case that the processes that are involved in producing false memories differ among the paradigms. Thus, Pezdek and Lam (p. 9), stated that "it has not been demonstrated that the mechanisms that operate to explain the DRM findings apply as well to memory for planting entirely new events in memory, specifically memory for child sexual abuse."

The question that arises is whether results of studies using different false memory paradigms are interchangeable and therefore equally appropriate as a base for conclusions about, for example, the accuracy of children's claims about sexual abuse. According to Wade and colleagues (2007), a bulk of evidence shows that false memory studies has improved our knowledge about false memory in real world settings since "some memory illusions can occur across different stimuli and different subject groups" (p. 26). So, these authors argue that false memory studies that have employed simple stimuli (such as words) can serve as a starting point for more complex, ecological valid stimuli (such as autobiographical memories). However, does the finding that for example children (e.g., Brainerd, Reyna, \& Forrest, 2002) and women falsely reporting childhood sexual abuse (Geraerts et al., 2006) 
have the tendency to falsely recall critical lures after studying DRM word lists mean that they are also more at risk for suggestive interview techniques?

The point is that semantic networks rather than the acceptance of suggestive information accounts for the development of false memories in a DRM paradigm (Brainerd et al., 2008; for an overview see Gallo, 2006). Between studies comparison has shown that suggestive interview techniques, at least in children, reveal different results as compared to DRM lists. Specifically, studies using different false memory paradigms have revealed different developmental trends. Studies using DRM lists have shown that the susceptibility to the DRM illusion increases with age. Children have less extensive semantic networks than adults and as a result critical lures are less likely to become activated (Brainerd \& Reyna, 2002; Sugrue \& Hayne, 2006; but see Ghetti, Qin, \& Goodman, 2002). This finding suits well with predictions of the FTT which hold that young children are less able to rely on gist memories than older children and adults. Therefore, young children are less likely to fall prey to the DRM illusion than older children and adults (Anastasi \& Rhodes, 2008; Metzger, Warren, Shelton, Price, Reed, \& Williams, 2008).

In contrast, studies using suggestion have found that false memories decrease with age with children concurring more to suggestion than adolescents and adults (Ceci, Ross, \& Toglia, 1987; Sutherland \& Hayne, 2001; for reviews, see Bruck \& Ceci, 1999). This can be explained because children's memory and source-monitoring functioning are not as optimal as adults' (Lindsay, Johnson, \& Kwon, 1991; for an overview see Robert \& Blades, 2000). Surprisingly, no attempt has ever been made to employ both paradigms (DRM and suggestion) in one single study. In this article, we present two experiments that took up this challenge and sought to examine whether children's false memories elicited by the DRM paradigm are related to false memories produced by suggestion. Experiment 1 examined the relationship between children's susceptibility to the DRM illusion and their acquiescence of suggestive questions by using a children's suggestibility measure (Bonn Test of Statement Suggestibility; BTSS-NL; Candel, Merckelbach, \& Muris, 2000; Endres, 1997). Experiment 2 focused on the relation between children's DRM illusion and their implanted false memories.

Concerning the relationship between children's false memories produced by both paradigms, we hypothesized that no relation exists between these false memories since the DRM paradigm triggers spontaneous semantic-related false memories whereas the other false memories are based on suggestion. Furthermore, this hypothesis is supported by 
different developmental trends for DRM- and suggestion-based false memories. That is, FTT predicts that the DRM memory illusion increases with age (Brainerd \& Reyna, 2002; Sugrue \& Hayne, 2006; but see Ghetti et al., 2002) whereas the source monitoring framework postulates that false memories induced by suggestion decreases with age (Ceci et al., 1987; Johnson et al., 1993; Sutherland \& Hayne, 2001; for reviews, see Bruck \& Ceci, 1999; Ceci \& Bruck, 1993). Also, Wilkinson and Hyman (1998) argued that memory errors based on suggestion may reflect different underlying processes than DRM-like intrusions, since the first is more based on schemas whereas the latter concentrates on semantic activation of related concepts.

\section{Experiment 1}

The goal of Experiment 1 was to examine whether children's susceptibility to suggestive information was related to children's false recall and recognition in the DRM paradigm. Furthermore, different age groups (5/6-year-olds, 7/8-year-olds, 9/10-year-olds, and 11/12-year-olds) were used to investigate a developmental trend in children's false memory development. To this end, hundred children were presented with DRM lists and a suggestibility measure.

\section{Method}

\section{Participants}

Hundred children from four age groups $(n=23,5 / 6$-year-olds, $M=5.70, S D=0.47$; $n=26,7 / 8$-year-olds, $M=7.62, S D=0.57 ; n=26,9 / 10$-year-olds, $M=9.69, S D=0.47 ; n=25$, $11 / 12$-year-olds, $M=11.24, S D=0.52$ ) were recruited from different elementary schools in the Netherlands. All children had parental consent. Children received a small present for their participation.

\section{Materials}

DRM lists Children were presented with ten 10 -words lists. The words on the lists were all semantically related to a non-presented word (i.e., critical lure, e.g., bread, smoke, and window). Lists were recorded on a $C D$ and played via a digital voice $C D$ recorder. The 
interval between word presentations was $2 \mathrm{~s}$. After each list presentation, participants were instructed to verbally recall all the words they remembered. A non-verbal filler task was employed between free recall and the presentation of the next list. List items were selected from the Dutch word association norms (Van Loon-Vervoorn \& Van Bekkum, 1991) and from the Dutch version of the DRM paradigm (Peters, Jelicic, \& Merckelbach, 2008). Using the Celex lexical database (Centre for Lexical Information, 1995), critical lures were matched on mean word frequency $(t(8)=0.22$, n.s.). Dutch word association norms showed that mean associative strength between the list words and their critical lures did not differ $(t(8)=1.69$, n.s.).

DRM recognition task The 78-word recognition test consisted of 40 studied words (i.e., 4 items from each list); the ten critical lures; 10 semantically-related distractors (i.e., the unpresented $11^{\text {th }}$ or $12^{\text {th }}$ word from each list), 18 unrelated distractors. Two parallel versions of the recognition test were created differing in the 4 studied items and the 18 unrelated distractors.

Bonn Test of Statement Suggestibility-NL (BTSS-NL). The BTSS-NL is a sufficiently reliable and valid tool to measure children's level of suggestibility (Candel et al., 2000). Like other suggestibility measures (Video Suggestibility Scale for Children; VSSC; Scullin \& Ceci, 2001; Gudjonsson Suggestibility Scale; GSS; Gudjonsson, 1984), the test consists of stimulus material and questions. Specifically, the BTSS-NL includes a short story, 4 coloured pictures, and 27 questions. Children listen to the story and look at the pictures illustrating the story. The story is about a boy who is roller-skating with his friend and bumps into another boy who is doing some shopping for his grandmother. Following this, children are asked what they remember about the event with the pictures still in front of them. After a $10 \mathrm{~min}$. interval in which children have to do a non-verbal task (i.e., make a drawing), 27 questions are asked. These questions can be subdivided into three categories: 1) memory questions (i.e., Memory scale) that intend to mask the real purpose of the test (e.g., "Did the mother of Sven forbid to roller-skate on the sidewalk?"); 2) suggestive questions (i.e., Yield scale) that either describe an incorrect statement in such a way that it results in a confirmative answer or that has two equal, but incorrect answers (e.g., "Was there a car or was there a bus on that picture depicting the accident?"; 3) repeated questions (i.e., Shift scale) that are immediate repetitions of the suggestive questions irrespective of which answer was given (e.g., "Think again. Was there a car or was there a bus on that picture depicting the accident?"). 
Design and Procedure

Children were tested individually in a separate room at their elementary school. To prevent BTSS-DRM carry over effects, a within subjects design was used in which all children first listened to the ten DRM-lists. After the recall of each list, a non-verbal filler task was used (i.e., make a drawing). Following the recall of the last list, a recognition test was presented to the children. They were instructed to say "yes" if they recognized the word as presented before and "no" if they experienced the word as new. Subsequently, the BTSS-NLstory was read out and the pictures were displayed. Then, the children had to recall the story. During a $10 \mathrm{~min}$. interval, children had to make a drawing. Finally, the 27 questions were asked. At the end, they were debriefed.

\section{Scoring}

DRM lists Free recall was scored in terms of number of correctly recalled words (i.e., true recall) and number of reported critical lures (i.e., false recall). Recognition was scored in terms of number of correctly recognized words (i.e., true recognition) and number of false alarms for critical lures (i.e., false recognition). Recall and recognition scores were expressed in proportions.

BTSS-NL Each correct answer to a memory question was assigned 1 point. The Memory scale was calculated by summing all correct answers (min. $=0$, max. $=8$ ). Suggestive and repeated questions were scored as follows. One point was assigned when a child yielded to the suggestion ( $\min .=0, \max .=12$ ) and when a child changed its answer in relation to the previously given answer $(\min .=0, \max .=7)$. The Yield and Shift scale, then, were computed by summing all points of each scale. The sum score of the Yield and Shift scale reflects the Total suggestibility scale $(\min .=0$, max. $=19$ ). Memory, Yield, Shift and Total suggestibility scores were expressed in proportions. 
Table 2.1 Mean proportion true recall, false recall, true recognition ( $A^{\prime}$ value), and false recognition ( $A^{\prime}$ value; standard deviations in parentheses)

\begin{tabular}{|l|l|l|l|l|}
\hline Age & 5/6-year-olds & $7 / 8$-year-olds & $9 / 10$-year-olds & $11 / 12$-year-olds \\
\hline Sample size & $\mathbf{n = 2 3}$ & $\mathbf{n = 2 6}$ & $n=26$ & $n=25$ \\
\hline True recall & $0.27(.09)$ & $0.37(.09)$ & $0.51(.11)$ & $0.58(.13)$ \\
\hline False recall & $0.13(.10)$ & $0.14(.15)$ & $0.25(.15)$ & $0.30(.16)$ \\
\hline True recognition & $0.87(.04)$ & $0.87(.07)$ & $0.91(.06)$ & $0.92(.04)$ \\
\hline False recognition & $0.79(.10)$ & $0.81(.08)$ & $0.85(.07)$ & $0.89(.05)$ \\
\hline
\end{tabular}

\section{Results}

$D R M$

Free recall Mean proportions of true and false recall for each age group are shown in Table 2.1. To examine the effect of age on true and false recall, a one-way analysis of variance (ANOVA) was computed using proportions of hits and critical lures as dependent variable and age (5/6-year-olds, 7/8-year-olds, 9/10-year-olds, and 11/12-year-olds) as independent variable. For true recall, we found a significant main effect of age $(F(3,96)=$ 39.52, $p<.001, \eta 2=0.55$ ). Post-hoc analyses using Bonferroni correction showed that true recall improved significantly across all age comparisons, with the exception of 9/10-yearolds vs. $11 / 12$-year-olds (5/6-year-olds, $M=0.27 ; 7 / 8$-year-olds, $M=0.38 ; 9 / 10$-year-olds, $\mathrm{M}=0.51$, all $p$ s $<.01$ ).

For false recall of the critical lures, there was a significant main effect of age $(F(3$, $96)=8.39, p<.001, \eta 2=0.21$ ) where post-hoc analyses using Bonferroni correction showed that four age comparisons were significant (5/6-year-olds vs. 9/10-year-olds; 5/6-year-olds vs. 11/12-year-olds; 7/8-year-olds vs. 9/10-year-olds; 7/8-year-olds vs. 11/12-year-olds, all ps $<.05)$. 
Recognition Mean proportions of true and false recognition for each age group are shown in Table 1. A one-way ANOVA was performed to examine the effect of age on true and false recognition. Regarding true recognition, results revealed a significant main effect of age $\left(F(3,95)=10.42, p<.001, \eta^{2}=0.25\right)$. Post-hoc analyses using Bonferroni correction showed that four age comparisons were significant (5/6-year-olds, $M=0.61$ vs. 9/10-yearolds, $M=0.76 ; 5 / 6$-year-olds, $M=0.60$ vs. $11 / 12$-year-olds, $M=0.78 ; 7 / 8$-year-olds, $M=$ 0.63 vs. $9 / 10$-year-olds, $M=0.76$; $7 / 8$-year-olds, $M=0.63$ vs. $11 / 12$-year-olds, $M=0.78$, all ps $<.01$ ) indicating that children displayed an age-related increase in true recognition.

For false recognition of the critical lures, we also found a significant main effect of age $\left(F(3,95)=9.41, p<.001, \eta^{2}=0.23\right)$. Similarly, post-hoc analyses using Bonferroni correction showed that four age comparisons were significant (5/6-year-olds, $M=0.41$ vs. 9/10-year-olds, $M=0.61 ; 5 / 6$-year-olds, $M=0.41$ vs. $11 / 12$-year-olds, $M=0.65 ; 7 / 8$-yearolds, $M=0.44$ vs. $9 / 10$-year-olds, $M=0.61 ; 7 / 8$-year-olds, $M=0.44$ vs. $11 / 12$-year-olds, $M=$ 0.65 , all $p s<.05$ ) indicating that false recall of critical lures increases significantly with age.

Since it is known that there are age differences in "yea-saying", recognition data were transformed into $A^{\prime}$, a non-parametric counterpart of the signal detection statistic $d$ (e.g., Brainerd, Reyna, \& Forrest, 2002; Howe, Cicchetti, Toth, \& Cerrito, 2004; Howe, 2007; Snodgrass \& Corwin, 1988). ${ }^{4}$ An $A^{\prime}$ value of .5 refers to an absence of true recognition (low accuracy: acceptance not higher for hits than for unrelated distractors) or false recognition (low false memory levels: acceptance not higher for critical lures than for related distractors) whereas an $A^{\prime}$ value close to 1 indicates perfect true recognition (high accuracy) or false recognition (higher acceptance for critical lures than related distractors). Using $A^{\prime}$, we found reasonably similar patterns of results for true and false recognition as revealed with untransformed data. Specifically, results indicated a significant main effect of age for true recognition $\left(F(3,94)=5.17, p<.01, \eta^{2}=0.14\right)$. Post-hoc Bonferroni analyses showed that the 5/6-year-olds and the 7/8-year-olds truly recognized fewer words than the $11 / 12$-year-olds (all $p \mathrm{~s}>.05$; see Table 1). With respect to false recognition, there was a significant main effect of age $\left(F(3,94)=8.74, p<.001, \eta^{2}=0.22\right)$ where post-hoc analyses using Bonferroni correction showed that $5 / 6$-year-olds were less likely to falsely recognize the critical lure

\footnotetext{
${ }^{4}$ Since our recognition task did not include critical lures from unpresented list, we used semanticallyrelated distractors as an approximation for calculating the $A^{\prime}$ value of the critical lures (see also Howe et al., 2004).
} 
than 9/10-year-olds and 11/12-year-olds (all $p s<.05$ ). Also, 7/8-year-olds significantly falsely recognized fewer critical lures than 11/12-year-olds $(p<.001)$.

\section{BTSS-NL}

Mean proportions of the Memory-, Yield-, Shift-, and Total suggestibility scale are shown in Table 2.2. A one-way ANOVA was conducted with BTSS-scores (Memory-, Yield-, Shift-, and Total suggestibility scale; 1 missing value) as dependent variable and age (5/6year-olds, 7/8-year-olds, 9/10-year-olds, and 11/12-year-olds) as independent variable. For the Memory scale, a significant age effect $\left(F(3,93)=10.90, p<.001, \eta^{2}=0.19\right)$ was present with 5/6-year-olds answering less memory questions correctly than the 7/8-year-olds, 9/10year-olds, and $11 / 12$-year-olds, all $p s<.05)$ and the $7 / 8$-year-olds answering less memory questions correctly than the $11 / 12$-year-olds $(p<.05)$.

With regard to the Yield scale, a significant age effect $\left(F(3,93)=7.53, p<.001, \eta^{2}=\right.$ 0.20 ) was found with $5 / 6$-year-olds concurring more to the yield questions than the $7 / 8$ year-olds, 9/10-year-olds, and 11/12-year-olds, all $p s<.05)$. For the Shift scale, there was also a significant main effect of age $\left(F(3,93)=5.25, p<.01, \eta^{2}=0.15\right)$ with only the $5 / 6$ year-olds, shifting significantly more than the $11 / 12$-year-olds, $p<.01$ ). Furthermore, we found a trend with 5/6-year-olds having higher shift ratings than the 9/10-year-olds ( $p=.05$ ).

Concerning the Total suggestibility score, results revealed a significant age effect $(F(3,93)=9.70, p<.001, \eta 2=0.24)$ with 5/6-year-olds being more suggestible than the $7 / 8$ year-olds, 9/10-year-olds (all $p s<.05$ ), and 11/12-year-olds.

\section{Relation DRM and BTSS-NL}

For each age group ${ }^{5}$, Pearson's correlations were computed between false recall and recognition on the one hand, and Yield-, Shift-, and Total suggestibility scale on the other hand. We did not find significant correlations (all ps $>.1$ ) indicating that falsely remembering critical lures is not related to accepting suggestive information.

\footnotetext{
${ }^{5}$ When we collapsed across age groups that did not significantly differ with respect to false recall and recognition on the one hand, and Yield-, Shift-, and Total suggestibility scale on the other hand, we did not find any significant correlations ( $p s>.05$ ).
} 
Table 2.2 Mean proportion scores and standard deviations (in parentheses) on the Memory-, Yield-, Shift-, and Total suggestibility scale of the BTSS-NL

\begin{tabular}{|l|l|l|l|l|}
\hline Age & $5 / 6$-year-olds & $7 / 8$-year-olds & $9 / 10$-year-olds & $11 / 12$-year-olds \\
\hline Sample size & $n=\mathbf{2 2}$ & $n=26$ & $n=26$ & $n=25$ \\
\hline Memory & $0.64(.16)$ & $0.74(.16)$ & $0.84(.14)$ & $0.85(.12)$ \\
\hline Yield & $0.67(.22)$ & $0.51(.22)$ & $0.45(.19)$ & $0.43(.15)$ \\
\hline Shift & $0.71(.24)$ & $0.58(.27)$ & $0.48(.36)$ & $0.38(.29)$ \\
\hline Total suggestibility & $0.69(.18)$ & $0.53(.19)$ & $0.46(.21)$ & $0.41(.16)$ \\
\hline
\end{tabular}

\section{Discussion}

In Experiment 1, two key findings were observed. First, we showed that children's susceptibility for the DRM illusion significantly increased with age while the acquiescence of suggestive information significantly diminished over time. Second, we found that the DRM illusion and the vulnerability for suggestion were not associated with each other.

The finding that children show an age-related increase in the DRM illusion has consistently been documented (for an overview see Brainerd et al., 2008; Brainerd \& Reyna, 2002; Sugrue \& Hayne, 2006; but see Ghetti et al., 2002). Similarly, with respect to the acceptance of suggestive information, a standard result is that younger children are more likely to fall prey to suggestion than older children and adults (Ceci et al., 1987; Sutherland \& Hayne, 2001; for reviews, see Bruck \& Ceci, 1999). As pointed out in the introduction, FTT and the source monitoring framework account for these findings.

More interestingly, it seems that children are not equally prone for the DRM illusion as for the inclusion of suggestive information. Apparently, children's susceptibility for semantic-based and suggestion-based false memories is distinct from each other. A limitation of Experiment 1 might be that, by using the BTSS-NL, we focused on false memories for details of experienced events. This might be problematic as the starting point of this study was Pezdek and Lam's (2007) and Wade et al's (2007) debate on the relationship between false memories elicited by DRM-lists and false memories for entire 
events. So, the question remains whether the DRM illusion is related to suggestively-induced false memories for entire events.

Evidence for this relation comes from a study that showed that people who have false memories for entire events are more at risk for the DRM illusion than a control group without these false memories. Clancy, McNally, Schacter, Lenzenweger, and Pitnam (2002), for instance, showed that people who reported to have recovered memories of alien abduction had higher DRM false memory rates than people who did not have such memories. Their experimental group consisted of people who recovered their memories during hypnotic therapeutic sessions. Although this study compellingly demonstrates that false memories in the DRM paradigm is related to other types of false memories, these results have never been shown in children.

The aim of Experiment 2 was to examine whether children's DRM performance was related to children's false memories for entire events. Children who participated in previous false memory implantation studies (Otgaar et al., 2008; Otgaar et al., 2009; Otgaar, Candel, Scoboria, \& Merckelbach, under review) were asked to participate and complete the DRM task.

\section{Experiment 2}

The purpose of Experiment 2 was to compare DRM task performance of children who developed false memories for entire events and children who did not develop such memories. We predicted two possible outcomes. In line with Clancy and colleagues (2002), we expected that children with false memories for entire events would have higher DRM false memory levels than children without false memories. However, based on the theories on false memory development as discussed in the introduction and on the results of Experiment 1, we hypothesized to find no differences in terms of DRM performance between children with and without false memories for entire events. 


\section{Method}

\section{Participants}

Forty children $\left(M_{\text {age }}=9.08, S D=1.40\right)$ participated with parental consent. All children were involved in previous false memory implantation studies (Otgaar et al., 2008; Otgaar et al., 2009; Otgaar et al., under review). In these studies, children were led to falsely remember entire events (abducted by a UFO, almost choking on a candy, being accused of copying of, moving to another classroom, receiving a rectal enema, being stuck with your finger in a mousetrap). Specifically, children were read true narratives about experienced events and one researcher-created false narrative indicating. They were interviewed twice with a one week interval in between about these events and encouraged to report everything they remembered about the events. Twenty children $\left(M_{\text {age }}=9.00, S D=1.03\right)$ then developed a false memory for an entire event (FM+ group) and twenty children $\left(M_{\text {age }}=\right.$ $9.15, S D=1.73$ ) did not have a false memory for an entire event (FM- group).

\section{Material}

DRM lists and recognition task Children were presented with the same DRM word lists and recognition task as in Experiment 1.

\section{Design and Procedure}

All children had to complete a DRM task in a separate room at their home. Children were asked whether they remembered the previous studies in which they participated. The majority of the children $(n=30)$ correctly indicated the procedure of the previous study.

\section{Scoring}

True and false recall and true and false recognition were computed as in Experiment 1. 


\section{Results}

Free recall

Mean proportions of true and false recall and true and false recognition for each false memory group are shown in Table 2.3. For recall, independent samples t-tests were carried out with proportions true and false recall as dependent variable and group ( $\mathrm{FM}^{+}$vs. $\mathrm{FM}^{-}$) as independent variable. With regard to true recall, we found no significant differences between the two groups $(t(38)=1.07, p=.29, d=0.35)$. We also found that the $\mathrm{FM}^{+}$group did not falsely recall more critical lures than the $\mathrm{FM}^{-} \operatorname{group}(t(38)=-0.88, p=.38, d=0.29)$.

\section{Recognition}

For recognition, independent samples t-tests were performed with proportions true and false recognition as dependent variable and group $\left(\mathrm{FM}^{+} \mathrm{vs}^{\left.-\mathrm{FM}^{-}\right)}\right.$as independent variable. For true recognition, no differences were detected between the $\mathrm{FM}^{+}$group $(M=$ $0.67, S D=.12)$ and $\mathrm{FM}^{-}$group $(M=0.69, S D=.14, t(36)=-0.54, p=.60, d=0.17,2$ missing values). Similar to false recall, the $\mathrm{FM}^{+}$group $(M=0.59, S D=.21)$ did not falsely recognize more critical lures than the $\mathrm{FM}^{-}$group $(M=0.58, S D=.21 ; t(36)=-0.13, p=.90, d=0.04)$.

When we transformed our recognition data into $A^{\prime}$ (see Experiment 1), we found similar results. The $\mathrm{FM}^{+}$group did not correctly recognize more words than the $\mathrm{FM}^{-}$group $(t(36)=0.93, p=.36, d=0.31)$. Moreover, the $\mathrm{FM}^{+}$group did not falsely recognize more critical lures than the $\mathrm{FM}^{-}$group $(t(36)=0.59, p=.57, d=0.19)$.

Table 2.3 Mean proportion true recall, false recall, true recognition ( $A^{\prime}$ value), and false recognition ( $A^{\prime}$ value) of the $\mathrm{FM}^{+}$and $\mathrm{FM}^{-}$group (standard deviations in parentheses)

\begin{tabular}{|l|l|l|}
\hline Group & \multicolumn{1}{|c|}{$\mathrm{FM}^{+}$} & \multicolumn{1}{|c|}{$\mathrm{FM}^{-}$} \\
\hline True recall & $0.45(.10)$ & $0.42(.09)$ \\
\hline False recall & $0.22(.15)$ & $0.18(.14)$ \\
\hline True recognition & $0.66(.09)$ & $0.68(.08)$ \\
\hline False recognition & $0.62(.10)$ & $0.64(.08)$ \\
\hline
\end{tabular}




\section{Discussion}

In Experiment 2, we examined whether children with false memories for entire events were more vulnerable for the DRM illusion than children without these memories. We found that children with false memories for entire events did not falsely recall and recognize more critical lures than a control group without false memories.

Our findings show that children who develop false memories triggered by suggestions are not more vulnerable to develop spontaneous false memories as elicited by DRM lists than children who are not susceptible to suggestion. Although Clancy et al's (2002) study has revealed contrasting results, this is the first study which shows that the findings reported in this study do not hold for children.

The finding that children with and without false memories are equally prone for the DRM illusion can be explained because semantic processing and concurring to suggestion have differential developmental trajectories. Whilst children are less able to extract the underlying gist of information than adults (Brainerd et al., 2008), they are more easily affected by suggestive information than adults (Ceci \& Bruck, 1993). More specifically, it could well be that children's semantic networks are less well developed than adults' which decreases the chance that non-presented material (i.e., critical lure) will be activated (e.g., Roediger, Balota, \& Watson, 2001). Also, because children lack efficient source monitoring abilities, they are more prone for suggestion than adults.

\section{General Discussion}

The present study explored whether two different false memory paradigms (i.e., DRM and suggestion) produce similar results. The current study was inspired by the ongoing debate by Pezdek and Lam (2007) and Wade and colleagues (2007) about the relation between different types of false memories. Pezdek and Lam (2007) argued that researchers should not use the same term (i.e., false memories) for different kinds of memory distortions as this could imply that similar processes underlie these memory distortions (see also Pezdek, 2007). Therefore, generalizing false memory findings to false memories of child sexual abuse could be problematic. Wade and colleagues, however, noted that different types of false memories can improve our insight into false memories occurring in real world 
situations and that when studies have high internal validity, they can be valuable in real world settings. This study examining children's vulnerability to semantic-based false memories and at the same time their susceptibility to suggestion-based false memories will contribute to this debate.

The current study is the first within study comparison showing that the susceptibility to the DRM illusion increases with age while accepting suggestive information decreases with age. Moreover, we reported two experiments showing that children's false recall of non-presented words is not related to concurring to suggestion.

In the present study, we found that reverse age effects were present with a developmental increase in DRM false memory rates and developmental decline in accepting suggestive information (Experiment 1). These effects are in agreement with on the one hand studies finding that the susceptibility for the DRM illusion is positively related with age (Anastasi \& Rhodes, 2008; Brainerd \& Reyna, 2002; Metzger et al., 2008; Sugrue \& Hayne, 2006; but see Ghetti et al., 2002) and the other hand studies showing that assenting to suggestion decreases with age (Ceci et al., 1987; Sutherland \& Hayne, 2001; for reviews, see Bruck \& Ceci, 1999; Ceci \& Bruck, 1993). From a FTT perspective, our reverse age effects can be explained since younger children are less able to extract gist information from word lists than older children. Since false memories arise chiefly out of gist memories, younger children will therefore less likely report the critical lure than older children (Brainerd \& Reyna, 1998). Indeed, it could well be that the age-related changes in semantic density could account for the finding that younger children are less vulnerable for the DRM illusion than older children and adults (e.g., Roediger et al., 2001). Moreover, at a similar time, presenting suggestive information creates verbatim traces that conflict with original presented information (Brainerd \& Reyna, 1998, 2002). Hence, since younger children retrieve more verbatim traces than older children, they will display an enhanced acceptance of suggested information (but see Brainerd et al., 2008).

In terms of the source monitoring framework, research has shown that younger children are less likely to correctly discriminate between sources of information than older children implying that false memories are more prevalent among younger than older children (Johnson et al., 1993). Indeed, our study shows that using the BTSS-NL, younger children concurred more to suggestion than older children. However, in the DRM task, younger children were less prone to falsely remember the critical lure than older children. A more recent extension of the source monitoring framework, the activation-monitoring 
theory (Roediger et al., 2001), could explain this finding. According to this theory, the inefficient use of source monitoring can not account alone for the developmental pattern of false memories. Specifically, age differences in false memories are also the result of agerelated differences in the activation of semantic networks. Thus, younger children posses lower spreading activation levels than older children leading to lower rates of the DRM illusion (see also Carneiro, Albuquerque, Fernandez, \& Esteves, 2007).

Our result that children's DRM performance is not related to the acquiescence of suggested information can be explained by the different procedures which evoke these false memories. While studying and recalling DRM word lists induces spontaneous false memories through the activation of semantic networks (Brainerd et al., 2008; Roediger et al., 2001), the BTSS-NL focuses on false memories generated by suggestion. Clearly, in children, these two false memories are not associated with each other. Indeed, Mazzoni (2002b) also argued that false memory researchers should exert caution in drawing conclusions from one false memory paradigm to another. This author (p. 37), for example, stated that " $[\mathrm{m}]$ emory scholars have operated under the implicit assumption that what is true for the DRM paradigm must also be true for other memory distortions as well" and that "that assumption is unwarranted."

Relatedly, researchers have recently warned that generalizing DRM studies to other types of false memories and to real life settings is not always guaranteed (Foley, Hughes, Librot, \& Paysnick, 2009; Plancher, Nicolas, \& Piolono, 2008). Foley and colleagues, for instance, examined the effect of imagery on DRM false memories. They found that imagery resulted in fewer DRM illusions than a non-imagery condition. This finding is in stark contrast with research showing the potentially dangerous effects of imagery in other types of false memories (e.g., Foley, Wozniak, \& Gillum, 2006). Also, Plancher and colleagues examined the effect of suggestion on DRM performance. They found that providing adult participants with false information about the existence of critical lures did not produce more DRM illusions than a control group without this information. Thus, although research shows that the provision of false information can result in elevated false memory levels (e.g., Otgaar et al., 2009), this seems not to occur with DRM false memories.

One potential caveat in the present study is that we did not use child-generated DRM lists to explore false memory rates. Recent studies have begun to use child-normed DRM list to examine developmental trends of false memories (Carneiro et al., 2007; Metzger et al., 2008). However, these studies showed that using child-generated DRM lists resulted in 
the same age-related increase of DRM illusions as when using adult-based DRM lists. Moreover, Metzger and colleagues showed that although child-generates lists led to an improved accurate retrieval of children, it did not affect false memory rates.

Our study has significant ramifications for the legal domain. ${ }^{6}$ Specifically, since children's DRM intrusions are not associated with children's suggestibility, one might wonder whether studies using DRM word list are appropriate to be generalized to legal cases in which suggestion (e.g., suggestive interview techniques) predominates. Obviously, our results show that in children a discrepancy exists between semantically-related false memories (i.e., DRM) and suggestion-based false memories. In legal cases in which the accuracy of children's claims of for example sexual abuse is questioned, suggestive interviewing techniques are often the motive for this mistrust (Bruck \& Ceci, 1999). According to our findings, studies on the DRM illusions are not capable in elucidating such cases. Specifically, in such cases, the ecological validity of the DRM paradigm is severely constrained.

As already stated, however, Wade and colleagues (2007) argued that results from different false memory paradigms can be generalized to real life situations since different false memory phenomena can be fostered through different stimuli and among a range of different participants. Although they correctly stated that "research findings are often taken out of context and applied to situations to which they are minimally relevant" (Wade et al., p. 24), we raise serious doubts concerning their statement of generalizing false memory findings, at least with regard to false memory paradigms used with children. Even though false memories can be formed across a considerable number of situations, this does not denote that different false memory paradigms are equally appropriate to explain questionable accounts of children's claims of for example sexual abuse.

Of course, this does not imply that findings from the DRM paradigm are never valuable to be generalized to real life settings. There are situations in which DRM findings are absolutely useful. Holliday, Reyna, and Brainerd $(2008$, p. 76) for example state that "[f]alse memories induced by meaning related information embody several features of forensically relevant memories. For child witnesses of domestic violence, for example, such violence is not usually a single episode but rather a series of repeated events that are

\footnotetext{
${ }^{6}$ See also Otgaar, H. (2009). Not all false memory paradigms are appropriate in court. In L. Strömwall \& P.A. Granhag (Eds.), Memory: Reliability and personality (pp. 37-46). Göteborg: Göteborg University.
} 
substantially similar but not exactly the same." Then, they (p. 76) argue that "in cases of repeated experiences of sexual abuse, young children because of limited gist-extraction abilities, will be less likely than older children and adults to incorporate gist-consistent events (that did not take place) in their memory reports." However, we stress that when children are suggestively interrogated, expert witnesses can only rely on false memory studies in which suggestion was used (see also Freyd \& Gleaves, 1996; Roediger \& McDermott, 1996) when they are asked to indicate whether children's testimonies are reliable or not.

In sum, the pivotal point of this study is that, at least in children, different false memory paradigms reveal different results. Children's DRM performance is not associated with accepting suggestive information. Hence, researchers and expert witnesses should be aware of the restrictions false memory findings have when generalizing to cases like for example sexual abuse. 


\section{Plausibility and children's false memories}

Otgaar, H., Candel, I., Merckelbach, H., \& Wade, K.A. (2009). Abducted by a UFO: prevalence information affects young children's false memories for an implausible event. Applied Cognitive Psychology, 23, 115-125. 


\begin{abstract}
This study examined whether prevalence information promotes children's false memories for an implausible event. Forty-four 7-8 and 47 11-12 year old children heard a true narrative about their first school day and a false narrative about either an implausible event (abducted by a UFO) or a plausible event (almost choking on a candy). Moreover, half of the children in each condition received prevalence information in the form of a false newspaper article while listening to the narratives. Across two interviews, children were asked to report everything they remembered about the events. In both age groups, plausible and implausible events were equally likely to give rise to false memories. Prevalence information increased the number of false memories in 7-8 year olds, but not in 11-12 year olds at Interview 1 . Our findings demonstrate that young children can easily develop false memories of a highly implausible event.
\end{abstract}


Both recent studies (e.g., Pezdek \& Hodge, 1999; Strange et al., 2006) and legal cases have demonstrated that children can develop memories of events that never happened, so-called false memories (Loftus, 2004). A well-known legal case is the "McMartin Preschool" trial in which several teachers were accused of ritually abusing hundreds of children across a 10-year period (Garven, Wood, \& Malpass, 2000; Garven, Wood, Malpass, \& Shaw, 1998; Schreiber et al., 2006). Some of the children recalled extremely bizarre, implausible events such as flying in helicopters to an isolated farm and watching horses being beaten with baseball bats. The charges against the teachers, however, were eventually dropped; videotapes of the investigative interviews indicated that the children were suggestively interrogated and many experts concluded that the children's memories were almost certainly false. Controversial cases like the McMartin trial have inspired researchers to investigate how children develop false memories of implausible experiences (Pezdek \& Hodge, 1999; Strange et al., 2006), yet the precise antecedents of implausible false memories are still ill-understood. The question we ask here is whether prevalence information - that is, details about the frequency of a false event-is a potential determinant of children's implausible false memories.

What do we know about the role of prevalence information in the development of false memories? Mazzoni, Loftus, and Kirsch (2001) describe a three-step process that explains how false memories are formed. According to this model, three conditions must be satisfied to create false memories. First, an event has to be considered plausible. Second, the event has to be evaluated as something that genuinely happened. Finally, images and thoughts about the event have to be mistaken as memory details. Consider, now, just the first stage of Mazzoni et al.'s model (event plausibility) and how prevalence information might affect perceived plausibility. Recent experiments have shown that prevalence information enhances the perceived plausibility of implausible events (Hart \& Schooler, 2006; Mazzoni et al., 2001; Pezdek et al., 2006b; Scoboria et al, 2006). Mazzoni and colleagues (2001) asked undergraduates to read false newspaper articles describing demonic possession. The articles implied, among other things (i.e., a description of what happens in a typical possession experience), that possessions were more common than people previously thought and after reading the articles participants were more likely to believe they had witnessed a demonic possession in the past. Other studies investigating the role of prevalence information in eliciting false beliefs have produced similar striking effects (Hart \& Schooler, 2006; Mazzoni et al., 2001; Pezdek et al., 2006; Scoboria et al., 2006). 
What we do not know, however, is whether prevalence information influences the development of false memories (stage 3 of Mazzoni et al.'s model) and not just false beliefs per se. This is an important issue in the false memory literature because several authors have argued that memories and beliefs, although related, are definitely not the same (Scoboria et al., 2004; Smeets et al., 2005). Moreover, the effect of prevalence information has only ever been tested on adults' beliefs. To date, no study has examined whether prevalence information affects the generation of children's false memories.

What do we know about event plausibility in the development of children's false memories? In short, research has produced interesting but varied results. Early studies showed that children were more likely to create false memories of plausible than implausible events (Pezdek \& Hodge, 1999; Pezdek et al., 1997), and researchers suggested that it may be difficult to implant false memories of an implausible event (i.e., receiving a rectal enema). In contrast, one recent study shows that children will falsely recall both plausible and implausible events to a similar extent (Strange et al., 2006). Three different explanations might account for these mixed findings. First, Strange et al. presented children with a doctored photograph of the false event whereas Pezdek and colleagues used false descriptions. Doctored photographs might be considered an extreme form of evidence -one that is very difficult for children to refute. It is probable, then, that the doctored photographs skewed the children's plausibility judgments which in turn caused them to develop false memories for the plausible and implausible event at a similar rate. Second, Strange et al. compared false events that were either plausible or implausible whereas Pezdek and colleagues $(1997,1999)$ contrasted false events that differed in terms of script knowledge (i.e., description of what typically occurs in an event). Specifically, they compared a high script knowledge event (i.e., lost in a shopping mall) with a low script knowledge event (i.e., receiving a rectal enema). However, the exact relation between script knowledge and plausibility is not clear (Scoboria et al., 2004). Third, the two false events used in Strange et al.'s and Pezdek et al.'s studies differed with respect to valence. Strange et al.'s events were positive (i.e., taking a hot air balloon ride and drinking a cup of tea with Prince Charles), whereas Pezdek and colleagues implanted false negative events in children's memory (i.e., lost in a shopping mall and receiving a rectal enema). Studies have shown that valence affects the development of children's false memories (Ceci et al., 1994b; Howe, 2007). Since plausibility, valence, and script knowledge seem to play a role in the development of false memories, the false events used in the current study were matched on these factors. 
To examine whether prevalence information can lead children to develop fullblown false memories of plausible and implausible events, and to examine developmental differences in the development of false memories, we adapted the false narrative procedure (e.g., Loftus \& Pickrell, 1995; Garry \& Wade, 2005; Pezdek \& Hodge, 1999; Pezdek et al., 1997), and exposed some 7-8 year old children and some 11-12 year old children to one true description and one false description of past experiences. Previous studies have shown that these age groups differ developmentally with respect to suggestibility and false memory formation (e.g., Ceci et al., 1987). The true description described the child's first day at school. The false description was either plausible and described almost choking on a candy, or implausible and described being abducted by a UFO. Half of the children in each group also received prevalence information in the form of a newspaper article. The article suggested that the target false event was much more common than the children probably thought.

Our predictions were straightforward: Based on the prevalence literature with adults, we predicted that children who heard false prevalence information would be more likely to report false memories than children without false prevalence information. With respect to the role of event plausibility, two predictions can be formulated. Based on studies by Pezdek and colleagues $(1997,1999)$, we would predict that regardless of prevalence information, plausible events would elicit more false memories than implausible events. However, based on a recent study by Strange and colleagues (2006), we would expect that plausible and implausible events are equally likely to elicit false memories. Finally, because younger children are more suggestible than older children (for an overview see Bruck \& Ceci, 1999), we expected that younger children would be more likely to develop false memories than older children.

\section{Method}

\section{Participants}

The study involved 91 primary school children (48 girls) from two different age groups $(n=44,7-8$ year olds, $M=7.68$ years, $S D=0.52 ; n=47,11-12$ year olds, $M=11.64$ years, $S D=0.53)$. Children participated after parents and teachers had given informed consent. All children received a small gift in return for their participation. The study was 
approved by the standing ethical committee of the Faculty of Psychology, Maastricht University.

Materials

True narratives. True narratives described children's first day at school. This event was chosen because it was a unique event that had happened to all children at age 4 . Children's parents were contacted by telephone to obtain the following personal details about each child's first school day: The family members or friends who escorted the child to school, and the teacher's and school's name. These details were incorporated in the true narratives.

An example of a true narrative was:

"Your mother told me that when you were 4 years old, you went for the first time to the elementary school. The name of the elementary school was Springer and it was located in Maastricht. The name of your teacher was Tom. Your mother took you to school".

False narratives. False events were selected from a pilot study. In that study, 49 children $(M=8.02 \text { years, } S D=1.20 \text {, range } 6-10)^{7}$ rated the plausibility and valence of 29 events on child-friendly 7-point Smiley scales (anchors: $(;)=$ implausible/ negative, $(\dot{)}=$ plausible/ positive) with bigger Smiley faces referring to more plausible/more positive events. Specifically, children had to indicate how likely the events were to happen to them (e.g., "How likely is it that you almost choke on a candy?"; i.e., personal plausibility; Scoboria et al., 2004) and how pleasant the events were for them (e.g., "How pleasant is it that you almost choke on a candy?"). To ensure that they understood the events, all children rated two practice items. Furthermore, 19 children $(M=8.74$ years, $S D=1.05$, range 7-10) were instructed to report everything they knew about each event and the total number of idea units served as our measure of children's script-knowledge about the events (Scoboria et al., 2004). Based on their ratings, we selected two events, almost choked on a candy and abducted by a UFO. These events were equal in terms of valence $\left(M_{\text {choking }}=1.65, S D_{\text {choking }}=\right.$

\footnotetext{
${ }^{7}$ Because the age range of our pilot sample did not completely overlap with the age groups of our study, we conducted a 2 (pilot group: younger vs. older children) x 2 (event: UFO vs. choking) ANOVA with the latter factor being a within subject factor to examine the effect of age on plausibility judgments. No significant interaction emerged $(p>.05)$ indicating that age did not have an impact on the plausibility ratings of our two events. Therefore, the plausibility ratings of our pilot sample can be extended to the older group of our study.
} 
$1.48, M_{\mathrm{UFO}}=1.94, S D_{\mathrm{UFO}}=1.98, t(47)<1$, n.s. $)$ and script knowledge $\left(M_{\text {choking }}=1.11, S D_{\text {choking }}\right.$ $=0.99, M_{\mathrm{UFO}}=0.74, S D_{\mathrm{UFO}}=1.05, t(18)=1.20, \mathrm{n} . \mathrm{s}$.), but differed in terms of plausibility with mean plausibility ratings being higher for the choking event $(M=5.86, S D=2.02)$ than for the UFO event $(M=1.63, S D=1.75, t(47)=10.07, p<.001)$. Age did not correlate with plausibility, valence, and script knowledge for the two events ( $p s>.05$ ). Children's parents confirmed that their child had never experienced the false events.

The false narratives were:

Almost choked on a candy: Your mother told me that you were at a birthday party when you were 4 years old. At this party you received a bag of candies. When you were at home again, you were allowed to have one candy. Your mother saw that you turned blue and she panicked. Then she hit you on the back and the candy came out.

Abducted by a UFO: Your mother told me that when you were 4 years old, you were abducted by a UFO. This happened when you were alone outside. You mother was inside the house. Then she suddenly saw through the window that a UFO took you.

False newspaper articles. For the true and false events a newspaper article was fabricated describing that the event took place quite frequently when participants were age 4. These false newspaper articles were similar in appearance to a local newspaper. Moreover, to personalize the newspaper articles, we included the children's hometown in the articles. The newspaper articles were identical in terms of lay-out, size, and color and were roughly matched for word count and level of detail. Depending on the event described, the articles contained a photograph of an elementary school, candies or a UFO (Figure 3.1). 


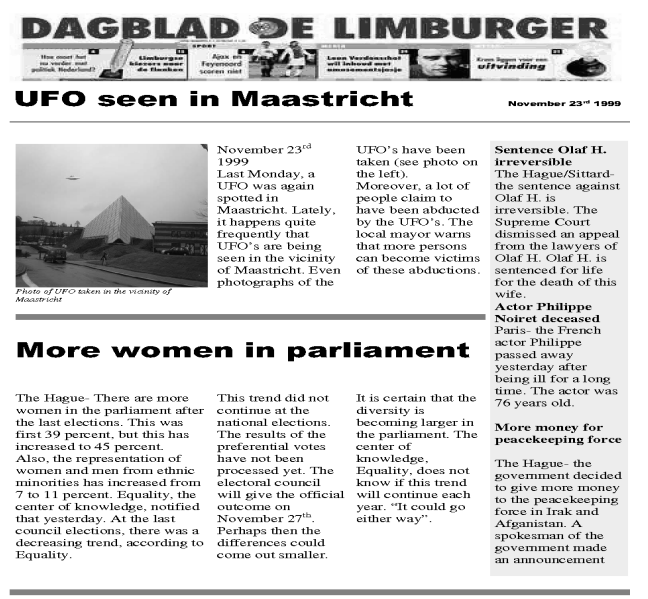

Figure 3.1 Example of a false newspaper article about UFO abduction (English translation).

\section{Design and Procedure}

The design was a 2 (Age: younger children vs. older children) $\times 2$ (Event type: plausible vs. implausible) $\times 2$ (Prevalence information: yes vs. no) between-subjects design. Children were randomly assigned to the plausible or implausible event and to the prevalence or no prevalence information condition. Each child was interviewed individually twice over seven days. All interviews were audio taped and transcribed. During the interviews, one true narrative and one false narrative were read aloud, with the latter always being presented in the second position. The procedure of the interviews was similar to that used by Wade, Garry, Read, and Lindsay (2002). At the start of Interview 1, children were told that we were interested in their memories for events that had happened when they were 4 years old. Children were instructed to report everything they remembered about the events. In the prevalence information condition, they were told that to help them remember the events they would be provided with a newspaper article. Subsequently, the interviewer read out the article to the child. Children who did not describe details of the target event were told that “many people can't recall certain events because they haven't thought about them for such a long time. Please concentrate and try again". If they still did not recall any details, the interviewer made use of context reinstatement and guided imagery. The purpose of these retrieval techniques was to take the children mentally back to the scene of the event. Specifically, children were told to close their eyes and they were asked to think about their 
feelings, who was with them, and about the time of the year. After this, children were asked again to recall any details about the event. If they still did not come up with details, the next narrative was presented or the interview was stopped. At the end of Interview 1, children were asked to think about the events every day until the next interview and they were instructed not to talk with others about the events. Parents were asked not to discuss these events with their children. Interview 2 was similar to Interview 1 . At the end of Interview 2, they were debriefed using ethical guidelines for false memory research with children (Goodman, Quas, \& Redlich, 1998).

\section{Results and Discussion}

An extensive number of children were extremely surprised during the debriefing when they were told that the false event did not happen to them. For example, one 8-year old child responded "It really did happen" where another one said "I really can remember seeing the UFO". After the debriefing, 39\% $(n=13)$ of the children remained absolutely confident that they experienced the false events. We debriefed these children until they understood the events were false. Together, these findings suggest that the false memories in this study were not the result of children falsely assenting or trying to please the interviewer.

\section{True events}

True memories were categorized as either remembered or not remembered. To be categorized as remembered, children had to report at least two of the three personal details correctly. Children's true recall was near ceiling. They remembered 88 (97\%) events at Interview 1 and 89 (98\%) events during Interview $2, \chi^{2}(1)=.07$, n.s.

\section{False events}

For the false events, two independent judges classified each memory report as no false memory, images but not memories or false memory according to criteria used by Lindsay et al. (2004). If a child attempted to recall the false event, but did not have any memory of the event or did not report any details that were beyond the false description, the report was categorized as no false memory. A report was judged as an image when children speculated about details and described images related to the false events. For 
example, one child reported: "I think I almost choked on a candy on the birthday of Mauk. I am not sure. It was not a pleasant feeling." To be classified as a false memory, children had to indicate that they remembered the event and provide details beyond those mentioned in the narrative, but related to the narrative. To give an example of a detail, one child stated that he remembered being taken to the UFO through a blue beam of light. If children stated that they thought the event and/or certain details could have happened, then this was not scored as a false memory. Furthermore, to minimize the effect of demand characteristics, direct responses to interviewer prompts were not classified as a false memory. The following dialogue from Interview 2 illustrates a child's false memory of the UFO abduction.

Child: "I saw cameras and flashes and some people in the UFO."

Interviewer: "How many people did you see?"

Child: "Approximately nine or ten."

Interviewer: "What kind of people?"

Child: "People like me, children."

Interviewer: "What else did you see?"

Child: "I saw some people and also some blue/green puppets were passing."

Inter-rater agreement for classification of the memory reports was high; $\mathrm{k}=.92$ for Interview 1 and $\mathrm{k}=.94$ for Interview 2 .

Collapsing across the conditions, at Interview 1, 33\% $(n=30)$ of the children developed a false memory. Thirty percent $(n=9)$ of these children assented to the false events immediately, that is prior to guided imagery and context reinstatement. Thirty-six percent of the children ( $n=33)$, with $67 \%(n=20)$ immediately assenting, "remembered" the false events at Interview $2, \chi^{2}(1)=26.61, p<.001$, Cramer's $V=.54$. Some of the children who rejected the false events at Interview 2 indicated, despite the explicit instruction at Interview 1, that they had discussed the false events with their parents. The increase in false memories over time is in line with previous studies with adults and children (e.g., Lindsay et al., 2004; Strange et al., 2006; Wade et al., 2002). Furthermore, 10\% ( $n=9)$ of the children were classified as having an image of the false events at Interview 1. At Interview 2, this percentage decreased to $7 \%(n=6), \chi^{2}(1)=58.53, p<.001$, Cramer's $V=.80$. 
Table 3.1 Percentage and number (between parentheses) of children who developed false memories at Interview 1 and 2

\begin{tabular}{|c|c|c|c|c|c|}
\hline & & \multicolumn{2}{|c|}{ Interview 1} & \multicolumn{2}{|c|}{ Interview 2} \\
\hline & & UFO & Choked & UFO & Choked \\
\hline \multirow{2}{*}{$\begin{array}{c}\text { 7-8 year } \\
\text { olds }\end{array}$} & Prevalence & $78(7)$ & $45(5)$ & $67(6)$ & $46(4)$ \\
\hline & No prevalence & $21(3)$ & $40(4)$ & $36(5)$ & $60(6)$ \\
\hline \multirow[t]{2}{*}{$11-12$ year olds } & Prevalence & $8(1)$ & $23(3)$ & $8(1)$ & $46(6)$ \\
\hline & No prevalence & $18(2)$ & $45(5)$ & $9(1)$ & $36(4)$ \\
\hline
\end{tabular}

Recall that the primary question in this study was whether prevalence information boosts the likelihood of plausible and implausible false memories. Table 3.1 shows the percentage and number of children who reported false memories as a function of interview and condition. To examine the role of age, event type, and prevalence information in the development of false memories, we conducted a logistic regression analysis with the dependent variable being false memory ( $0=$ no false memory/images, $1=$ false memory). $\ln$ this analysis, we only focused on "genuine" false memories and did not collapse across false memories and images. Although non-parametric methods, such as logistic regression, often lack the statistical power to detect interactions (Sawilowsky, 1990), there are four important points to note about these data. First, the only significant interaction found was an Age $x$ Prevalence information interaction at Interview 1. Prevalence information enhanced the development of 7-8 year old children's false memories but not 11-12 year old children's false memories, and this effect occurred at Interview $1(B=2.16, S E=.96$, Wald $=5.05$, $\operatorname{Exp}(B)=8.68, p<.05)$, but not at Interview $2(B=-2.05, S E=.93$, Wald $=.05, \operatorname{Exp}(B)=.82$, n.s.). Indeed, 7-8 year old children who received prevalence information were approximately 2 times more likely to report false memories at Interview 1 than their 7-8 year old counterparts who did not receive prevalence information $(B=1.29, S E=.64$, Wald $=4.08$, $\operatorname{Exp}(B)=3.64, p<.05$; see Figure 3.2). These findings fit with previous research showing that prevalence information increases the plausibility of events (Hart \& Schooler, 2006; Mazzoni et al., 2001; Pezdek et al., 2006; Scoboria et al., 2006). But they also extend these findings by showing that prevalence information can increase the likelihood of young children's false 
memories. However, the older children who received prevalence information were equally likely to report false memories as their control counterparts at Interview 1 ( $B=-.90, S E=.71$, Wald $=4.08, \operatorname{Exp}(B)=.41$, n.s.).

A counterexplanation for the effect of prevalence information in the younger age group is that, although children's responses to the debriefing suggest that they developed full-blown false memories, they might have complied with the researcher. Since younger children are more compliant that older children (Gudjonsson, 1989, 1992; Richardson \& Kelly, 2004), the younger group could have been more willing to please the interviewer when confronted with prevalence information. Moreover, in our study, children received prevalence information combined with the suggestion that their mother/father told us that the false event had happened. Future studies should examine the effect of prevalence information alone upon false memory formation.

Second, prevalence information did not have an effect on younger children's false memories at Interview 2. The decrease of false memories of the younger children who received prevalence information might account for this finding. Eight children (27\%) who reported a false memory at Interview 1 rejected these events at Interview 2. Moreover, two of these children were in the 7-8-year old prevalence information condition. Furthermore, the percentage of false memories of the younger children who did not receive prevalence information increased at Interview 2. This increase is in accordance with previous research (e.g., Lindsay et al., 2004; Strange et al., 2006; Wade et al., 2002).

Third, the plausibility of the false event did not affect the development of false memories. That is, both younger and older children were equally likely to report false memories of choking on a candy and being abducted by a UFO (Interview 1: $B=.43, S E=.48$, Wald $=.81, \operatorname{Exp}(B)=1.54$, n.s.; Interview 2: $B=.78, S E=.46$, Wald $=2.82, \operatorname{Exp}(B)=2.17$, n.s.). These findings fit with recent research that shows that children will falsely remember pseudo-events regardless of whether they are everyday events or bizarre events (Strange et al., 2006).

Fourth, the younger children were more likely to report false memories than the older children at Interview $2(B=1.05, S E=.46$, Wald $=5.16, \operatorname{Exp}(B)=2.87, p<.05)$. This finding concurs with other studies on developmental differences in false memory formation. Younger children are more prone to suggestive techniques than older children, presumably because they do not have the source-monitoring capabilities to discriminate between 
experienced and imagined events (Lindsay et al., 1991; for an overview see Robert \& Blades, 2000).

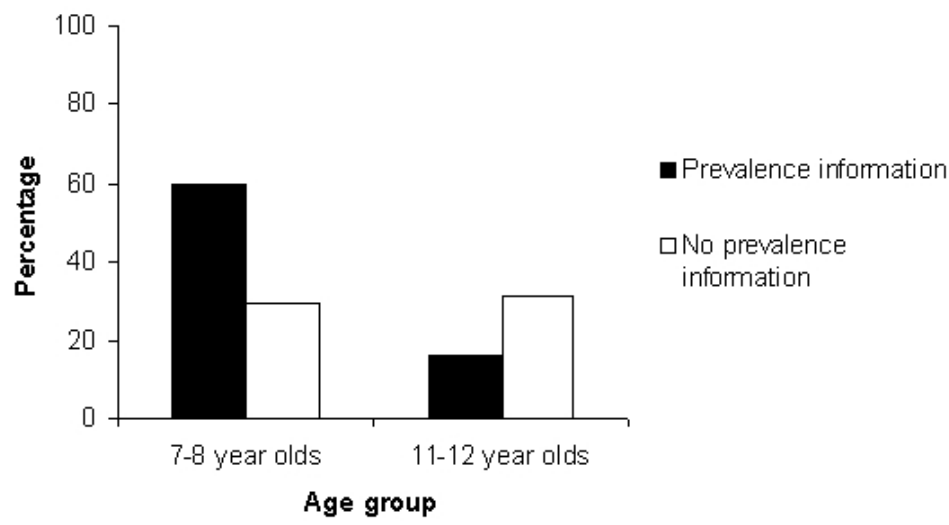

Figure 3. 2 Percentage of false memories in the prevalence information condition and in the no prevalence information condition at Interview 1.

\section{Conclusion}

This study examined the effect of prevalence information on implanting plausible and implausible false memories in 7-8 and 11-12 year old children. Our central finding is that combining false descriptions with prevalence information increased the rate of false memory reports in younger children during an initial interview. Prevalence information made younger children more likely to report memories of a fictitious plausible event (almost choking on a candy) and a fictitious implausible event (being abducted by a UFO). A substantial number of children (over $70 \%$ ) falsely remembered that they were abducted by a UFO. Although previous studies have looked at the cognitive characteristics of individuals who report UFO abductions (Clancy, McNally, Schacter, Lenzenweger, \& Pitman, 2002; McNally et al., 2004), this is the first study that succeeded to implant false memories of UFO abductions. The implications of this finding for forensic and clinical contexts are clear. Although we do not want to claim that children's testimonies about bizarre and implausible 
events, like those in the "McMartin Preschool" case, are always false, this study clearly shows that children easily develop false memories about a highly implausible event. 


\section{Script knowledge and children's false memories}

Otgaar, H., Candel, I., Scoboria, A., \& Merckelbach, H. (in press). Script knowledge enhances the development of children's false memories. Acta Psychologica. 


\begin{abstract}
The present study examined whether script knowledge contributes to the development of children's false memories. Sixty 7-year old and sixty 11-year old children listened to two true narratives and one false narrative describing either a script-present event (i.e., fingers being caught in a mousetrap) or a script-absent event (i.e., receiving a rectal enema) which were controlled for plausibility and pleasantness. Moreover, half of the children in each condition received additional script information about the false events. Across two interviews, children had to report everything they remembered about the events. Script knowledge affected children's false memories in that children developed more false memories for the script-present than for the script-absent event. Moreover, at the first interview, additional script information inhibited the development of children's images into memories.
\end{abstract}


Children are able to give detailed descriptions about events they experience in daily life (see Fivush, 1997; 1998). Although these descriptions can appear truthful, studies have shown that children can "remember" entire events that did not happen to them, also known as false memories (e.g., Otgaar, Candel, \& Merckelbach, 2008). A common procedure in these studies is to present children with false narratives or doctored photographs suggesting that they took part in a fictitious event (i.e., implantation paradigm: e.g., Otgaar, Candel, Merckelbach, \& Wade, 2009; Pezdek \& Hodge, 1999; Strange, Sutherland, \& Garry, 2006). Subsequently, they are encouraged to report everything they remember about the alleged event.

These studies have demonstrated that many children can be brought to falsely remember a plethora of events ranging from plausible (i.e., lost in a shopping mall,) to implausible events (i.e., abducted by a UFO). However, the exact precursors of these implanted false memories remain largely unknown. The aim of the present study was to examine whether schematic or script knowledge (i.e., knowledge structures specifying sequences of actions; Fivush, 1997) is a critical precursor of children's implanted false memories.

Most of the limited work examining the role of script knowledge has focused on the effect of script knowledge on beliefs and memories for adults. The findings of these studies have been mixed. Both Hart and Schooler (2006) and Scoboria and colleagues (2006) found that the provision of script knowledge of an event did not affect participants' beliefs about that event. To our knowledge, only one study has found that script knowledge does have an impact on false beliefs, but only when the target event is presented in a familiar context (Pezdek, Blandon-Gitlin, Lam, Hart, \& Schooler, 2006). Specifically, Pezdek and colleagues (2006) presented the event (i.e., receiving a rectal enema) as having occurred in the hospital (Study 1) or at home (Study 2). When participants read script information about receiving a rectal enema at home, they were more convinced that they experienced the event than when the knowledge was situated in the hospital. Pezdek and colleagues (2006) suggested that medical indications for receiving an enema, such as constipation, are quite familiar in home settings. Therefore, existing knowledge about constipations could easily overlap with a description of receiving a treatment for it.

While these studies suggest that providing script information could influence beliefs, they do not examine the contribution of existing knowledge upon belief and memory formation. Nor has this prior work controlled for key differences between target events 
which confound the results (see below). Finally, the studies cited above focus solely on the impact script knowledge has on beliefs in adults. Whether script knowledge contributes to the development of children's false memories, however, is a rather unstudied area of research.

Although research has shown that script knowledge affects false memories for details of experienced events (e.g., Elischberger, 2005; Kleider, Pezdek, Goldinger, \& Kirk, 2008; Nemeth \& Belli, 2006; Ornstein et al., 1998), only Pezdek and colleagues (1997; 1999) have provided evidence that script knowledge might be involved in the formation of false memories for entire events. That is, they suggested that events can only be implanted when they are plausible and script-relevant knowledge exists in memory. Pezdek and Hodge (1999) demonstrated that children developed more false memories for an event with more script knowledge (i.e., lost in a shopping mall) than for an event with less script knowledge (i.e., receiving a rectal enema). However, event plausibility and script knowledge were confounded in this study. The one study which examined both found no relationship between script knowledge and plausibility (Scoboria et al. 2004).

Interestingly, recent research suggests that event plausibility is not a critical determinant in the development of young children's false memories (Otgaar et al., 2009; Strange et al., 2006). Recent work by Ghetti and Alexander (2004) demonstrates that children tend not to use plausibility when evaluating unremembered events at or before the age of 7, whereas from the age of 9, children use plausibility in a manner similar to adults to reject false events. Because plausibility of events has not been well controlled in the preceding work on script knowledge, it is unclear how children use script information when considering unremembered events. Hence, work which examines the impact of script knowledge upon children's false memory formation, which controls for the plausibility of events, is needed.

Another manner in which events have likely differed in past research is in the degree to which they are judged as pleasant (or unpleasant) to experience. Studies which have contrasted events such as receiving a non-invasive medical procedure (e.g., an X-ray) or moderate unpleasant events (e.g., lost in a shopping mall; Pezdek \& Hodge, 1999) with receiving an enema have the additional confound that the enema event is typically viewed as invasive and uncomfortable, and therefore may be less likely to be endorsed as recalled.

To date, no study has examined whether script knowledge affects children's false memories for entire events while holding plausibility and pleasantness constant. Studying 
this issue has obvious theoretical and practical significance. Concerning the theoretical aspect, research has shown that although beliefs and memories are interrelated constructs, they are certainly not equivalent (Scoboria et al., 2004; Smeets, Merckelbach, Horselenberg, \& Jelicic, 2005). So, it is relevant to examine whether script knowledge impacts the formation of entire false memories. Besides this, it is theoretically unclear what level of knowledge about an event has to be present to facilitate memory performance and whether adding script knowledge would promote memory development (Pezdek et al., 1997; Pezdek \& Hodge, 1999). It is possible that children form false memories even when they have no knowledge about the event, or it may be that at least some small degree of knowledge must be present for a false memory to form. For example, the Mazzoni and Kirsch (2002) metacognitive model of false belief and memory formation predicts that lack of knowledge about an event may be used to reject an unremembered event as not having occurred (see Ghetti, 2008, for a similar application in children). Research on children's metamemory abilities indicates that younger children may be less able to use their knowledge effectively to determine whether events did or did not occur (see Ghetti \& Alexander, 2004; Koriat, Goldsmith, Schneider, \& Nakash-Dura, 2001). As children develop their metacognitive awareness, they likely become increasingly able to correctly reject events that have not occurred based upon their knowledge.

From a practical point of view, little is known about whether just having knowledge about an event has ramifications for falsely remembering an event (e.g., Loftus, 1993). Fortunately, children often have little information about traumatic events. Wellknown legal cases such as the "Wee Care Nursery School" and "McMartin Preschool" trials, however, clearly demonstrate that children can develop full-blown false memories of traumatic events (Ceci \& Bruck, 1993; Garven, Wood, Malpass, \& Shaw, 1998). Could it be possible that the children who developed false memories in these cases had some degree of detailed knowledge about the types of events they supposedly had experienced prior to being interviewed?

A paradigm specifically developed to induce false memories for entire events is the aforementioned implantation paradigm (e.g., Loftus \& Pickrell, 1995; Garry \& Wade, 2005; Pezdek \& Hodge, 1999; Pezdek, Finger, \& Hodge, 1997). Other than the Pezdek and Hodge (1999) study noted above, this paradigm has never been used to examine specifically whether script knowledge affects children's (or adult's) false memories. Using this approach is important, because it focuses upon actual false memory formation, rather than changes in 
belief and memory ratings as done in studies mentioned previously. Connected to this is the fact that, in contrary to the implantation paradigm, memory ratings used by the abovementioned studies do not gather exact information about the precise content of memory.

The aim of the present study was to investigate whether script knowledge affects the development of children's false memories. To control for confounding event characteristics, two target events were selected from a pilot group of 6-13-year old children, which demonstrated similar levels of plausibility and discomfort, but which differed in the amount of script knowledge. Using the implantation procedure, 7-year old and 11-year old children listened to fabricated narratives about a moderately plausible, script-absent event (i.e., receiving a rectal enema; Appendix A) or a moderately plausible, script-present event (i.e., fingers being caught in a mousetrap). Half of the children received additional script information about their event. Across two interviews, children had to indicate everything they remembered about the event.

On the basis of Pezdek and colleagues model (1997; 1999; 2006), that argued that script-relevant information must be retrieved from memory to facilitate the construction of an image of a false event, we hypothesized that for moderately plausible events, the scriptpresent event would evoke more false memories than the script-absent event. Regarding the role of additional script information, we predicted two possible outcomes. On the one hand, additional script information could enhance script relevant information about the target events, thereby boosting false memory rates for the events. On the other hand, additional script knowledge could also suppress false memory creation. This prediction is based on the idea that additional script knowledge could restrict imagination and/or inhibit recall fluency, because extra knowledge would include specific details, people, and locations, and thereby lowering chances for the construction of false memories (Garry \& Wade, 2005; see also Tesser \& Leone, 1977). This final prediction is also related to the discrepancy detection principle (Hall, Loftus, \& Tousignant, 1984) in which the likelihood of false memory formation will be reduced as awareness of discrepancies between an experienced event and suggested information increases. Hence, additional script information could result in a reduced overlap between an experienced event and suggested information which would end in the suppression of false memories.

With respect to age, many authors have noted that 7-year olds are more suggestible and more prone to false memory formation than 11-year olds (e.g., see for an overview Bruck \& Ceci, 1999; Ceci, Ross, \& Toglia, 1987). Therefore, we expected that the 
younger age group would assent more to the false events than the older ones. Furthermore, based upon Ghetti's (2008) work, we anticipated that if younger children are less effective at using a lack of script knowledge to reject the occurrence of events, then younger children should show more false memories for the script-absent event than older children.

\section{Method}

Participants

Participants were 120 primary school children (51 girls) from two different age groups ( $n=60,7$-years old, $M=7.37, S D=0.52$, range 7-8; $n=60,11$-years old, $M=11.33$, $S D=0.47$, range 11-12). Children received a small present for their participation upon completion. Informed consent was provided by the school and the children's parents. The study was approved by the standing ethical committee of the Faculty of Psychology, Maastricht University.

\section{Materials}

True narratives. Questionnaires were sent to the parents to obtain for each child two true events that happened to him/her at the age of four. Specifically, they were instructed to describe two moderately significant experienced events (e.g., birthday party, family trip) including what the event was, where it took place, when it took place and which who was present. These details were implemented in each of the true narratives, which were approximately five to six sentences in length. An example of a true narrative (translated from Dutch) was:

"Your mother told me that when you were 4 years old, you went to Euro Disney in France. This was for your birthday. Your parents and grandparents also joined you. You came there by bus. You mother told me you really loved the fairy forest."

False narratives. False events were selected from a pilot study in which 103 children $(M=8.48$ years, $S D=1.67$, range $6-13)$ rated the plausibility and pleasantness of 48 events on a 7-point Smiley scale (anchors: $:$ = implausible/negative, $(;=$ plausible/positive) with bigger Smiley faces indicating more plausible/more positive events. Specifically, children indicated how likely the events were to happen to them (e.g., "How likely is it that you personally could have received a rectal enema?"; i.e., personal plausibility; Scoboria et 
al., 2004) and how pleasant the events were for them (e.g., "How pleasant do you think it will be to receive a rectal enema?"). To make sure that they understood the procedure, two practice items were added. One might wonder whether children are able to rate the plausibility and pleasantness of events of which their knowledge may be limited (i.e., receiving a rectal enema). However, the Dutch equivalent of "rectal enema" (i.e., darmspoeling) is rather concrete and therefore contains more information than the English term, a circumstance that may have helped children to provide those ratings for this item. The majority of the pilot events was taken from literature on false memories (e.g., taking a hot air balloon ride; Wade, Garry, Read, \& Lindsay, 2002). Moreover, a randomly selected subgroup of the pilot group ( $n=55, M=8.56, S D=1.18$, range $6-11$ ) was asked to provide script knowledge for each of these events. Specifically, they were asked to report what typically happens when such an event occurs. The number of idea units was our measure of script knowledge (Scoboria et al., 2004). For example, if a child reported that an enema occurs at the hospital, then this was counted as 1 idea unit. Based on children's ratings, two critical events were selected: an event with no/very low script knowledge (script-absent event; "receiving a rectal enema"; $M_{\text {script }}=.18, S D=.66$, range $0-3$ ) and an event with script knowledge (script-present event; "fingers being caught in a mousetrap"; $M_{\text {script }}=1.00, S D=$ 1.12 , range $0-4), t(53)=3.40, p<.01, d=0.87$. Both events were similar in terms of pleasantness $\left(M_{\text {mousetrap }}=1.55, S D=1.63, M_{\text {rectal enema }}=1.09, S D=.45\right), t(100)<1$, n.s. $(1$ missing value $)$ and plausibility $\left(M_{\text {mousetrap }}=4.86, S D=2.69, M_{\text {rectal enema }}=4.60, S D=.2 .48\right)$, $t(100)<1$, n.s. $(1 \text { missing value })^{8}$. Parents of the children participating in the current study confirmed that their children had not experienced the target events.

Additional script knowledge. For the false events, additional script knowledge adopted from Pezdek and colleagues $(1997 ; 1999)$ and Ceci, Huffman, Smith, and Loftus (1994) was incorporated in the description of the narratives. More precisely, the procedures that were involved in these events were added (For examples of the narratives with/without additional script knowledge, see Appendix A). As a manipulation check, 18 children ( $M=$ $9.44, S D=2.12$, range 7-13) were asked about script knowledge of the target events before and after the presentation of additional script knowledge. Children reported more script knowledge about the target events after the presentation of additional script knowledge

\footnotetext{
${ }^{8}$ Younger (6-7-year old) and older (11-12-year old) children's plausibility, pleasantness, and script knowledge ratings did not statistically differ for the two target events (all ps > .05).
} 
$\left(M_{\text {mousetrap }}=5.55, S D=2.50, M_{\text {rectal enema }}=4.33, S D=1.71\right)$ than before $\left(M_{\text {mousetrap }}=2.67, S D=\right.$ $1.24, M_{\text {rectal enema }}=0.61, S D=0.98, t_{\text {mousetrap }}(17)=-4.91, p=.001, d=1.04, t_{\text {rectal enema }}(17)=-$ $8.58, p<.001, d=2.25)$.

\section{Design and Procedure}

This study relied on a 2 (Age: younger children vs. older children) $\times 2$ (Event type: script-absent vs. script-present) $\times 2$ (Additional script knowledge: yes vs. no) betweensubjects design. Children were randomly assigned to event type and to additional script knowledge.

Interviews were administered individually, twice over a seven-day period. A digital voice device recorded all interviews. The procedure of the interviews was adopted from Wade et al. (2002). During each interview, children listened to two true narratives and one false narrative. The false narrative was always located in the third position. Before Interview 1 started, the interviewer told each child that we were interested in their memories for events that occurred when they were 4 years old and that they had to report everything they could remember about these events. Children who were unable to say anything about the events were told that "many people can't recall certain events because they haven't thought about them for such a long time. Please concentrate and try again." If they still did not come up with any details, context reinstatement and guided imagery techniques were applied to bring the children mentally back to the scene of the event. More precisely, children were told to close their eyes and were instructed to think about their feelings, who was with them, and about the time of the year. Next, children were asked once more to recall any details about the events. If they were still unable to come up with any additional information, the next event narrative was presented.

After the first interview, children were told that they had to think about these events every day and they were encouraged to come up with more details during the second interview. Moreover, they were instructed not to talk with others about the events. Likewise, children's parents were asked not to discuss the events with their children. Interview 2 was identical to Interview 1. Debriefing occurred at the end of the second interview and was constructed according to ethical guidelines for false memory research with children (Goodman, Quas, \& Redlich, 1998). 
Scoring

True memories were classified as either remembered or not remembered. A memory was classified as remembered if a child reported at least two of the three correct details (i.e., where, when, with whom) provided by the parents correctly. Using criteria adopted from Lindsay, Hagen, Read, Wade, and Garry (2004), children's responses to the false events were coded as no false memory, images but not memories or false memory. Thus, a child that tried to recall, but did not have any memory of the event and did not report any details related to the event, was labeled as having no false memory. Images included children's speculations about the event and image descriptions related to the event. A false memory was scored when a child indicated that it remembered the false event and reported details not mentioned in the narrative, but related to the false event. If a child merely indicated that the event could have happened and/or thought the event happened, then this was not classified as a false memory. Also, to counteract the effect of demand characteristics, direct positive responses (e.g., "yes") to interviewer prompts were not categorized as a false memory. Two raters who were blind to the conditions and hypotheses of the study classified transcripts; inter-rater agreement (K) was high: .91 and .95 for Interview 1 and Interview 2, respectively.

\section{Results}

True events

A maximum of 240 true events could be reported, with children remembering 214 (88\%) events at Interview 1 and 229 (95\%) events at Interview 2, $\chi^{2}(1)=6.59, p<.01$, Cramer's $V=.12$. No significant age differences were found in remembering true events at both interviews (all $p s>.05$ ).

False events

Twenty-two percent $(n=26)$ of the children had an image of the false event at Interview 1 , while at Interview 2, 23\% $(n=27)$ of the children were similarly classified, $\chi^{2}(1)=$ .02 , n.s. This 11 -year-old child's report is an example of an image of receiving a rectal enema: "I think they did something with my stomach, something with a small tube. And that had to be at the hospital or at the doctor." 
Furthermore, 22\% ( $n=26)$ of the children indicated that they experienced the false event at Interview 1, with $42 \%(n=11)$ of them instantly, that is preceding the guided imagery and context reinstatement techniques, reporting a false memory. At Interview 2, this pattern remained rather similar with $21 \%(n=25)$ of the children reporting having experienced a false event $\left(\chi^{2}(1)=.03\right.$, n.s). This time, $76 \%(n=19)$ of these children immediately reported a false memory, Appendix B gives examples of false memories for both events.

Recall that the aim of the present study was to examine whether script knowledge enhances the development of children's false memories. In doing so, logistic regression analyses were conducted with false memory $(0=$ no false memory/images, $1=$ false memory) as the dependent variable and event type, age, additional script knowledge, and corresponding two-way and three-way interactions as predictor variables. No significant interactions were detected at both interviews (all ps > .05). Therefore, logistic regression analyses were computed with only event type, age, and additional script knowledge as predictor variables. As expected, a significant main effect for event type was found at both interviews. Specifically, children who were provided with the mousetrap-event (scriptpresent event) were more likely to create a false memory than children who received the enema-event (script-absent event; Interview $1: B=-1.37, S E=.50$, Wald $=7.51$, adjusted $O R$ $=.25, p<.01$; Interview $2: B=-1.57, \mathrm{SE}=.53$, Wald $=8.82$, adjusted $O R=.21, p<.01$; see Figure 4.1). Notwithstanding the main effect of event type, $23 \%$ of the 7 -year-olds $(n=7)$ at Interview 1 and $19 \%$ of this subgroup $(n=6)$ at Interview 2 falsely remembered the rectal enema event (see Table 4.1).

Although some 7-year-old children (Interview 1: $n=7$; Interview 2: $n=6$ ) falsely reported a rectal enema event, their memory report was limited. Specifically, an ANOVA with the dependent variable being number of words used for describing the false events, showed a significant main effect of event type (i.e., mousetrap event vs. rectal enema event; $F(1,29)=5.01, p<.05$, partial $\left.\eta^{2}=.15\right)$ with 7-year-old children using more words for describing the mousetrap event $(M=35.89, S D=26.61)$ than for the rectal enema event $(M$ $=17.85, S D=13.54)$. However, although the number of words for describing the rectal enema event was limited, these reports fulfilled the false memory criteria. 


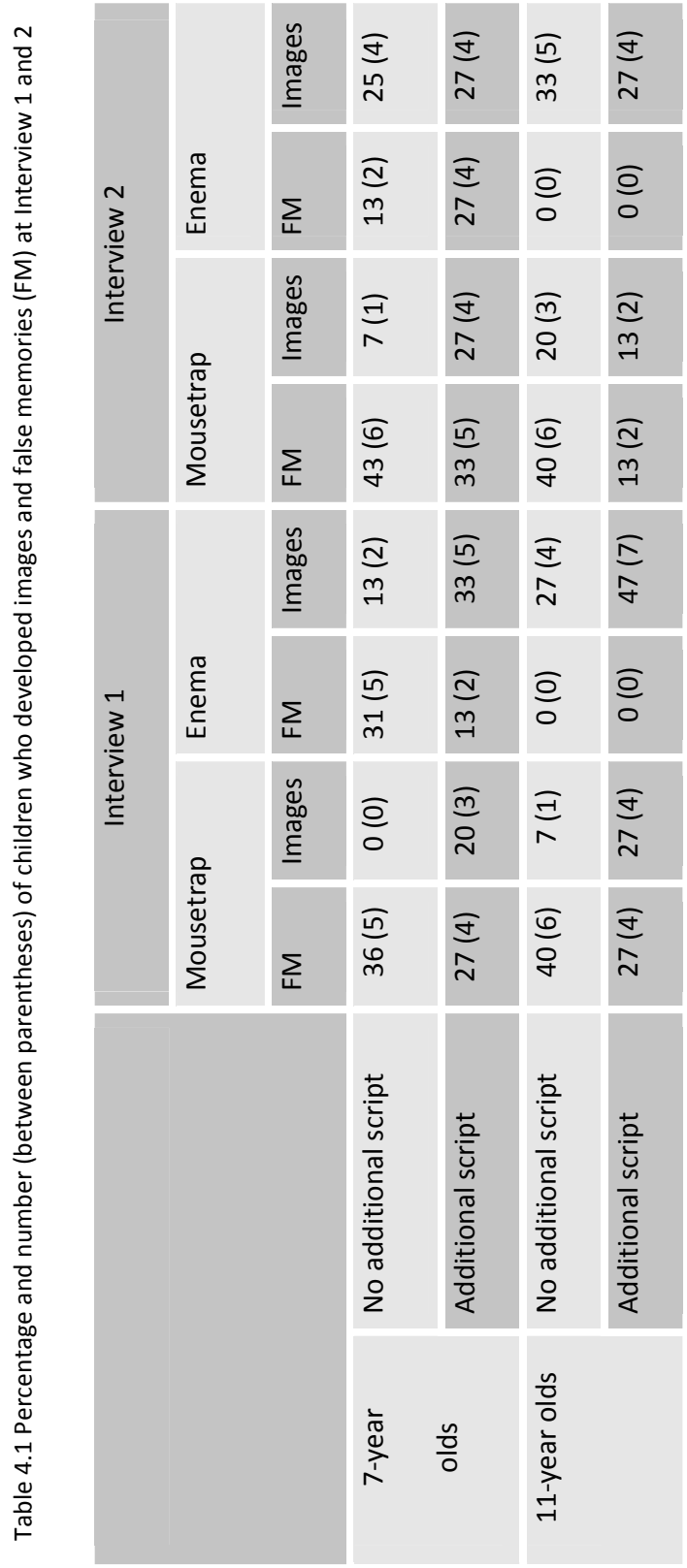




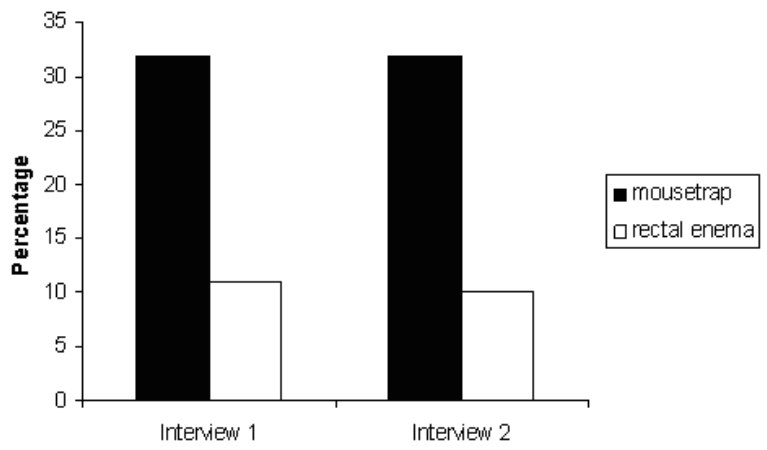

Figure 4.1 Percentage of children's false memories for the mousetrap-event and rectal enema-event at both interviews.

Concerning the explorative role of additional script knowledge, results indicated that additional script knowledge did not contribute to false memory creation at both interviews (Interview 1: $B=.68, S E=.48$, Wald $=2.05$, adjusted $O R=1.97$, n.s.; Interview 2: $B$ $=.38, S E=.48$, Wald $=.62$, adjusted $O R=1.46$, n.s.). To explore whether providing additional script information suppressed false memory construction, we conducted exploratory analyses of the effects of each upon the relative rates of development of images vs. memories. In other words, logistic regression analyses contrasting the images and memory categories for Interview 1 revealed main effects for age $(B=1.73, S E=.79$, Wald $=4.82$, adjusted $O R=5.64, p<.05)$, event type $(B=-2.70, S E=.85$, Wald $=10.15$, adjusted $O R=.07$, $p<.01)$, and additional script knowledge $(B=2.04, S E=.78$, Wald $=6.89$, adjusted $O R=7.71$, $p<.01)$. At Interview 2 , a significant main effect emerged for event type $(B=-1.87, S E=.66$, Wald $=7.93$, adjusted $O R=.16, p<.01)$, and the main effect for age was marginal $(B=1.25$, $S E=.68$, Wald $=3.34$, adjusted $O R=3.48, p<.07)$. The effect for additional script knowledge, however, was no longer significant $(B=.51, S E=.62$, Wald $=.63$, adjusted $O R=$ 1.67, n.s.). Furthermore, a significant age effect was present at Interview $2(B=1.06, S E=$ .50, Wald $=4.51$, adjusted $O R=2.89, p<.05$ ) with younger children concurring more to the false events than older children.

Interestingly, additional script knowledge was associated with greater frequency of images whereas no script information was associated with more memories, but only following the first interview. Thus, the addition of script information inhibited the formation of memories at the time it was presented. Furthermore, younger children were more likely than older children to be categorized as having a memory than just an image and the 
mousetrap event was more likely to be categorized as memory whereas the rectal enema event was more likely to be labeled as images during both interviews (see Table 4.1).

\section{Discussion}

The aim of the present study was to examine whether script knowledge affects the formation of children's false memories. This study is the first demonstration showing that children more easily develop false memories for events of which they have knowledge (i.e., fingers being caught in a mousetrap) than for events of which their knowledge is very limited (i.e., receiving a rectal enema). Furthermore, we found that at the second interview, younger children developed more false memories than their older counterparts. A subsidiary aim of our study was to explore whether additional script information would boost false memory development. On the contrary, additional script knowledge inhibited the development of children's images to false memories during the first interview.

Our finding that the script-present event (i.e., fingers being caught in a mousetrap) elicited more false memories than the script-absent event (i.e., receiving a rectal enema) is in agreement with Pezdek and colleagues' research (1997; 1999; 2006). These authors argued that events are likely to be implanted when they are plausible and when scriptrelevant knowledge exists in memory. In our study, events differed in script knowledge, while we held other factors (plausibility, pleasantness) constant. Clearly, in our study, children possessed more script knowledge about the mousetrap event than about the enema event. So, presented with a fictitious narrative about a script-present event (e.g., the mousetrap event), children more easily retrieve script-relevant knowledge about this event from memory (e.g., knowing what a mousetrap looks like). If they subsequently develop an image of the event, it may well be the case that the image is misattributed to a real event and that details of related script knowledge (i.e., knowing how a mousetrap looks like) will be "transferred" to this misattribution. Our finding that more false memories occurred for the mousetrap-event than for the enema-event fits nicely with what Pezdek and colleagues (1997; 1999) dubbed "the lack of knowledge inference". This inference that was first described by Gentner and Collins (1981), consists of metaknowledge about events that people use when they have to evaluate whether an event has happened to them or not. 
Concerning the rectal enema event, children might not know exactly what a rectal enema is and therefore conclude that they never received a rectal enema.

The finding that children developed more false memories for the script-present than the script-absent event could be related to findings showing that children reject false events if they are perceived as highly memorable (Ghetti, 2008; Ghetti \& Alexander, 2004). According this research, when children believe a false event is memorable, they interpret their lack of memory of the event as an indication that the event did not occur and therefore reject it (see also Mazzoni \& Kirsch, 2002). So, in the current study, the rectal enema event could have been considered to be extremely memorable which resulted in more children rejecting the rectal enema event as an experienced event than children rejecting the mousetrap event.

We also showed that in the second interview, younger children were more likely to develop a false memory than the older children. This corresponds to other studies reporting developmental differences in false memory formation (e.g., Pezdek \& Hodge, 1999; Strange et al., 2006). Younger children are more likely to concur to suggestive methods, such as fictitious narratives, than older children. Our finding is related to research suggesting that younger children do not yet posses optimal source-monitoring capabilities to distinguish between real and fictitious events (Lindsay, Johnson, \& Kwon, 1991; for an overview see Robert \& Blades, 2000). This age effect, however, was only present at the second interview. At the first interview, $13 \%(n=16)$ of the younger children assented to the false events against $8 \%(n=10)$ of the older children, yet this difference did not reach statistical significance.

An exploratory enterprise in our study was to examine whether additional script knowledge would strengthen false memory effects. We, however, did not find that providing children with additional script knowledge leads to enhanced false memory ratings. It could well be that a single presentation of additional script knowledge is just not enough to establish a well-structured script of the event. Indeed, developmental research shows that only after repeated experience, children are able to construct well-organized scripts of events (see for an overview Farrar \& Goodman, 1992; Hudson, Fivush, \& Kuebli, 1992). Therefore, it is possible that children need to be repeatedly exposed to additional script knowledge in order to find any effects on false memory rates. One factor that could also play a role in this context is that even for younger children a single presentation of additional 
information might be easy to identify as an external source (e.g., presented by someone else), thereby lowering the chances for source misattributions.

Also, our additional script information was rather generic, and thus may not have promoted a sense of familiarity. Desjardins and Scoboria (2007) recently found that providing participants with self-relevant information is effective in producing elevated false memory levels. According to these authors, self-relevant knowledge may trigger selfschematic processes, thereby fostering the development of false memories (see also Markus, 1977). It may well be that personally-crafted script information would aid in the production of false memories.

Interestingly, at Interview 1, for children who formed images or memories each factor (age, event type, additional script knowledge) significantly influenced which type emerged. Thus, higher age was associated with more images and lower age with more memories; the script-absent (enema) event was associated with more images and the scriptpresent (mousetrap) event with more memories. Furthermore, adding script knowledge was associated with more imagery and no additional script knowledge with more memories. This final observation is particular interesting as it suggests that the addition of script knowledge may have inhibited the development of images into memories. This is in agreement with the idea which posits that the provision of detailed information may in fact constrain the memory search, and in fact inhibit the development of false memories (Garry \& Wade, 2005). Furthermore, this finding is related to the discrepancy detection principle (Hall et al., 1984) which states that the greater the distance is between an experienced event and suggested information (e.g., additional script knowledge), the less likely that the suggestive information will be accepted. Therefore, in our study, one could contend that adding extra knowledge about an event increased the gap between an experienced event and suggested information which ended in the inhibition of false memories.

The finding that adding extra knowledge inhibited the development of false memories adds to evidence that the distinctiveness of information reduces false memory rates (Ghetti, Qin, \& Goodman, 2002; Hege \& Dodson, 2004; Howe, 1998; 2008). Specifically, in our study, the addition of extra knowledge could have made the false events more distinctive which in turn led to an inhibition of false memories. Moreover, it seems that this effect is time-dependent because this effect was only present at Interview 1 . It could well be that, at Interview 2, children who received additional knowledge about the false events did not regard it as unique anymore, because they had thought about the events between 
Interview 1 and 2. Hence, the passage of time could have decreased the distinctiveness of the false events such that extra knowledge did not inhibit false memory rates at Interview 2.

A further striking result in our study was that a substantial number of the 7-yearold children (Interview 1: $n=7$; Interview 2: $n=6 ; 23 \%$ ) "remembered" receiving a rectal enema at age 4, while none of the 11-year-olds falsely remembered this event. This finding could be related to the proposition that younger children are less able to reject false events when they have limited knowledge about them (Ghetti, 2008). This result is also in sharp contrast with Pezdek and colleagues' finding $(1997 ; 1999)$ that 4 children $(10 \%)$ adopted the enema event. We suspect that our finding has to do with our Dutch translation of "rectal enema" (i.e., darmspoeling), that includes more information than the English words. Accordingly, although 7-year-old children did not know exactly what a rectal enema is, they could still make some loose associations about the term. To give an example, one child reported that something went into his stomach and that he felt water going through his stomach. The words "stomach" and "water" could be the only associations that popped up into children's memory when they were presented with the rectal enema event. Since children have a more structured script of a mousetrap event, more associations can be created about this event which in turn could have caused more detailed and elaborated false memory reports of the mousetrap event.

The results of the current study bear relevance to legal cases where children have background knowledge about a non-experienced event and are suggestively interrogated about this event. They support the idea that having knowledge about an event facilitates the development of false memories of such an event, an idea that has received, up until now, little empirical attention (e.g., Loftus, 1993); yet providing children with additional information could also constrain the development of false memories. Clearly, there is a difference between the exact impact of innate knowledge and adding extra information on false memory formation. Hence, studying under which circumstances script knowledge would facilitate and/or suppress false memory formation would be of utter interest in future research. 
Appendix A Examples of the narratives with/without additional script knowledge.

Rectal enema event with additional script knowledge:

"Your mother told me that when you were 4 years old she let you eat too much. After a couple of days of junk food though, you started to feel really sick. You couldn't go to the bathroom. Your mother thought you should have a rectal enema. An enema is when you have some warm water put into your bottom to help you. Your mother remembered telling you that the enema wouldn't hurt and that it would make you feel better. You were scared anyway though, because when your mother took you into the bathroom, she remembered that you cried a lot."

Rectal enema event without additional script knowledge:

"Your mother told me that when you were 4 years old, you received a rectal enema."

Mousetrap event with additional script knowledge:

"Your mother told me that when you were 4 years old, you were at the attic at someone's place. You did not know that there well all mousetraps. When you did not pay attention, you finger got caught in a mousetrap. Your mother remembered that you said it hurt and that you were crying. Then your mother brought you to the hospital to release the mousetrap from your finger. The doctor then putted a bandage on your finger"

Mousetrap event without additional script knowledge:

"Your mother told me that when you were 4 years old, you finger got caught in a mousetrap." 
Appendix B Examples of false memories for the script-present and script absent event Mousetrap event:

Child: "I fell and there was suddenly a mousetrap. Then I placed my hand in front of the mousetrap. Then the clicking mousetrap got caught in my index finger, right here." Interviewer: "Where did this happen?"

Child: "This happened at my uncle and aunt's place. And then I cried. I cried a lot and then my mother came and brought me downstairs. Then we went outside and went to city hospital by bike, because it had to be in plaster. And then we were at the emergence department or something like that, and then I received an injection. And then I fell asleep."

Rectal enema event:

Child: "I was four years old and then I had to go to the doctor. Then he had a look at my stomach and there was [inaudible word]. And then I had to lie down and there was something in my stomach, but I know what. It was a sort of little stone which was connected to my heart and little pipes. And then he got rid of it." 



\section{Valence and children's false memories}

Otgaar, H., Candel, I., \& Merckelbach, H. (2008). Children's false memories: Easier to elicit for a negative than for a neutral event. Acta Psychologica, 128, 350-354. 
Abstract

The present study examined the role of valence in the development of children's implanted false memories. Seventy-six 7-years-old children listened to two true and one false narrative. The false narrative was either neutral ("moving to another classroom") or emotional negative ("being accused by the teacher for copying off your neighbor"). In addition, half of the children were presented with their class photograph while listening to the narratives. During two interviews, children recalled as many details as possible from the true and false events. Results showed that the negative event elicited more false memories than the neutral event. The presentation of a true photograph did not promote the development of false memories. 
There is an abundance of studies showing that it is relatively easy to elicit false memories, i.e., memories for events that were never experienced, in both adults and children (e.g., Loftus, 2004). Loftus and Pickrell (1995), for example, demonstrated that exposing participants to suggestive narratives promotes the development of false memories. In their study, adults listened to false narratives describing how they were lost in a shopping mall in their childhood. Next, they were instructed to recall everything they could remember about the event. After two interviews, $25 \%$ of the participants $(n=6)$ reported details about the never experienced event. More recently, Wade and colleagues (2002) demonstrated the suggestive power of doctored photographs. In their study, adults were confronted with false photographs depicting themselves during a hot air balloon ride. Over three interviews, they were instructed to recall the event as detailed as possible. Fifty percent $(n=10)$ of the participants eventually concurred with the hot air balloon ride. Despite this straightforward finding, Lindsay et al. (2004) questioned the ecological validity of the doctored photograph paradigm. These authors argued that in real life, people rarely encounter doctored photographs. They do, however, look occasionally at true photographs. Some traumamemory-oriented psychotherapists even use true photographs to help their clients to remember negative events that might have happened to them in their childhood (cf. Poole, Lindsay, Memon, \& Bull, 1995). To examine the effects of true photographs on the development of false memories, Lindsay et al. (2004) presented half of their adult participants with true class photographs that served as a memory cue (photograph condition). All participants were given a false narrative describing that they put "slime" (i.e., a brightly colored gelatinous compound used as a toy) in the teacher's desk when they were a child. Sixty-six percent of the participants $(n=18)$ in the photograph condition developed a false memory for the slime event as compared to $25 \%$ of the participants $(n=5)$ in the nophotograph condition. Lindsay et al. argued that three mechanisms might account for these findings. First, the presentation of the photograph may have strengthened the apparent authenticity of the suggestive narrative. Second, the photographs may have encouraged participants to speculate about details of the false event. Third, the photograph might have triggered memories of perceptual details (e.g., the teacher's appearance) which then might have become mixed up with imaginative details of the false event.

Like Lindsay et al.'s study, subsequent studies relying on photographs to elicit false memories in adults and children have focused exclusively on innocuous target events (see for an overview Garry \& Gerrie, 2005). Thus, Wade et al. looked at false memories for a 
hot air balloon ride, whereas Strange et al. (2006) used "drinking a cup of tea with a member of the British royal family" as one of their target events. Legal cases, however, are often about negative events. Therefore, the question arises whether negative events might become the target of false memories as easy as more neutral events. Moreover, no false memory studies using true photographs have concentrated on negative and neutral target events. Also, studying the effect of true photographs on memories for negative events is of practical interest, since many trauma-oriented therapies use true photographs as a means to discuss mainly emotional negative events (Poole et al., 1995).

There are only a handful of studies that used the false narrative paradigm to examine whether valence of false target events affects the development of false memories. These studies have come up with mixed findings. For example, Ceci and colleagues (1994) demonstrated that fewer children assented to a negative false event ("falling off a tricycle

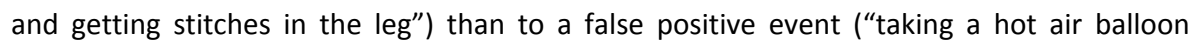
ride"). On the other hand, Hyman et al. (1995) found that adults who were exposed to false feedback information were equally likely to develop false memories for a negative event ("an overnight hospitalization") and a positive event ("a birthday party with pizza and a clown"). In sum, few studies involving children looked at false memories for a more ecologically valid negative event.

The purpose of the present study was to examine the role that valence of target events plays in the development of children's false memories. We hypothesized that a negative target event would elicit more false memories than a neutral one. This expectation was based on recent findings by Talmi and colleagues $(2004,2007)$ that negative emotional information is more highly associated and interrelated in memory than neutral information. Moreover, research suggests that the associative structures that underlie emotional information may be available earlier than neutral information during the development (e.g., Pollack \& Kistler, 2002). Therefore, to the extent that false memories rely heavily on interconnected associative structures (for a review, see Gallo, 2006), we expected that a false narrative about a negative event would elicit more false memories than a false narrative about a neutral event. Our hypothesis that a negative target event would evoke more false memories than a neutral one is also based on the paradoxical negative emotion hypothesis (Porter et al., under review; Porter et al., 2008). According to this hypothesis, negative information will be well recalled over time, but will also be more vulnerable for memory distortion over time than other information. This counterintuitive prediction could 
be explicated from an evolutionary perspective. That is, although negative events should be well remembered to avoid future dangers, it would be of adaptive value to include relevant information about negative events from other reliable sources (e.g., family, therapists, or researchers). Indeed, recent studies using misinformation and implantation paradigms suggest that negative information increases the susceptibility for false memory formation (e.g., Candel, 2006; Nourkova, Bernstein, \& Loftus, 2004; Porter et al., 2003; Porter et al., 1999). According to Porter and colleagues (under review), the intense (negative) emotion associated with the negative information does not protect memory from false memory effects, but actually increases the likelihood for memory distortion. A subsidiary aim of the present study was to explore whether the presentation of a true photograph would have an effect on false memory rates. To test this, children were presented with either a neutral or a negative false narrative that was either accompanied with a true class photograph or not. Based on Lindsay et al. (2004), we expected that a true photograph would promote false memories for both negative and neutral target events.

\section{Method}

\section{Participants}

Seventy-six second grade children $(M=7.62$ years, $S D=0.59 ;$ range 7-9) participated in this study. All children had parental consent and received a small present in return for their participation. The study was approved by the standing ethical committee of the Faculty of Psychology, Maastricht University.

\section{Materials}

True narratives. Children's first grade teachers provided written information about two moderately unique class events that happened to all children a year ago. Event descriptions had to contain information about what the event was, where it took place, and when it took place. These details were integrated in the true narratives. True narratives had a length of approximately 3 sentences. An example would be "Your teacher from the first grade, miss/mister (name of the teacher), told me that the entire class had to perform a musical. This happened in the summer."

False narratives. Our two target events were selected from a pilot study. In that study, 54 children $(M=8.93$ years, $S D=2.14$; range $7-13)$ rated the plausibility and valence 
of 10 class events (e.g., "seeing the teacher faint") on two different 7-point Smiley scales (anchors: $:$ : = implausible/negative, $(:)$ = plausible/positive) with bigger Smileys indicating more plausible/more positive events. Specifically, children were asked how likely to happen the events were for them (i.e., personal plausibility; Scoboria et al., 2004) and how pleasant the events were for them. Children crossed the smiley face that corresponded to their answers. Based on the valence ratings, we selected two events: a neutral event (i.e., "moving to another classroom"; $M=4.28, S D=2.24$ ) and a negative event (i.e., "being accused by the teacher for copying off your neighbor"; $M=1.34, S D=1.27, t(52)=-9.18, p<$ $.001,1$ missing value). These events did not differ in terms of plausibility ( $M_{\text {neutral }}=6.11, S D=$ $1.53, M_{\text {negative }}=5.93, S D=1.78, t(53)<1$, n.s.). Furthermore, a randomly selected group of 18 children $(M=9.44, S D=2.12$, range $7-13)$ also had to provide script knowledge about the target events. That is, they were instructed to report the typical procedures of our target events. Script knowledge was assessed by using the number of idea units that children reported (Scoboria et al., 2004). For example, when a child reported that all belongings should be brought to the other classroom when the whole class has to move to another classroom, this counted as 1 idea unit. Script knowledge did not significantly differ between the two events $\left(M_{\text {neutral }}=3.33, S D=1.28, M_{\text {negative }}=2.83, S D=1.54, t(17)=1.28\right.$, n.s. $)$.

The false narratives were complemented with self-relevant details of the name of the teacher and the grade in which the events allegedly happened. The following descriptions were used as the neutral and negative false narrative, respectively: "Your teacher from the first grade, miss/mister (name of the teacher), told me that your class suddenly had to move from one classroom to another. You had to take all your belongings with you to the other classroom" and "Your teacher from the first grade, miss/mister (name of the teacher), told me that he told you a year ago that you were copying off your neighbor. This shocked you very much, because you were not copying at all." The teachers confirmed that the children had never experienced these events.

Photographs. Photographs were authentic class photographs from the first grade.

\section{Design and Procedure}

The study employed a 2 (photograph: yes vs. no) x 2 (valence: neutral vs. negative) between-subjects design. Children were randomly assigned to one of the four conditions. They were interviewed individually twice, with one week in between. All interviews were audio taped and transcribed. At the beginning of the first interview, children were told that 
we were interested in what they could remember of some class events that happened to them a year ago. During each interview the two true narratives and the false narrative were read aloud. The false narrative was always presented in the third position. The interview procedure was similar to that used by Lindsay et al. (2004). Children were instructed to report freely about the events. In the photograph condition, children were shown a photocopy of their class photograph when the narratives were read to them. If children were not able to recall an event, they were told that "many people can't recall certain events because they haven't thought about them for such a long time. Please concentrate and try again". Children who still did not report any details of the event, were involved in guided imagery and context reinstatement techniques. Specifically, children were told to close their eyes and were taken mentally back to the scene of the event. Next, they were asked to think about their feelings, who was with them, and about the time of the year. In such cases, the order of instructions was fixed. Subsequently, children were asked once more to recall the event as detailed as possible. If they were still not able to come up with details, the next narrative was presented.

At the end of the first interview, children were instructed to think about the events every day and if they could remember anything else at the following interview. In addition, children in the class photograph condition received a copy of the photograph. They were instructed to use the photograph as memory cue when thinking about the events. Moreover, all children were asked not to talk with others about the events. Also, parents were instructed not to discuss the events with their child. Interview 2 was identical to Interview 1 . At the end of the second interview, children were debriefed.

\section{Scoring}

Responses to true events were only classified as remembered if a child correctly recalled at least two of the three (what, where, when) event details provided by the teacher. Responses to the false events were scored as false memories if a child stated that it remembered the false events and reported details beyond those mentioned in the false narrative. Likewise, if a child attempted to recall, but did not have any memory of the event, its report was classified as "no false memory". These criteria were adopted from guidelines formulated by Strange et al. (2006). Two trained, independent raters scored all false reports. Inter-rater agreement for Interview 1 and Interview 2 (к) was .87 and 1.00, respectively. 


\section{Results}

True events

A total of 152 events had to be recalled. One hundred and twenty-one events (80\%) were remembered at Interview 1, while at Interview 2, 136 events (89\%) were remembered, $\chi^{2}(1)=25.75, p<.001$, Cramer's $V=.41$.

\section{False events}

At Interview 1, 57\% $(n=43)$ of the children developed a false memory and $23 \%$ ( $n$ $=10$ ) of these developed a false memory after having been exposed to guided imagery and context reinstatement techniques. Of these 43 children, no child rejected the false event at Interview 2. At interview 2, 74\% $(n=56)$ of the children "remembered" the false event, $\chi^{2}(1)$ $=35.37, p<.001$, Cramer's $V=.68$. Five percent $(n=3)$ of these children assented to the false narratives after confrontation with the guided imagery and context reinstatement techniques. The increase of false memories over time is in accordance with previous studies (e.g., Lindsay et al., 2004; Wade et al., 2002). The following report from Interview 2 is an example of a negative false memory.

Child: I can remember I was doing math. I was sitting next to a boy or a girl, I don't remember. Then I did something, and the boy said: "Why are you copying my work?" But I was only grabbing my pencil. Then he told the teacher and she said: "Why did you cheat?" But I really didn't.

Interviewer: How did you feel?

Child: I was scared because I thought I would get punished. 
Figure 5.1 shows the percentage of children developing a false memory as a function of valence of false target events and absence or presence of photographs.

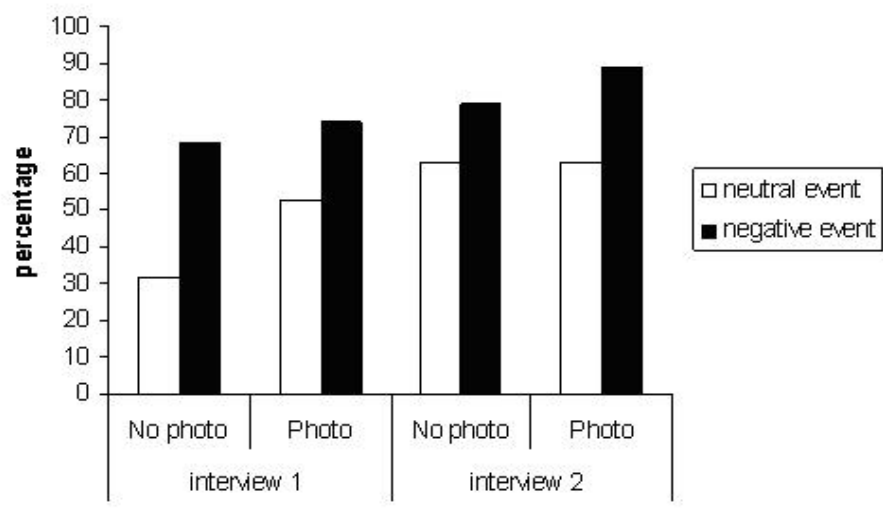

Figure 5.1 Percentage of children who developed false memories at Interview 1 and 2

For data obtained at both interviews, we conducted separate logistic regression analyses, with valence and photographs as predictor variables and presence/absence of false memories as criterion. We found a non-significant Valence $x$ Photograph interaction at both interviews (Interview 1: $B=.62, S E=.99$, n.s.; Interview 2: $B=-.82, S E=1.15$, n.s.). However, there was a significant main effect of valence at both interviews (Interview 1: $B=-$ 1.24, $S E=.49$, Wald $=6.36, \operatorname{Exp}(B)=.29, p<.05$; Interview 2: $B=-1.14, S E=.56$, Wald $=4.16$, $\operatorname{Exp}(B)=.32, p<.05)$ with the negative narrative eliciting more false memories than the neutral narrative. The main effect of photograph was non-significant at both interviews (Interview 1: $B=.59, S E=.49$, n.s.; Interview 2: $B=.29, S E=.54$, n.s.).

\section{Discussion}

The aim of the present study was to examine the role of valence of false target events in the development of children's false memories. Our study is the first to show that a more ecologically valid false target event with negative connotations is more likely to give rise to a false memory than a neutral false target event, a finding that has obvious implication for the legal domain (see below). This valence effect is in accordance with recent research suggesting that negative information increases the susceptibility for false memory 
formation (e.g., Candel, 2006; Nourkova et al., 2004; Porter et al., 2003; Porter et al., 1999). Moreover, our valence effect is in agreement with the paradoxical negative emotion hypothesis which states that negative material will not only be recalled well over time, but will also be at risk for the development of false memories (Porter et al., under review). Furthermore, we also found that at least in children, the presentation of a recent photographic cue (i.e., a class photograph from previous year) does not enhance the development of false memories.

As demonstrated by Talmi and colleagues (2004, 2007), emotionally negative information and neutral information are organized differently in memory. That is to say, negative information is more interrelated than neutral material. As a result, the presentation of negative information - either true or false- might increase the possibility that other negative material becomes activated in memory. This, in turn, could affect the development of a false memory for a negative event. Thus, in the current experiment, the presentation of the negative false narrative about the teacher's accusation of copying off might have activated negative class events that actually did happen to the children, such as getting punished for being boisterous in the classroom. As a by-product of this activation, children might be more willing to believe that the negative false event has also happened to them and this may raise the probability that they develop a false memory for the event. Since neutral information is less interrelated in memory than negative-emotional information, this "chain reaction" will not occur when children are presented with neutral false information.

In terms of fuzzy-trace theory (Brainerd \& Reyna, 1998), one could argue that negative narratives produce relatively more gist memory while neutral narratives produce relatively more verbatim memories. Indeed, recent research suggests that gist representations often include valence (e.g., negative/positive evaluation of an event) and emotions (see for an overview Rivers et al., 2008). Given the fact that gist memories are more stable over time than verbatim memories and given that false memories are almost always gist-based (Reyna, Holliday, \& Marche, 2002), one predicts that negative narratives more readily evoke false memories than neutral narratives. This prediction is borne out by the current data.

Our finding that children are more likely to develop a false memory for a negative event than for a non-negative event seems difficult to reconcile with the studies by Ceci et al. (1994) and Hyman et al. (1995). These authors reported that a negative event elicited fewer or a similar number of false memories as compared with a positive event. However, 
plausibility of the target events might account for this pattern of findings. In our study, negative and neutral target events were similar in terms of plausibility ${ }^{9}$. Ceci et al. and Hyman et al. did not control for this factor and therefore it might be well the case that their negative target events were less plausible than their positive target, producing the overall null effect of similar levels of false memory. As plausible events are more likely to give rise to false memories than implausible events (Pezdek et al., 1997; Pezdek \& Hodge, 1999; but see Otgaar, Candel, Merckelbach, \& Wade, 2009; Strange et al., 2006), controlling this factor in studies on false memories is crucial.

Our finding also seems to be in contrast with Howe's (2007) study in which children falsely recalled more neutral words than negative words. Howe's study, however, focused on spontaneous false memories using word lists whereas the present study focused on implanted false memories using false narratives. Recently, it has been debated whether both paradigms have the exact same underlying mechanisms (see Pezdek, 2007; Pezdek \& Lam, 2007; Wade et al., 2007). Clearly, this issue warrants further study.

Our false memory rates are higher than those in other false memory studies (e.g., Strange et al., 2006). Note, however, that we combined false narratives and true photographs to implant false memories. Recently, Garry and Wade (2005) found that false narratives produce higher false memory rates than doctored photographs. Furthermore, Lindsay et al. (2004) showed that true photographs evoke higher levels of false memories than studies using doctored photographs. Therefore, it is likely that our combination of false narratives and true photographs engendered higher false memory rates than other false memory studies.

The presentation of a true photograph associated with the false target event did not promote the development of children's false memories. At first sight, this null finding is

\footnotetext{
${ }^{9}$ One might argue that our valence effect is confounded with using only two target events and that our valence effect is actually a stimulus effect. However, since we controlled for plausibility and script knowledge, our valence effect is not due to other factors. Moreover, Pezdek and colleagues (2006) argued that it is justified to use only two target events in false memory studies, since "it would be methodologically difficult to maintain credibility with the subjects while suggestively introducing multiple false events" (Pezdek et al., 2006, p. 1634). Also, they mentioned that there are important false memory studies which used only one false target event (i.e., lost in a shopping mall, by Loftus \& Pickrell, 1995; put Slime in the teacher's desk, by Lindsay et al., 2004; take a hot air balloon ride, by Wade et al., 2002).
} 
at odds with Lindsay et al. (2004) who reported that exposing adult participants to a true photograph increased their number of false memories. These discrepant findings might be explained by children's heightened levels of suggestibility. Specifically, children are more susceptible to suggestive information than adults (for an overview see Bruck \& Ceci, 1999), which creates ceiling effects in the case of children being exposed to an extra memory cue like a photograph. So, even without being exposed to a true photograph, the number of children with a false memory after two interviews in our study (i.e., 71\%) dramatically exceeded the number of adults with a false memory in Lindsay et al.'s (2004) study (i.e., $27 \%$ ). Obviously, many children were influenced by the authoritativeness of the suggested false narrative. As a result, the true photograph did not possess an additional value.

In the legal arena, children are usually interrogated about negative events (Bruck \& Ceci, 1999). Although we admit that our negative target event is a far cry from false memories about childhood sexual abuse, the current study may help to bridge the gap between the psychological laboratory and court cases in which such memories play a crucial role. That is, our study clearly demonstrates that interrogations characterized by suggestive interview techniques are catastrophic in that they increase the likelihood that children come up with "memories" about fictitious events. The argument that is sometimes heard in court i.e., this memory report must be true because it describes such a horrible event (e.g., Ceci \& Bruck, 1993) - is, as our data show, on shaky grounds. 


\title{
Differentiating between children's true and false
}

\author{
memories
}

Otgaar, H., Candel, I., Memon, A., \& Almerigogna, J. (in press). Differentiating between children's true and false memories using Reality Monitoring criteria. Psychology, Crime \& Law 


\begin{abstract}
The present study examined the efficacy of the Reality Monitoring (RM) criteria in differentiating between children's true and false memories. Two independent judges rated 190 transcripts of children's true and false memory reports along the RM criteria. Results showed that, overall, the RM criteria failed to distinguish between children's accounts of true and false events. However, when examining each RM criterion separately, we found that more visual details were present in children's true memories than in their false memories. Results also showed that more RM criteria were present at the second interview than at the first interview.
\end{abstract}


Whether children's accounts of events are based on fabrication (e.g., false memories) or true experience has spawned widespread scientific interest (e.g., Strömwall, Bengtsson, Leander, \& Granhag, 2004; Vrij, 2008). In legal settings in which the veracity of children's statements is often doubted (see Ceci \& Bruck, 1993), determining whether these statements refer to authentic or invented events can be of crucial weight. The purpose of the current study was to examine whether children's true and false memories can be discriminated using the Reality Monitoring approach (Johnson \& Raye, 1981).

In the past decades, a variety of verbal deception techniques has been developed to asses the authenticity of statements. A frequently used technique in forensic settings is the Criteria-Based Content Analysis (CBCA; Köhnken, Schimossek, Aschermann, \& Hofer, 1995; Raskin \& Esplin, 1991; Vrij \& Mann, 2006). Inspired by children's alleged claims of sexual abuse, the CBCA is based on the Undeutsch hypothesis which posits that accounts of experienced events about sexual abuse qualitatively and quantitatively differ from accounts of invented events (Steller, 1989; Undeutsch, 1989). Hence, the CBCA concentrates on the presence or absence of 19 criteria (e.g., logical structure, details, corrections) supposed to discriminate between truthful and deceived accounts.

The CBCA, however, has been criticized (see Vrij, 2005). That is, studies have shown that CBCA scores are affected by event familiarity (Blandon-Gitlin, Pezdek, Rogers, \& Brodie, 2005; Pezdek et al., 2004), coaching (Vrij, Akehurst, Soukara, \& Bull, 2004) and that false positives (i.e., wrongfully asserting that an account is true) are extremely likely to occur (Ruby \& Brigham, 1997). Furthermore, the CBCA is criticized because it lacks any theoretical grounding (Sporer, 1997).

A more promising instrument to distinguish truthful and fabricated statements is the Reality Monitoring (RM) approach. In contrast to the CBCA, the RM method contains solid theoretical underpinnings (Johnson \& Raye, 1981; Vrij, 2008). According to this approach, memory characteristics of experienced events qualitatively and quantitatively differ from memory characteristics of fabricated events. Specifically, memories originating from true experiences would include more perceptual information (visual details, sounds, smells, tastes and physical feelings related to the event), contextual information (information regarding when and where the event happened), and affective information (details about feelings or apperceptive reactions to the event) than memories based on fabrication. The latter would consist of more information concerning cognitive operations (details about thoughts, reasoning, and inferences of events) that govern these memories. 
Over the past decades, researchers have examined whether the RM framework could be used as a tool to detect deception (for an overview see Masip, Sporer, Garrido, \& Herroro, 2005; Sporer, 2004). Based on this approach, researchers (e.g., Vrij, Mann, Kirsten, \& Fisher, 2007) constructed a list of RM criteria (see Table 6.1) as a means of assessing the likelihood of a statement being true or false.

However, whether the RM criteria are useful in differentiating between recollections of true events and "recollections" of false events -events that individuals falsely report to have experienced-, is to date unclear. According to Vrij (2008, p. 265), "the findings to date give only a weak indication that observers can distinguish between true and false memories by employing the RM tool. Moreover, he (p. 265) argues that "research in this area is scarce, and the issue has not yet fully been explored."

Recent studies focusing on the discriminative power of the RM tool have generally found that it operates above chance level when deciding whether a statement is true or deceptive (see Masip et al., 2005). The standard procedure in these studies is that participants have to describe a true event or have to make up a report about a nonexperienced event (i.e., lie). Then, the presence of specific RM criteria is used to examine whether they can discriminate between truth-tellers and liars. Sporer and Sharman (2006), for example, instructed participants to write reports of invented or experienced events. Next, participants had to rate to qualitative details of their own statements using RM criteria. They showed that participants rated statements of experienced events as more qualitatively detailed (more clear, realistic, sensory information, spatial details and temporal information) than invented statements.

Obviously, examining whether the RM tool is valuable in distinguishing true and false memories would be of practical importance. Consider for example studies (e.g., Otgaar, Candel, \& Merckelbach, 2008; Otgaar, Candel, Merckelbach, \& Wade, 2009; Strange, Sutherland, \& Garry, 2006) and legal cases (e.g., "McMartin Preschool”, Wee Care Nursery School"; Ceci \& Bruck, 1993; Garven, Wood, Malpass, \& Shaw, 1998) that showed that children are easily led to develop full-blown false memories of non-existing events. Clearly, people involved in legal cases (e.g., interrogators, researchers, parents) might wonder whether children describe a true or a fictitious event. With this in mind, the present study focused on the potential of the RM technique in distinguishing children's true and false memories. 
As far as we know, only two studies to date have examined whether RM criteria are successful in differentiating true and suggested accounts of events. Schooler, Gerhard, and Loftus (1986) were the first to examine the efficiency of the RM approach. In their study, half of the participants viewed a slide in which a yield sign was depicted while the other half did not witness this sign. However, the participants who did not view the sign were led to believe that the original slide contained a yield sign. Results showed that $25 \%$ ( $n$ $=21$ ) of these participants endorsed this suggestion. Furthermore, participants were instructed to provide a verbal description about the event. Transcripts of these descriptions were then presented to independent raters who had to decide whether each transcript was based on a true or fabricated experience using RM criteria (e.g., sensory details, cognitive processes). Results showed that transcripts could be accurately split into true or suggested accounts of events (i.e., $62 \%$ overall accuracy).

In a related study, Porter, Yuille, and Lehman (1999) led participants to believe they experienced entire false events (e.g., serious animal attack). Specifically, participants were read a true and a false narrative about events they had experienced in their childhood. One of the narratives was invented by the experimenters and described a fictitious event. Next, participants were asked what they could remember about the events. Results indicated that $26 \%(n=20)$ of the participants assented to the false events. Participants were also instructed to rate their own memories of the events along several dimensions (e.g., confidence, vividness, details, coherence). Interestingly, participants judged their true memories as more vivid (i.e., a RM criterion) than their false memories.

The above-mentioned studies, however, concentrated exclusively on adult participants and relied merely on a small subset of the RM criteria. No study up until now has examined whether children's true and false recollections can be discriminated using the RM criteria. The present study has the unique opportunity to test the merits of the RM tool by using transcripts of children's true and false memories from studies by Otgaar and colleagues (2008; 2009; under review). In these studies, Otgaar and co-workers implanted several false events (e.g., UFO abduction, receiving a rectal enema) into children's memory using the same procedure. More precisely, children were presented with true and false narratives about events that they supposedly had experienced some years ago. Next, across two interviews, children had to report everything they could remember about the events.

On the basis of the RM approach (Johnson \& Raye, 1981), we on the one hand hypothesized that children's true and false memories could be distinguished. Specifically, we 
hypothesized that children's true memory reports would contain more perceptual, contextual, and affective information than children's false memory reports. In contrast, we predicted that children's false memory statements would include more references to cognitive operations than children's true memory statements.

On the other hand, one could assert that the RM tool is not efficient in distinguishing between children's true and false memories. This prediction stems from the underlying nature of true and false memories. According to Pezdek and colleagues (1997; 1999), false memories are formed because people connect false events with pre-existing schemas (i.e., organized knowledge structures) and scripts (i.e., typical sequence of events; Fivush; 1997). Thus, when people freely imagine about these events, an increased likelihood exists that details of these pre-existing schemas are transported to these images resulting in highly detailed, coherent and well-integrated false memories. Accordingly, since these memories would be as detailed as true memories, the RM method would not be able to detect any differences between children's true and false recollections. A recent study indeed found that true and false memories were alike in terms of CBCA criteria (Blandon-Gitlin, Pezdek, Lindsay, \& Hagen, 2009).

We also predicted that at Interview 2, children's true and false memories would include more RM details than at the first interview (T1). The reason for this is two-fold. First, our participants were instructed to think about the true and false events between the two interviews and to report more information during the second interview (T2; see Otgaar et al., 2008; 2009). Hence, children's true and false memory reports could become more elaborate over time resulting in an increase in perceptual, contextual, affective, and cognitive details (see also Bruck, Ceci, \& Hembrooke, 2002; Ceci, Huffman, Smith, \& Loftus, 1994). Second, children's memory benefits from repeated interviews. That is, children have the tendency to report more details over time (Quas et al., 2007).

\section{Method}

True and false memory reports

The current study included 190 transcripts $\left(n_{\mathrm{T} 1 / \text { false }}=56, n_{\mathrm{T} 1 / \text { true }}=54 ; n_{\mathrm{T} 2 / \text { false }}=40\right.$, $\left.n_{\mathrm{T} 2 / \text { true }}=40\right)$ of children $\left(M_{\mathrm{age}}=9.13, S D=2.16\right.$; range $\left.7-12\right)$ from three studies by Otgaar and colleagues (2008; 2009; under review). Although across the studies, 99 and 114 children 
developed false memories at the first and second interview respectively, only 94 and 96 transcripts from both interviews were appropriate for this study since some recordings were incomplete or inaudible. In the previous studies, different false events were inserted into children's memory. That is, almost choking on a candy, being abducted by a UFO, being accused of copying off someone else's work, moving to another classroom, receiving a rectal enema, and being stuck with your finger in a mousetrap. Specifically, children were read narratives about a true event and a fictitious event that we supposedly received from their parents. Then, children were encouraged to report everything they remembered about the events across two interviews with one week in between. When children could not remember anything about the events, they were provided with context reinstatement and guided imagery techniques. True events referred mainly to moderate significant events (e.g., going on a holiday, first day at school) and were obtained and confirmed by the children's parents. Children's responses were coded as a false memory when they stated that they remembered the false event and provided additional event-related details.

\section{Design and Procedure}

This study employed a 2 (Veracity: True vs. False) x 2 (Interview 1 vs. 2) between subject design. We regarded Veracity and Interview 1 and 2 as between subject factors since our aim was to examine differences in the presence of RM criteria between true and false memory transcripts and transcripts from Interview 1 and transcripts from Interview 2. Of importance, the majority $(n=160)$ of the transcripts from both interviews were not from the same children. The reason for this is that in our previous studies, some children developed false memories at Interview 1 or Interview 2 while other children falsely remembered the events at both interviews. However, all children in these studies were instructed to think about the true and false events between the two interviews and to come up with more information at Interview 2.

Transcripts of children's true and false memories were coded by two independent raters. Both raters were trained in the use of RM criteria as specified by Vrij and colleagues (2007) and Colwell, Hiscock, and Memon (2002). Specifically, the training was supervised by the third author. The training started with a general introduction into the background literature of Statement Validity Analysis and Reality Monitoring. The raters were also presented with detailed information regarding the coding criteria with examples and definitions to ensure consistency (for a detailed description see Memon, Fraser, Colwell, 
Odinot, \& Mastroberardino, in press). Both raters were blind to the children's experimental condition.

The RM tool distinguishes in total six different types of details. Visual details are defined as any action or thing that was seen in the event (e.g., "He walked into the room", consists of three visual details: he, walked, and room). Spatial details consist of any information relating to the location and positioning of items (e.g., "he put it on the table", contains one spatial detail: on). Temporal details are defined as any information related to the timing of events (e.g., "shortly after the man arrived", contains one temporal detail: shortly after). Auditory details refer to any speech- or sound-related information (e.g., "she asked my name", contains one auditory detail). Cognitive operations are defined as suppositions, thoughts, reasoning, and attributions of intent (e.g., "he didn't make a fuss when he dropped the laptop, he didn't care, it wasn't his business", contains one cognitive operation). Finally, affective details include information about emotion and feelings (e.g., "it hurt a lot", contains one affective detail). One point was assigned to each detail. A total RM score was computed by summing all details.

As a check on the reliability of the coding system, about one-third $(n=71)$ of all transcripts were coded by both raters. Overall inter-rater reliability using intra-class correlations (ICC) was excellent with ICC $=.97$. Inter-rater reliability values for the separate reality monitoring criteria varied from .79 (auditory) to .96 (temporal). Following these analyses, the two coders compared their results and disagreements were discussed.

\section{Results}

\section{Response length}

Table 6.1 and 6.2 present the means of the RM criteria as a function of true and false memories and time of interview, respectively. We found that age was significantly correlated with total RM scores $(r=.22, p<.01)$. Since some researchers have argued that response length of true and false narratives could exert a confounding effect on the discrimination of true and invented accounts (see Masip et al., 2005; Sporer, 2004), we conducted a 2 (Veracity: True vs. False) x 2 (Interview 1vs. 2) between subjects ANCOVA with age as covariate to examine whether children's true and false accounts significantly differed in terms of the number of words. No significant interaction was observed $(p>.05)$. However, 
we found a significant main effect of Interview $(F(1,185)=7.34, p<.01, r=0.17)$ with statements at Interview $2(M=49.60, S D=28.67)$ containing more words than at Interview 1 $(M=40.30, S D=26.13)$. Furthermore, results showed that children's true $(M=45.43, S D=$ 30.37) and false statements $(M=43.03, S D=24.55)$ did not significantly vary with respect to the number of words $(p>.05)$. Therefore, we did not include the response length of children's true and false narratives as a covariate in further analyses.

Table 6.1 Means and standard deviations (in parentheses) of RM criteria as a function of children's true and false memories

\begin{tabular}{|c|c|c|c|c|c|}
\hline & & True & False & & \\
\hline & RM criteria & $M(S D)$ & $M(S D)$ & $F$ & $d$ \\
\hline \multirow{6}{*}{$\begin{array}{l}\text { Memories } \\
(N=190)\end{array}$} & Visual & $12.26(6.65)$ & $9.46(5.52)$ & $10.41 *$ & .47 \\
\hline & Temporal & $1.85(2.23)$ & $1.89(2.13)$ & 0.01 & .01 \\
\hline & Spatial & $2.05(1.72)$ & $2.11(1.78)$ & 0.06 & .04 \\
\hline & Auditory & $0.34(0.85)$ & $0.34(0.74)$ & 0.00 & .00 \\
\hline & Cognitive & $1.46(1.51)$ & 1.59 (1.75) & 0.33 & .08 \\
\hline & Affective & $0.14(0.45)$ & $0.61(0.67)$ & $32.57^{*}$ & .83 \\
\hline
\end{tabular}

Note. $* p<.001$ 


\section{Total RM scores}

To examine whether the RM criteria could discriminate between children's true and false accounts and whether the second interview would contain more RM details than the first interview, a 2 (Veracity: True vs. False) $\times 2$ (Interview 1 vs. 2) between subjects ANCOVA with age as covariate was executed on total RM scores. No significant interaction between children's true and false memories and time of interview emerged ( $p>05$ ). Furthermore, results showed that children's true and false memory reports ${ }^{10}$ did not significantly differ on total RM scores $(F(1,185)=1.71$, n.s. $)$.

As expected, however, we found a significant main effect of time of interview $(F(1)$ $185)=8.85, p<.01, r=0.19)$ with true and false memory reports containing more RM details at the second $(M=19.15, S D=10.62)$ than at the first interview $(M=15.51, S D=9.39)^{11}$.

\section{RM criteria}

A MANCOVA with age as covariate was performed to examine the six RM criteria as a function of children's true and false memories and time of interview. This revealed no significant interaction between children's true and false memories and time of interview for all RM criteria ( $p>.05$ ). However, we found a significant main effect of Veracity (true/false; Pillai's Trace $=0.27$, multivariate $F(3,186)=10.93, p<.01$, partial $\left.\eta^{2}=0.27\right)$ and a significant main effect of Interview (Pillai's Trace $=0.07$, multivariate $F(3,186)=2.30, p<.05$, partial $\eta^{2}$ $=0.07)$. We used the more conservative Pillai's Trace statistic to prevent concerns of sphericity (for more information see Howell, 2002, pp. 519-524). To investigate which RM criterion contributed to the main effects of Memories and Interview, we conducted six follow-up univariate ANCOVAs using Bonferroni correction.

\footnotetext{
${ }^{10}$ Twenty-nine percent $(n=28)$ of the false memory reports were from children who developed false memories after context reinstatement and guided imagery instructions. A 2 (Veracity: True vs.

False/Guided Imagery) x 2 (Interview 1 vs. 2) ANCOVA with age as covariate showed that true and false memory reports did not differ on total RM scores $(F(1,116)=1.15$, n.s.). However, also no main effect of time of interview emerged $(F(1,116)=1.03$, n.s. $)$.

${ }^{11}$ When we performed a repeated measure analysis on children who developed false memories at Interview 1 and $2(n=15)$, we also found that children's true and false memory reports did not significantly differ in terms of total RM scores $(F(1,28)=.03$, n.s.). Moreover, results showed that children's memory reports at the second interview $(F(1,28)=13.82, p<.001, r=0.57 ; M=21.63, S D=$ 11.85) contained more RM details than at the first interview $(M=14.47, S D=7.09)$.
} 
Table 6.2 Means and standard deviations (in parentheses) of RM criteria as a function of time of interview

\begin{tabular}{|c|c|c|c|c|c|}
\hline & & Interview 1 & Interview 2 & & \\
\hline & RM criteria & $M(S D)$ & $M(S D)$ & $F$ & $d$ \\
\hline \multirow{6}{*}{$\begin{array}{l}\text { Memories } \\
(N=190)\end{array}$} & Visual & $9.99(6.04)$ & $12.01(6.38)$ & $7.05^{* *}$ & .39 \\
\hline & Temporal & $1.58(1.89)$ & $2.26(2.47)$ & $5.86^{*}$ & .36 \\
\hline & Spatial & 1.84 (1.59) & $2.43(1.90)$ & $8.33^{* *}$ & .43 \\
\hline & Auditory & $0.24(0.61)$ & $0.49(0.98)$ & $4.23^{*}$ & .30 \\
\hline & Cognitive & $1.45(1.52)$ & $1.63(1.77)$ & 1.13 & .16 \\
\hline & Affective & $0.41(0.67)$ & $0.34(0.55)$ & 0.7 & .12 \\
\hline
\end{tabular}

First, we found that children's true memory reports had significantly more visual details than children's false memory reports. Surprisingly, results also showed that affective details were more predominant in children's false memory reports than true memory reports. The other RM criteria (i.e., temporal, spatial, auditory, and cognitive), however, did not distinguish between children's true and false accounts of events (see Table 6.1 and 6.2).

A third key finding was that, at the second interview one week later, children's true and false recollections included significantly more visual, temporal, spatial, and auditory information than at the first interview (all Fs $>1$, see Table 2).

\section{Affective details}

Our finding that more affective details were present in children's false memories than in true memories might be explained since $76(79 \%)$ of our false memory reports were about negative events (i.e., receiving a rectal enema, almost choking on a candy, being accused of copying off, being stuck with your finger in a mousetrap) whereas 20 (21\%) reports were about a neutral event (i.e., moving to another classroom). Therefore, we examined whether our false negative statements boosted the affective details in our transcripts using a 3 (Veracity: True, False negative, $_{\text {False }}$ neutral $) \times 2$ (Interview 1 vs. 2) between subjects ANOVA. This analysis revealed a significant main effect of Veracity $(F(2,184)=$ 19.36, $p<.001, r=0.06)$. Post-hoc analyses using Bonferroni correction showed that indeed the false negative accounts contained more affective references $(M=0.70, S D=0.69)$ than 
the false neutral $(M=0.30, S D=0.47)$ and true accounts $(M=0.14, S D=0.45)$. Thus, the reporting of affective details will vary with the nature of the event. To investigate whether the affective details confounded our results, a 2 (Veracity: True vs. False) x 2 (Interview 1 vs. 2) between subjects ANCOVA with affective details and age as covariate was performed on total RM scores. No significant interaction between children's true and false memories and time of interview emerged $(p>.05)$. Moreover, children's true and false memory reports did not significantly differ from each other $(p>.05)$ and transcripts at Interview 2 contained more RM details than at Interview $1(F(1,184)=10.58, p<.001, r=0.21)$.

\section{Discussion}

The purpose of the current study was to examine whether the RM tool could discriminate between children's true and false memories. The key finding of our study is two-fold. First, we found that the RM tool as a whole was inefficient in discriminating between children's true and false recollections. However, when considering each RM criterion separately, we showed that children's true statements included more visual information than their false statements. Furthermore, we found that children's false memories contained more affective details than their true memories. However, this finding was likely due to the fact that our false memories predominantly were about negative events (e.g., receiving a rectal enema). Second, our study showed that over time the number of RM details increased significantly. Specifically, we found that, except for the affective and cognitive details, memories contained more RM details after a 1 week delay.

Our finding that the RM criteria failed to discriminate between children's true and false memories is in contrast with what the RM framework (Johnson \& Raye, 1981) would predict. According to this framework, memories about true experiences would contain more perceptual, contextual, and affective details than memories about imagined and nonexperienced events. Clearly, it seems that although a bulk of recent studies show that the RM criteria are valuable in discriminating between true accounts of events and invented accounts of events (see Masip et al., 2005), a huge mismatch seems to exist between accounts of deliberately invented events and accounts of suggested events. Indeed, Johnson (1988) also acknowledged that when people give a verbal recount of their memories, this causes memories, especially memories about imagined events, to be more concrete than 
they really are. A result might be that differences between memories about true and imagined events will decrease.

Hence, the results presented here are broadly consistent with the work of Pezdek and colleagues (1997; 1999) and others (e.g., Hyman, Husband, \& Billings, 1995; Loftus \& Bernstein, 2005) who stated that false memories arise in part because of a mixture of knowledge from related true events with information from suggested events. So, for example, when people imagine about a false event that they could have almost choked on a candy, information about choking (i.e. schemas) and details about what typically occurs during choking (i.e., scripts) is activated and transported to these images. This in turn results in highly detailed and coherent false memories which are experienced as authentic as true memories. This may in part explain why, in the current study, false memories do not differ from true memories in terms of total RM criteria. Indeed, Strange, Hayne, and Garry (2008) recently found that "once children had developed a false memory, [...] adult raters could not detect any difference in the quality of their true and false reports" (p. 598).

Although we found false memories being highly similar to true memories, true memories contained more visual details than false memories. Obviously, this finding is in accordance with the RM framework. However, studies have revealed mixed results with respect to the number of visual details in true and false memory reports. Specifically, some studies (e.g., Vrij et al., 2008) have found that visual details did not yield significant differences between true and invented reports while other studies did detect differences in visual details between true statements and fabricated statements (e.g., Strömwall \& Granhag, 2005). Clearly, this matter demands further investigation.

Unexpectedly, we found that affective details were more prevalent in children's false memories than in true memories. The RM framework would predict the opposite. This finding, however, might have been confounded because children's false memories referred mainly to negative events (e.g., almost choking on candy) which led to many affective details in their false memory statements. Furthermore, children's true memories were predominantly about neutral events. Indeed, results showed that the amount of affective details was higher in the false memory statements about negative events than in the false memory statements about neutral events and the true memory statements. Thus, it appears that false memories about negative events may appear more truthful, at least in terms of affective criteria. 
Interestingly, we also showed that children's memory at Interview 2 consisted of more RM details than at the first interview. As already stated, in the implantation paradigm (e.g., Pezdek \& Hodge, 1999; Otgaar et al., 2008; Strange et al., 2006) used in our previous studies, participants are often encouraged to report additional details at the second interview. Although one would expect to find children reporting less over time (e.g., Quas, \& Schaaf, 2002), this result clearly shows that this process boosts RM details for true and false memory transcripts. So, it is likely that children rehearsed the events between the two interviews which could have made their memory reports more detailed. Furthermore, recent research shows that repeated interviews are beneficial for children's memory (Quas et al., 2007). Since it is probable that children regarded the false events as a true experience, repeated interviewing could have made children's true and false memories more detailed over time.

Furthermore, the finding that both true and false memories contain more RM details at the second interview is particularly interesting as it suggests that both true and false memories are equally regarded as referring to an authentic experience. This is consistent with literature showing that in child abuse investigations, children came up with highly convincing and believable accounts (e.g., Schreiber et al., 2006). Furthermore, our result is in accordance with earlier work showing that repeated recall increases RM details over time (e.g., Alonso-Quecuty \& Hernandéz-Fernaud, 1997; Granhag, Strömwall, \& Landström, 2006).

However, at a similar time, the result that more RM details were present at the second than at the first interview has to be interpreted with caution. As stated above, we regarded time of interview as a between subjects factor because the majority of the transcripts at Interview 1 and 2 did not belong to the same children. Therefore, our purpose was to examine whether transcripts obtained at Interview 2 differ from transcripts at Interview 1 in terms of RM criteria. It might be the case that other factors (e.g., individual differences) could have also contributed to this result. Yet, when we analyzed a subgroup of children who had false memories at both interviews, we found an even stronger effect of time of interview with memory reports at Interview 2 containing more RM details than at Interview 1.

Three potential limitations of the current study need to be mentioned. First, true and false memory reports were drawn from three different studies from Otgaar and colleagues (2008; 2009; under review). Therefore, true and false memory reports were not 
from the same participants which could have affected our results. So, differences between true and false memory reports in terms of RM criteria could have been influenced by other factors. Only few studies implemented true and false memory reports as a within subjects factor in their design (e.g., Blandon-Gitlin et al., in press; Porter et al., 1999). Second, children's narratives were rather short which could have made RM analyses difficult. It could be that children did not mention some details (e.g., auditory details) because they did not regard them as important or because these details were not part of the event. Relatedly, research shows that limited reports are a key feature when children have to describe experienced events, such as sexual abuse (Sjöberg \& Lindblad, 2002). Third, research shows that false memories are not only the products of memory distortions, but might also be affected by social influences (Ceci \& Bruck, 1993). Therefore, examining memory characteristics between true and false memories using the RM tool could be affected by this issue.

With respect to the practical implications of our study, our results are not encouraging for researchers in forensic settings who want to use the RM tool as an index to assess the veracity of children's questionable accounts. Our results clearly demonstrate that children's false memories are qualitatively and quantitatively similar to true memories in terms of RM criteria. Although some studies show that the RM criteria can differentiate between true accounts of events and intentionally invented accounts of events (see Masip et al., 2005), this seems not to be the case for children's false memories. This finding is important since in legal cases it might be quite exceptional that children deliberately fabricate events. In fact, a wealth of research (e.g., Otgaar et al., 2008; in press; Strange et al., 2006) shows that children are more easily led in unintentionally developing false memories for events, therefore rendering the RM tool an inefficient instrument. Moreover, well-known legal cases as the "McMartin Preschool" and "Wee Care Nursery" trials (Ceci \& Bruck, 1993; Garven et al., 1998) show that children truly can believe that their false memories refer to experienced events. The overarching message is that practitioners in the forensic field should not use the RM tool when children's statement were likely the result of suggestive practices. We agree with Memon and colleagues (in press) in that analyzing statements with the RM tool should not be undertaken when no information is present about the circumstances that have led to these statements. 



\section{Children's omission and commission errors}

Otgaar, H., Candel, I., Smeets, T., \& Merckelbach, H. (in press). "You didn't take Lucy's skirt off": The effect of misleading information on omissions and commissions in children's memory reports. Legal \& Criminological Psychology. 


\begin{abstract}
The current study explored the effect of misleading information on omissions and commissions in children's memory reports. Fifty-nine younger $\left(M_{\mathrm{age}}=4.16\right)$ and 59 older $\left(M_{\text {age }}=9.44\right)$ children were instructed to remove three pieces of clothing from a puppet. Half of them were provided with false evidence that they had removed only two items, while the other half was provided with false evidence that they had forgotten to mention one piece of clothing. In three neutral interviews separated by a one-week interval, children had to report which pieces of clothing they had removed. Omission errors significantly decreased after repeated interviews. Likewise, commission errors significantly declined after repeated questioning. Younger and older children were equally likely to make omission errors, whereas commission errors were more likely to occur in younger than older children. Also, we found that commission errors more readily occur than omission errors. Thus, children are easily led into developing commission and omission errors.
\end{abstract}


Although many studies show that misleading information can elicit memories for details of an event that were not present (i.e., commission errors; Loftus, 2005), little is known about the effect that misleading information may have on omission errors (i.e., leaving out details). Obviously, the latter issue bears relevance to those legal cases (e.g., child sexual abuses cases) in which perpetrators repeatedly told the victims that certain events did not happen. With such cases in mind, the question arises to what extent children exclude accurate details from their reports when they have been presented with misleading information. The present study addressed this question.

Studies in which adults and/or children are exposed to misleading information show that many of them include such information into their subsequent reports. These studies typically rely on the misinformation paradigm (Loftus, 2005). Specifically, participants are first presented with a sequence of slides or a video fragment about an event or they have to participate in a staged event. Next, they receive misleading information (i.e., misinformation) about the event in the form of, for example, a narrative. Following this, participants are instructed to recall the event as detailed as possible. Generally, results show that a nontrivial percentage of participants accepts the misinformation and reproduces it as though it was part of the original event (e.g., Loftus, Miller, \& Burns, 1978; Sutherland \& Hayne, 2001). For example, in their classical experiment, Loftus and colleagues (1978) exposed their participants to a sequence of scenes about a car accident at an intersection with a stop sign. Next, half of the participants was given the false suggestion that the stop sign that they had seen was a yield sign. When later asked what traffic sign they remembered, many of them tended to claim that they had seen a yield sign. This misinformation effect was not evident in the control group. Studies indicate that this effect decreases with age, with younger children being more susceptible to misinformation than older children and adults (Saywitz, 1990; Sutherland \& Hayne, 2001).

Although studies have repeatedly demonstrated that it is relatively easy to contaminate both adults' and children's memory with misleading information such that commission errors (e.g., falsely reporting a yield sign) occur, few studies have looked at whether misleading information can create omission errors (i.e., leaving out details) in memory reports (see Wright \& Loftus, 1998). Nevertheless, both from a theoretical and practical point of view, this issue is highly relevant. From a theoretical perspective, it is informative to know whether suggestions can make memories less accessible or memory details less likely to be reported and if so, whether this is an age invariant effect. From a 
practical perspective, the issue of omission errors in reports bears significance to those legal cases (e.g., sexual abuse cases) in which perpetrators told their victims that an event (e.g., abuse) did not happen, when in fact it did. This issue has also been noted by Zajac and colleagues (2003) and Williams and colleagues (2002).

Williams and co-workers (2002) examined whether incomplete misleading information can lead children to make omission errors. Specifically, in their studies, child participants took part in an interactive event. After this, half of them were presented with post-event information excluding a specific scene of the event. On a subsequent test, they were asked to report what they had seen. Results showed that children who had been given the misleading information less frequently claimed to have seen the specific scene than control children who were not presented with the incomplete post-event information (Williams et al., 2002; for similar results with adult participants see Wright, Loftus, \& Hall, 2001).

Whereas the above-mentioned studies (Williams et al., 2002; Wright et al., 2001) focused exclusively on omission errors, Pezdek and Roe (1997) examined children's propensity for making omission, commission, and change errors. In their study, 4- and 10year-old children were touched in a certain way or not touched at all. Next, they were presented with information that they had not been touched when in fact they had (i.e., omission suggestion), that they had been touched when in fact they had not (i.e., commission suggestion), or that they had been touched in a different way (i.e., change suggestion). Children's memories could be easily changed, but commissions or omissions were less likely to occur.

Candel, Hayne, Strange, and Prevoo (2009) also examined how misleading questions affect omissions and commissions in children's reports. In their study, children had to listen to a class presentation about China. Three days later, they were asked suggestive questions which consisted of three types: questions suggesting that certain details were mentioned when in fact they were not (commission suggestion), questions implying that some details were absent (omission suggestion), and questions suggesting that details were presented differently (change suggestion). The following day, children were presented with a recognition task about items referring to the information relating to the suggestive interview. As was the case in Pezdek and Roe's (1997) study, children were more likely to show change errors than omission and commission errors. Also, there was no statistical difference between the proportion of children who made a commission error and the 
proportion of children who exhibited an omission error, implying that both types of error are equally likely to occur (see, for similar conclusion in a study of adults, Merckelbach, van Roermund, \& Candel, 2007).

All above-mentioned studies examined omission and commission errors in a very static environment in that an event was always followed by misinformation. So far, no study explored the effect of misleading information on children's memory omissions and commissions during an interactive (i.e., an event in which the children themselves played an active role) and therefore probably more realistic event. Although Pezdek and Roe (1997) examined the impact of misleading information on omissions and commissions in children's reports, in their study, these children participated in a rather passive event (i.e., being touched). Clearly, investigating this issue would be of practical significance since for example child abuse cases can be predominantly interactive in nature. Hence, the aim of the current study was to examine whether misleading information could provoke omission errors in children's reports for an interactive event.

In the present study, both younger and older children were instructed to take off three pieces of clothing from a puppet. Half of the children was provided with false evidence showing that they had removed only two items (i.e., omission suggestion), while the other half was provided with false evidence indicating that they forgot to mention one piece of clothing (i.e., commission suggestion). During three follow-up interviews, children had to indicate which pieces of clothing they had removed. Crucially, different interviews were conducted by different interviewers so as to decrease children's tendency to comply with the interviewers' expectations and wishes (see Candel, Merckelbach, Loyen, \& Reyskens, 2005; Meyer \& Jesilow, 1996; Ost, Foster, Costall, \& Bull, 2005; Ost, Ghonouie, Cook, \& Vrij, 2008).

Based on the discrepancy detection principle (Hall, Loftus, \& Tousignant, 1984) and on Candel et al.'s (2009) and Merckelbach and colleagues' (2007) findings, we expected that misleading information would yield comparable rates of omissions and commissions in children's reports. According to the discrepancy detection principle, people more readily accept misleading information when this information overlaps with the original information and when they do not detect any discrepancies between the original and misleading information. It is reasonable to argue that in the omission and commission condition, the discrepancy between original and misleading information is nearly equal. As a result, the effect of misleading information on the development of memory omissions and 
commissions would be the same. We had no strong predictions about how omissions and commissions in reports would develop after repeated questioning. In fact, studies have only looked at this for commission errors and they have revealed mixed findings. Some studies (e.g., Bjorklund, Bjorklund, Brown, \& Cassel, 1998; Otgaar, Candel, \& Merckelbach, 2008) show that children's commission errors and details increase after repeated interviews, while others (e.g., Ceci et al., 1994; Powell, Roberts, Ceci, \& Hembrooke, 1999; Salmon \& Pipe, 1997; Strange, Hayne, \& Garry, 2008) show that children's commission errors decline or remain stable across multiple interviews. To the best of our knowledge, no study examined whether repeated interviews affect omission rates. On the basis of an extensive body of literature (e.g., see for an overview Bruck \& Ceci, 1999; Ceci, Ross, \& Toglia, 1987), we also hypothesized that younger children would assent more often to our misleading information than older children.

\section{Method}

\section{Participants}

Participants were 118 elementary school children classified as younger $(n=59$, $M_{\text {age }}=4.16, S D=0.36$, range $\left.4-5\right)$ or older $\left(n=59, M_{\text {age }}=9.44, S D=0.70\right.$, range 8-11) children. Children's teachers and parents provided informed consent. All children received a small present for their participation. The study was approved by the Standing Ethical Committee of the Faculty of Psychology and Neuroscience, Maastricht University.

\section{Materials}

Puppet. An $80 \mathrm{~cm}$ tall puppet, named Lucy, was used in our study. This puppet wore pink-colored clothes (e.g., hat, skirt, shoes, pants, jacket).

Questionnaire. Children's parents received a questionnaire one week after the second interview. They were instructed to question their child about the experiment (e.g., "Which pieces of clothing did you take off?").

Design

The study employed a 2 (Age: younger children vs. older children) $\times 2$ (Misinformation: omission suggestion vs. commission suggestion) x 3 (Time: Interview 1 vs. Interview 2 vs. Interview 3) mixed design with the latter being a within subjects factor. 
Children were randomly assigned to the omission suggestion $(n=60)$ and commission suggestion condition $(n=58)$. Children were tested individually three times, each with an interval of one week. All interviews were recorded with a digital voice device. To minimize the effect of demand responses, each child was interviewed by three different (female) confederates on three different occasions. To counter order effects, the interviewers were pseudo-randomly assigned to each interview.

\section{Procedure}

Our study consisted of six phases. At the start of Phase 1, children were informed that we were interested in their memories of events. Next, children were instructed as follows: "You are now going to another room, a changing room, to remove some pieces of clothing from a puppet called Lucy. When you are done, I will ask you what you remember of this." Then, confederate 1 asked children to remove the skirt, hat, and shoes of the puppet in the changing room and to place them next to the puppet on the table. The sequence of actions was counterbalanced across all children. When they had completed these actions, confederate 2 asked them to return to the interview room. During Phase 2, a baseline interview was conducted by confederate 2 who asked children which actions they had to perform.

At Phase 3, children received either the omission suggestion or the commission suggestion. In the omission suggestion condition, children were told that they could not have taken off the second piece of clothing and that their memory was incorrect about this. To provide them with evidence that they did not perform this action, confederate 2 took them back to the changing room. Before they entered the room, the critical piece of clothing that they had taken off was placed back on the puppet again. Children were then told they misremembered the critical action, because the critical piece of clothing was still on the puppet and was not placed on the table.

For children in the commission suggestion condition, the procedure was similar except for the following. When they recalled the clothes they took off, they were told they forgot to mention one piece of clothing; the jacket of the puppet. To substantiate this, children had to go back to the changing room. Before children entered the changing room, a confederate had placed the jacket on the table next to the puppet so that children were led to believe they had taken it off. The sequence and timing of the interviews were the same as those for the omission suggestion condition. 
Phase 4 consisted of the immediate post-suggestion interview. Specifically, children were interviewed by confederate 3 about which actions they had performed (i.e., Interview 1). Specifically, they were told that confederate 2 had to leave and that therefore confederate 3 had to interview them. After a one-week interval, confederate 1 asked children to recall once more which actions they had carried out a week earlier (i.e., Phase 4; Interview 2). Finally, by using a questionnaire, children's parents were asked their children what the experiment was about and what pieces of clothing they removed during the experiment (i.e., Phase 5; Interview 3). When the parental questionnaires were returned, children were debriefed using ethical guidelines for false memory research with children (Phase 6; Goodman, Quas, \& Redlich, 1998).

\section{Scoring}

One point was assigned to each piece of clothing that children correctly reported to have taken off. If they reported a piece of clothing semantically related to the critical items (e.g., cap, dress, boots), a point was assigned. Children made an omission error when they did not mention the critical piece of clothing and correctly reported the two other pieces of clothing. Furthermore, a commission error was made when children indicated that they remembered removing the jacket of the puppet and correctly reported the other three pieces of clothing.

\section{Results}

To investigate whether children spontaneously omitted or added pieces of clothing, we examined whether children correctly recollected the pieces of clothing they had to remove. Prior to the first interview (at baseline), 95\% ( $n=112$ ) of the children correctly remembered removing the three pieces of clothing. Results showed that in both conditions, it was quite exceptional that children reported nothing or only one piece of clothing. Specifically, at Interview 2, only one child (1\%) was not able to recall a single piece of clothing and at Interview 3 , one child (1\%) remembered to have taken off only one piece of clothing. Only in the commission suggestion condition, children spontaneously added pieces of clothing (e.g., stating to have taken off five pieces of clothing). Specifically, two children reported to have taken off five pieces of clothing (i.e., indicating spontaneous commission): one (1\%) at the first interview and the other (1\%) at the third interview. 
To investigate whether our omission suggestion and commission suggestion were successful at each of the three interviews, we conducted Chi-Square analyses to compare each condition with a control condition. For the omission suggestion condition, our control group consisted of all children of the commission suggestion condition in which one of the three pieces of clothing was randomly assigned to be their critical item. At each of the three interview, we showed that the omission suggestion group was more likely to omit the critical item than the control group (Interview $1: \chi^{2}(1)=27.47, p<.001$, Cramer's $V=.48$; Interview 2: $\chi^{2}(1)=4.49, p<.05$, Cramer's $V=.19$; Interview $3: \chi^{2}(1)=4.55, p<.05$, Cramer's $\left.V=.24\right)$. For parallel comparison, we performed independent samples t-tests to compare the number of non-critical items omitted by the children between the omission suggestion group and control group at each interview separately. For none of the interviews, there were significant differences between the omission suggestion and control group in terms of omitting non-critical items (all ps > .05). For the commission suggestion group, children in the omission suggestion condition served as our control group. However, since no children in the control group reported to have taken off the jacket, our suggestive manipulation proved to be successful ${ }^{12}$.

To examine whether repeated interviewing would affect children's memory omissions and commissions, Cochran's Q non-parametric tests were conducted. As to the omission suggestion condition, at Interview 1, 45\% ( $n=27)$ of the children in this condition failed to mention the critical piece of clothing. This percentage significantly dropped to $20 \%$ $(n=12)$ at Interview 2 and 13\% $(n=6)$ at Interview $3^{13}$ (Cochran's $\left.Q(2)=22.24, p<.001\right)$. Also, across the three interviews, each piece of clothing was similarly likely to be omitted (all $p s>.05)$. Thus, there were no significant differences in omitting different pieces of clothing. As for the commission suggestion condition, at Interview 1, 66\% $(n=38)$ of the children falsely reported to have taken off the puppet's jacket and this percentage significantly declined at Interview 2 and 3 to 55\% $(n=29)$ and 42\% $(n=14)$, respectively (Cochran's $Q(2)$ $=7.80, p<.05$; see Figure 1 ).

\footnotetext{
${ }^{12}$ An additional control group $\left(n=35, M_{\text {age }}=7.54, S D=0.61\right.$, range 6-9) in which children did not receive suggestive information was compared with the omission and commission group. Similar results were found in that children in the omission suggestion group were more likely to omit the critical piece of clothing than the control group $(p<.05)$. Likewise, commission errors were more likely to occur in the commission suggestion group than in the control group $(p<.05)$.

${ }^{13}$ Eighty parents correctly completed the questionnaire.
} 
With respect to age, separate Chi-Square analyses were carried out in which we found that younger and older children were equally likely to omit the critical pieces of clothing across the three interviews (all ps $>.05$ ). Interestingly, a different age pattern emerged for the commissions. Specifically, at Interview 1, younger children were about twice as likely to develop a memory commission than the older children $\left(\chi^{2}(1)=7.63, p<\right.$ .01 , Cramer's $V=.36)$. Identical findings were found at Interview $2\left(\chi^{2}(1)=8.65, p<.01\right.$, Cramer's $V=.40)$ and $3\left(\chi^{2}(1)=5.13, p<.05\right.$, Cramer's $V=.39$; see Figure 7.1).

To test whether children's memory reports are equally vulnerable to omissions and commissions, we conducted three-way (Misinformation: omission suggestion vs. commission suggestion; Manipulated Reporting Error (omission or commission): yes vs. no; Age: young vs. old) loglinear analyses at each of the three interviews. At Interview 1, we found that both younger and older children were more likely to develop a memory commission than to omit the critical piece of clothing $\left(L R(2)=1.79, p>.05 ; \chi^{2}(1)=5.02, p<\right.$ .05 , Cramer's $V=.21)$. Similar results were found at Interview $2\left(L R(2)=2.71, p>.05 ; \chi^{2}(1)=\right.$ $14.22, p<.001$, Cramer's $V=.36)$ and $3\left(L R(2)=0.36, p>.05 ; \chi^{2}(1)=5.87, p<.05\right.$, Cramer's $V=.29$; see Figure 7.1).

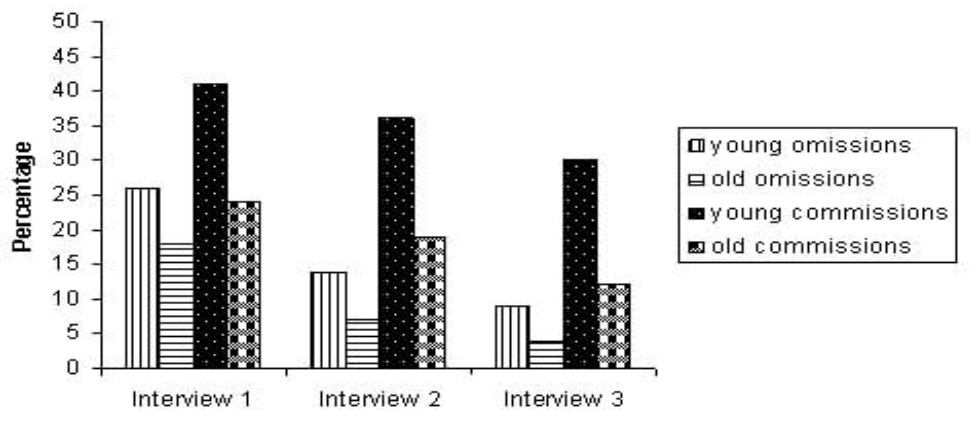

Figure 7.1 Percentage of young and older children's memory omissions and commissions across three interviews. 


\section{Discussion}

The present study explored whether children were equally likely to omit and commit details of an interactive event as a result of misleading information. Our major findings can be catalogued as follows. First, we found that the number of children that failed to mention the critical piece of clothing decreased significantly over time. Similarly, high rates of commission errors made immediately after the suggestive interview were not stable over three weeks. Instead, the number of children making such errors declined as a function of repeated interviewing. Furthermore, results showed that across three interviews, younger and older children's memory details were equally likely to be omitted whereas adding details was more likely to occur in younger than older children. Also, our study showed that, on average, commission errors were easier to elicit than omission errors in children's reports.

This is the first study showing that a single suggestive manipulation may have a dramatic impact on omission errors in children's reports. That is, at the first interview, almost half of the children in the omission suggestion condition $(45 \%, n=27)$ did not report an action that they performed themselves. However, we also showed that this impact on children's omission errors was less likely to persist over time. Specifically, our results showed that across three interviews, the number of children that omitted the critical piece of clothing significantly declined. Thus, it seems that although misleading information can cause children's memories to be omitted, this may not be a long-lasting phenomenon. Nonetheless, we found that at the third interview, $13 \%(n=6)$ of the children continued to omit the critical piece of clothing.

Like omission errors, commission errors were found to decline across three interviews. As previously noted, studies have reported mixed results with respect to commission errors and repeated interviews. Specifically, some studies (e.g., Bjorklund et al., 1998; Otgaar et al., 2008) showed that commission errors increase over time and with repeated interviews, while other studies (e.g., Ceci et al., 1994; Powell et al., 1999; Salmon \& Pipe, 1997; Strange et al., 2008) show that commission errors decline or remain constant after multiple interviews over time. However, in the majority of these studies (e.g., Bjorklund et al., 1998; Otgaar et al., 2008), participants were presented repeatedly with 
misleading information whereas in our study, children were exposed only once to false suggestions. Apparently, then, this single suggestive manipulation in the commission suggestion condition was not powerful enough to affect children's commission errors over time or keeping them at a constant high level. However, it would be challenging to examine how multiple suggestive manipulations would affect omissions and commissions in children's reports.

Our study clearly shows that omission and commission errors follow a uniform course over time. This suggests that there may be comparable mechanisms underlying these two effects. Although omissions and commissions may be (partly) driven by social aspects of memory (e.g., conformity, Gabbert, Memon, \& Wright, 2006), it could also be that omissions and commissions are the result of profound reality monitoring errors. Particularly, studies focusing on commissions show that they are related to fundamental memory errors (Loftus, 2003; Loftus, Donders, Hoffman, \& Schooler, 1989). Relatedly, future studies should examine whether commissions and omissions figure only in memory reports or whether they are really reflecting accessibility of memory traces.

We also found that younger and older children were equally likely to omit critical items from their reports after repeated interviews. This result is in contrast with multiple studies demonstrating that younger children are more likely to accept suggestive information than older children (see for an overview Ceci \& Bruck, 1993). Although at Interview 3, more young children failed to report the critical piece of clothing than older children, this difference was quite small (i.e., $n=4$ vs. $n=2$ ). Hence, this difference could not attain statistical significance. We did find, though, that commission errors are more prevalent among younger than older children; an effect that is consistently documented across a wide range of studies (see Ceci \& Bruck, 1993).

Of particular interest is that contrary to other studies (e.g., Candel et al., 2009; Pezdek \& Roe, 1997), children in our study participated in an interactive event in which they actively had to take off different pieces of clothing. Interestingly, research shows that memory for self-performed actions is far more superior that memory for passive events (Engelkamp, 1995). This is related to findings showing that information is well remembered when it pertains to the self (Symons \& Johnson, 1997). So, it is reasonable to say that this underlies the fact children in our study developed strong memories for removing the pieces of clothing. Hence, our study shows that despite these strong memories, children were still highly vulnerable for making omission and commission errors. 
Our findings are difficult to reconcile with Pezdek and Roe's (1997) study in which no significant differences were found between the omission/commission suggestion group and a control group in terms of omitting or adding details. We did find that our experimental manipulations (omission/commission suggestion) were successful relative to a control group. However, as Wright and colleagues (2001) have pointed out, Pezdek and Roe used small sub-samples in each of their conditions $(n=16)$ which resulted in low statistical power.

A more notable result was that children's reports were more likely to contain commission errors than omission errors. This result seems to contradict Candel et al.'s (2009) study in which falsely reporting non-presented details and omitting presented details were equally likely to occur. Moreover, this finding is discordant with the discrepancy detection principle (Hall et al., 1984). Our findings imply that, in the omission suggestion condition, children were more aware of the discrepancy between the misleading information and their original information than in the commission suggestion condition. Therefore, these children were more likely to discard misleading information than children in the commission suggestion condition.

Our result is more in line with the source monitoring framework (Johnson, Hashtroudi, \& Lindsay, 1993) which refers to the processes involved in determining the sources of our memories. According to this framework, memories based on an authentic experience contain more perceptual, contextual, and affective details while fabricated memories contain more cognitive information (see also Johnson \& Raye, 1981). Crucially, people use these details when they have to decide whether their memories originate from a true or fabricated experience. In our study, children developed true memories of removing three pieces of clothing. From a source monitoring perspective, it could be stressed that it would be relatively difficult to suggestively omit these memories since they would contain an abundance of perceptual, contextual, and affective information and would be considered to be an authentic experience. However, in the commission suggestion condition, it would be relatively easy to come to believe to have taken off a piece of clothing since children already had true memories of removing three other pieces of clothing that importantly had the same color (i.e., perceptual information). Therefore, children can be easily led to misattribute the removal of the jacket to a genuine experience.

To recap, our study illustrates that in children's reports, commission errors are easier to elicit than omission errors. Meanwhile, during the first and second interview, omission errors were found in a substantial minority of children. Accordingly, our study 
could have practical implications in the forensic context. While legal cases and studies commonly focus on whether misleading information can result in the formation of commission errors, our knowledge about how misleading information can produce omission errors is limited. Admittedly, our study is not fully analogous to forensic situations. However, we believe that studies like the current one could illuminate cases in which children do not report certain details of horrendous events because of misleading information of interviewers or perpetrators (e.g., Zajac et al., 2003). 
8

General discussion 
False memory research has provided us with a voluminous body of findings showing that false memories can easily be evoked by using different experimental manipulations. For instance, false memories can be elicited by studying semantically associated words or by providing suggestive information. Whilst these findings have fueled our knowledge about the fallibility of memory, there is a lack of research on the precise antecedents of false memories. Obviously, knowing which factors are involved in false memory creation could clarify under which conditions adults and children are most likely to develop false memories (see also Pezdek \& Hodge, 1999). The purpose of the current dissertation was to compare different false memory paradigms (Chapter 2) and to identify potential antecedents of children's false memory development (Chapters 3, 4, and 5). Moreover, this dissertation aimed to examine whether children's false memories differ from their true memories in terms of Reality Monitoring criteria (Chapter 6) and whether misleading information would equally impact children's omission (i.e.,. leaving out details) and commission errors (i.e., false details) after repeated questioning (Chapter 7). This chapter recaps and discusses the findings of the previous chapters in light of current false memory research. Furthermore, recommendations will be given for future research avenues.

\section{Different false memory paradigms}

False memories can be elicited using different false memory paradigms. Chapter 2 described two experiments that aimed to elucidate the relationship between children's false memories triggered by the DRM paradigm and false memories induced by suggestion. The background for these experiments originated from the debate between Pezdek and Lam (2007) and Wade and colleagues (2007). This debate focused on the question whether different false memory paradigms elicit equivalent false memory illusions.

The two experiments reported in Chapter 2 show that in children, different false memory paradigms reveal different results. Specifically, Chapter 2 demonstrated that children's DRM illusions are not related to children's acceptance of suggestive information. A potential explanation for this finding is that DRM illusions and suggestion-based false memories have different developmental trajectories. So, the development of the DRM illusion hinges on age-related differences of semantic networks (Bjorklund, 2004), while 
false memories caused by suggestion are due to source monitoring differences (Lindsay, Johnson, \& Kwon, 1991). Since semantic networks and efficient source monitoring are less well developed in children than in adults (Bjorklund, 2004; Robert \& Blades, 2000), DRM illusions are less prevalent in children whereas suggestion-based false memories are more common among children than adults. The point made in Chapter 2 was that due to a lack of a relationship between these types of false memories, one should be cautious when generalizing DRM findings to legal proceedings in which children's reports are the result of suggestive interviewing techniques. Note though that other memory researchers have argued similarly (see DePrince, Allard, Oh, \& Freyd, 2004; Freyd \& Gleaves, 1996; Gobbo, 2002; Mazzoni, 2002a; 2002b; Memon, 2002; Roediger \& McDermott, 1995a, 1996). Freyd and Gleaves, for instance, criticized Roediger and McDermott's (1995) original article about the DRM illusion on two grounds. First, they argued that false memories for words cannot be equated with false memories for entire events. So, DRM illusions are more related to semantic memory while false memories for entire events are more associated with autobiographical memory. Second, they noted that DRM false memories are related to words that were studied whereas false memories of, for example, abusive events are quite different from events that are truly experienced. Thus, these authors caution against the inappropriate application of DRM findings to the domain of contested memories of abuse.

Mazzoni (2002a) also recommended implementing a dichotomy in false memory research. This author clarifies DRM illusions as naturally occurring distortions and false memories due to external suggestions as suggestion-dependent memory distortions. Mazzoni claimed that although mechanisms responsible for both categories of could somehow overlap, it has not been demonstrated yet that similar processes underlie these different types of false memories. Therefore, assuming that DRM findings can also account for suggestion-based false memories is unwarranted. DePrince and colleagues (2004) noted that this assumption is likely caused by the term false memory which is used for DRM illusions as well as for memory errors triggered by suggestion. Pezdek and Lam (2007) therefore proposed to make a distinction between false memories for details which they termed flawed memories and false memories for entire events.

The overall portrait which surfaces is that unless future research shows that DRM false memories and suggestion-based false memories have similar underlying processes, memory researchers should exert caution in generalizing DRM results to false memories for entire events (e.g., sexual abuse). Tentative evidence indicates that different mechanisms 
could operate in the development of children's false memories. Particularly, previous studies (e.g., Sugrue \& Hayne, 2006; Sutherland \& Hayne, 2001) and the results described in Chapter 2 show that divergent developmental trends occur in DRM- and suggestion-based false memories. This points to different mechanisms involved in children's false memory occurrence. Thus, it seems that false memories are multi-dimensional with one type of false memories relying on semantic networks while the other type of false memories relying on suggestion.

It should be mentioned though that the usefulness of the DRM paradigm is not criticized and that DRM findings have advanced our knowledge about memory distortions. More specifically, research relying on the DRM paradigm has encouraged theory building. Thus, based on the large corpus of studies using this paradigm, Brainerd and Reyna (2005) formulated their Fuzzy Trace Theory (FTT), which is widely recognized as an overarching framework for understanding false memory and their persistence. The contribution of the DRM paradigm to the field of false memories lies not so much in its application to specific court cases, but in the theoretical notions that it generated, notions that in turn can be helpful for elucidating false memories as they occur in real life.

With respect to the forensic field, Holliday and colleagues (2008) remarked that DRM findings can be useful in court cases since DRM illusions share similarities with children's memory reports in forensic contexts. They argued that in many child sexual abuse cases, children have experienced repeated acts of sexual abuse which are quite similar to each other. As children are less able to extract the gist of meaningful information, they will be less likely to falsely report gist-consistent sexual acts than adults. In these particular cases, DRM findings could be of absolute value.

\section{Event characteristics}

Which specific characteristics are related to false memories for entire events? The studies highlighted in Chapter 3, 4, and 5 set out to examine event characteristics contributing to the false memory effect. Three event characteristics that were of keen interest in the present thesis were plausibility, script knowledge, and valence. 
Plausibility

Starting with Pezdek and colleagues' (1997; 1999) findings, event plausibility has been shown to play a vital role in false memory development. Specifically, people are more likely to remember that they have experienced a plausible false event than an implausible false event. However, in contrast to Pezdek and colleagues' results, Strange et al. (2006) found that children were equally prone to develop false memories for a plausible and an implausible event. To further unravel the role of event plausibility, Chapter 3 focused on manipulating the plausibility of false events (i.e., abducted by a UFO vs. almost choked on a candy) by presenting children with prevalence information. Here, it was shown that young children more often develop false memories when they are presented with information implying that the false events occurs frequently than young children who did not receive this information. Also, consistent with Strange et al.'s work, no differences were found between children's false memory rates for a plausible (i.e., almost choking on candy) and implausible event (i.e., being abducted by a UFO). Hence, this study shows that even for extremely implausible false events, children can come up with quite elaborate memory reports. These findings support the observation that children in legal contexts can give highly detailed and compelling descriptions of extremely bizarre and unusual events (see Ceci \& Bruck, 1993; Garven et al., 1998; 2000).

That manipulating plausibility affects children's false memory levels implies that the use of prevalence information significantly boosts event plausibility levels, which, in turn, has consequences for the implantation of false memories. Prevalence information has been employed in other studies (see Van Golde, Sharman, \& Candel, in press; Hart \& Schooler, 2006; Mazzoni et al., 2001; Pezdek et al., 2006; Scoboria et al., 2006), yet its effect has only been studied in the context of adults' false beliefs. Specifically, in these studies, adult participants had to rate the plausibility of possible experienced childhood events before and after they received prevalence information. In short, it was found that plausibility levels increased after the presentation of prevalence information. Overall, it seems that manipulations that target plausibility are highly efficient in adults' false memory development. Indeed, other manipulations, such as imagination, have recently also been shown to increase plausibility levels and affect false memory rates (Mazzoni \& Memon, 2003; Pezdek, Blandon-Gitlin, \& Gabbay, 2006; Sharman \& Scoboria, in press).

However, since Chapter 3 shows that plausibility did not affect children's false memory creation, one may wonder what role prevalence information plays precisely in 
children's false memory development. One distinct possibility is that the addition of prevalence information makes younger children more willing to comply and to incorporate the suggestion of the interviewer than older children. This possibility is consistent with the general finding that younger children are more likely to comply and agree with suggestive information (see Bruck \& Ceci, 1999).

Recent research (e.g., Ghetti, 2003; 2008; Ghetti \& Alexander, 2004; Mazzoni \& Kirsch, 2002) explains the formation of false memories in terms of metacognitive factors. These factors refer to the knowledge and beliefs that people have about their own cognitions. Mazzoni and Kirsch's model posits that false memories occur when certain metacognitive beliefs affect people's decisions about memorial experiences. For example, prevalence information could make children's mental images of the event more vivid and clear and lower their criterion for judging an event as remembered. That is, because people generally believe that their true memories contain vivid and clear characteristics, prevalence information may cause children to accept the false event as an authentic experience.

However, this research (Ghetti, 2008; Ghetti \& Alexander, 2004) also shows that certain metacognitive beliefs develop through childhood (e.g., relying on event salience). This would imply that younger children rely less on these beliefs and are more dependent on external sources (e.g., prevalence information) to judge the likelihood of an event. Also, the finding that event plausibility did not affect false memory rates could be related to children's limited inferential capacities to decide whether certain events are plausible or not. Ghetti and Alexander for instance demonstrated that the plausibility of events did not affect young children's decisions about the likelihood of false events. In sum, the results described in Chapter 3 suggest that children do not use plausibility as adults do to decide whether events happened or not. Therefore, children are equally likely to develop a false memory for an implausible as a plausible event.

\section{Script knowledge}

The effect of knowledge about the target event on the development of false memories for that event was examined in the study described in Chapter 4. This chapter showed that children were more likely to assent to an event (i.e., being stuck with your fingers in a mousetrap) of which they had knowledge than to an event (i.e., receiving a rectal enema) of which their knowledge was limited. This finding corresponds closely to recent studies showing that schematic processing (i.e., processing of organized information) including script processing increases the susceptibility to memory distortions (Kleider et al., 
2008; Nemeth \& Belli, 2006; Ornstein et al., 1998). Apparently, schematic processing promotes a type of memory search that enhances the likelihood for false memory formation. In particular, when children are presented with a false event (e.g., being stuck with your fingers in a mousetrap) of which they already possesses knowledge, they will search for event-related knowledge that aids in constructing an image of the event. When children have more knowledge about an event, this search process will easily generate an image of the event which can eventually lead to a false memory (see Pezdek \& Hodge, 1999).

Interestingly, Chapter 4 also showed that presenting children with additional knowledge about a false event could at the same time inhibit the development of false memories. Seemingly, providing children with extra information about an event constrains the memory search process. This constraint decreases the probability of creating an image about the false event, which leads to smaller chances to develop false memories for the false event (Garry \& Wade, 2005). An alternative explanation for this finding is that extra knowledge could have caused the false events to become more distinctive (Ghetti et al., 2002). Research shows that distinctive information reduces the likelihood of false memory formation (e.g., Hege \& Dodson, 2004).

As was the case in Chapter 3, metacognitive factors (e.g., Ghetti, 2003; 2008; Ghetti \& Alexander, 2004; Mazzoni \& Kirsch, 2002) could also account for the results described in Chapter 4. The Mazzoni and Kirsch's model assumes that limited knowledge about an event reduces the probability that events will be believed to have happened and falsely remembered. This assumption bears resemblance to the lack of knowledge inference (Gentner \& Collins, 1981), which holds that people use metaknowledge when evaluating whether an event has been truly experienced or not. With this in mind, one could argue that people do not know precisely what receiving a rectal enema entails and therefore infer not having experienced this event. Furthermore, the script-absent event (i.e., receiving a rectal enema) could have been experienced as more memorable (e.g., salient; Ghetti, 2003; 2008), which led more children to reject the script-absent than the script-present event (i.e., being stuck with your fingers in a mousetrap). To recap, Chapter 4 clearly shows that having knowledge about an event increases children's susceptibility to false memory about that event. Moreover, providing additional information about that event inhibits the development of children's false memories. 
Valence

In Chapter 5, it was argued that memory is more likely to be distorted for negative material than for neutral material. The results presented in that chapter confirm this prediction with children displaying higher false memory rates for a false negative event (i.e., being accused of copying of your neighbor) than for a false neutral event (i.e., moving to another classroom). This finding has recently been supported by studies using misinformation, implantation, and DRM paradigms (Brainerd et al., 2008; Candel, 2006; Porter et al., 2008). So, although some clinicians (e.g., Faller, 1996; Summit, 1992) have argued that in cases of horrendous events, children always tell the truth, this chapter clearly shows that this position does not necessarily hold.

Corson and Verrier (2007), however, showed that false memories are more likely to occur under high arousal conditions and that valence per se does not affect false memory rates. The difference between valence and arousal is that valence refers to the emotional aspect of an event (e.g., positive, negative) while arousal specifies the intensity of an event (e.g., calm, exciting; Kensinger \& Schacter, 2006). This raises the question whether valence or arousal is related to the development of false memories. One critical difference between their study and studies (Brainerd et al., 2008; Candel, 2006; Porter et al., 2008) showing that negative information is more vulnerable for false memory formation is that in the latter studies, valence of stimuli was manipulated. Specifically, in these studies, participants were presented with information varying in emotional content, while in Corson and Verrier's study (2007) participants had to undergo a mood induction task followed by an evaluation of their mood in terms of valence and arousal. Thus, valence in Corson and Verrier's study was a dependent and independent variable, while in the other studies valence was employed as an independent variable. This difference is likely related to the discrepant findings of valence on false memory formation.

A possible account for (Brainerd et al., 2008; Candel, 2006; Porter et al., 2008) the impact of valence on false memory development, is that emotional presented information leads to increased relational processing (e.g., spreading activation) instead of item-specific processing. Studies (e.g., Brainerd et al., 2008; Howe, 2008) show that relational processing of information increases the chance for false memory creation. Research also demonstrates that negative emotional material is more interrelated in memory than neutral information (Talmi et al., 2004; 2007). Specifically, negative emotional material is more linked to other negative material than neutral material. As false memories are mainly the products of 
interconnected associated networks (for a review, see Gallo, 2006), one expects to find more people falsely assent to negative than to neutral information. For example, when children are presented with negative false information (e.g., accused of copying off), this information could activate other related negative information (e.g., being kept in school). As a result, children might become more likely to incorporate the false information into their memory.

\section{Age}

The findings reported in Chapter 2, 3, 4, and 7 show a clear relationship between age and false memory development. That is, younger children are more likely to assent to false suggestive information than older children. Moreover, this age difference remains after repeated interviews. Three explanations might accommodate these results. First, younger children have more problems to determine the sources of their memories than older children (e.g., Lindsay, Johnson, \& Kwon, 1991). So, in the current thesis, younger children might more readily confuse the sources of false events than older children and erroneously assume that the false events refer to a genuine experience.

Secondly, in terms of FTT (Brainerd \& Reyna, 1998), the finding that younger children more likely concur to suggestive information than older children may be related to the developmental trajectory of verbatim traces. Although FTT predicts that false memory development increases with age when false memories rely on gist traces, like in the case of DRM illusions, the FTT also provides an explanation for the age-related increase of suggestion-based false memories. Specifically, the presentation of suggestive information produces verbatim traces that conflict with already stored information. Because younger children are more likely to retrieve verbatim traces than older children, they are more likely to include suggestive information than older children.

A third explanation might be that younger children are more willing to concur to false information from other people (e.g., interviewers, parents) than older children (Ceci \& Bruck, 1993). Specifically, younger children more likely succumb to social pressure than older children. This finding seems to be related to the finding that younger children have weaker memory traces of events than their older counterparts which makes them more reliant on information from others (Ceci, Ross, \& Toglia, 1987). 


\section{False memory characteristics}

Legal cases show that children's testimonies about traumatic events are commonly seen as indicative of an authentic experience (Garven et al., 1998). However, as already said, when exposed to misleading information, children can quite easily come up with fabricated accounts of events. Chapter 6 tested the efficiency of a verbal detection instrument, Reality Monitoring (RM; Johnson \& Raye, 1981), in discriminating between children's true and false memories. Although the RM framework proposes that memories based on an experienced event qualitatively and quantitatively differ from "memories" based on non-experienced events, Chapter 6 shows that this position does not hold for children's true and false memories. Specifically, no differences were found between children's true and false memories in terms of overall RM criteria. Apparently, children regard their false memories as originating from a true experience; an interpretation that is supported by Pezdek and colleagues' model (1997; 1999).

The RM model assumes that false memories arise as the result of available schemas and scripts of which details will be transferred into the construction of false memories. This will end up into highly detailed and elaborate false memory reports. Therefore, RM criteria are ineffective in distinguishing children's true and false memories. From a practical point of view, this implies that RM criteria are not useful in forensic contexts, where the issue is to determine the authenticity of children's alleged claims of, for example, sexual abuse.

A corpus of evidence shows that verbal detection measures as Criteria Based Content Analysis (CBCA; Köhnken, et al., 1995; Raskin \& Esplin, 1991; Vrij \& Mann, 2006) and RM are capable in differentiating between true accounts and deliberately invented accounts. However, it seems that when false memories are implanted, these tools are dysfunctional (but see Porter et al., 1999). Moreover, not only are children's true and false memories qualitatively and quantitatively alike, also adults' accounts of true and false events correspond. Blandon-Gitlin and colleagues (2009) recently showed that, like the RM criteria, the CBCA criteria fail to determine whether adults' statements are based on fact or fiction. 


\section{Compliance or memory distortion?}

A significant issue that intrigues false memory scholars is whether the presentation of suggestive information can result in real memory aberrations (see Loftus, 2005; Loftus \& Hoffman, 1989; McCloskey \& Zaragoza, 1985). Numerous studies have demonstrated that when exposed to suggestion, both children and adults can develop false memories of events and details (e.g., Davis \& Loftus, 2007; Otgaar et al., 2009; Sutherland \& Hayne, 2001). Research also shows that such commission errors (i.e., false memories) are similar to veridical memories in terms of subjective ratings, and in their behavioral concomitants such as reaction times and food preferences (e.g., Bernstein, Laney, Morris, \& Loftus, 2005; Lindsay et al., 2004; Loftus et al., 1989; McNally et al., 2004). This indicates that commission errors are sustained by memory traces -albeit incorrect ones- and cannot be explained solely as manifestations of social pressure (e.g., conformity). So far, no study has examined whether suggestion-induced omission errors reflect a pure memory phenomenon (i.e., erasure of correct traces).

Chapter 7 examined to what extent suggestive misleading information might elicit commission errors (i.e., false memories) and omission errors (i.e., failure to report correct information) after repeated interviews. This chapter showed that presenting misleading information can make children falsely deny information (i.e., omission errors). Furthermore, it showed that commission errors were more easily elicited than omission errors and that both commission and omission errors significantly declined over time.

Thus, it is possible to create omission errors with false suggestions. But do social phenomena (e.g., compliance with suggestions provided by adults) underlie these errors? Or are suggestion-induced omission errors the result of memory traces that have been erased or -to use a less dramatic description- have become inaccessible? The latter possibility comes close to concepts like repression and amnesia and it has drawn the attention of researchers interested in delayed disclosure of child abuse (e.g., Sjöberg \& Lindblad, 2002). Meanwhile, as Wright and colleagues (2001, p. 481) write: "little empirical attention has been focused on the question of whether a perpetrator, or others, could act in such a way to make a memory less likely to be retrieved". 
In a recent study, we examined whether memory erasure would likely be involved in omission errors. ${ }^{14}$ In this study, 75 seven-year old children were instructed to remove three pieces of clothing from a puppet. Next, they were provided with false evidence suggesting that they took off two pieces. During two follow-up interviews with a one week interval in-between, children had to indicate which pieces of clothing they had removed. After the second interview, children had to complete a choice reaction time task. During this task, different pictures of clothing were displayed, including the item that the child falsely denied to have removed (i.e., removed omitted item), items that were not removed, and items that the child admitted to have removed. For each item, children had to indicate whether it had been removed by pressing one of two buttons, one labeled yes and one labeled no.

The task started with 48 practice trials intended to familiarize the children with the procedure. During these trials, children received feedback when they responded slowly (i.e., no response after $5000 \mathrm{~ms}$ ) or incorrectly. After the practice trials, children were presented with 144 experimental trials divided into three blocks of 48 trials. Each trial began with the presentation of a picture of one of the items which remained on the screen until a response was made with a maximum of 5000 ms. Blocks were separated by a self-paced break.

The rationale behind this task is that if the memory trace for removing the omitted item is erased or inaccessible, it should be processed identical to the items that were never removed. Given that they share the same response button (the no-button), no difference in behavioral data is expected between these types of items. If, on the other hand, behavioral data differ between items that have never been removed and omitted items, this indicates interference, meaning that the memory has not been erased. In that case, the omission errors must be attributed to other mechanisms than erasure such as compliance.

\footnotetext{
${ }^{14}$ See Otgaar, H., Meijer, E.H., Giesbrecht, G., Smeets, T., Candel, I., \& Merckelbach, H. (in revision) Children's suggestion-induced omission errors are not caused by memory erasure.
} 


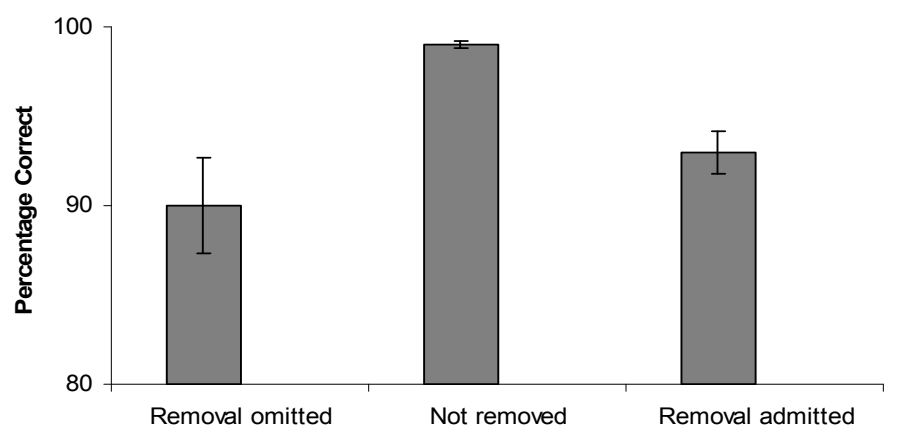

Figure 8.1. Percentage correct responses of item type (removal omitted, not removed, removal admitted) of the omission suggestion group

We found that children made more errors when they were presented with removal omitted pieces of clothing than when they were presented with the not removed pieces of clothing (see Figure 8.1). This implies that the presentation of the removal omitted items induced a response conflict (see Farwell \& Donchin, 1991; Loftus et al., 1989; Meijer, Smulders, Merckelbach, \& Wolf, 2007), apparently because memory traces of these items were still present and created interference.

All in all, this study provides tentative evidence that children's omission errors are manifestations of compliance. These findings bear relevance to discussions about factors that are responsible for memory and delayed disclosure of abuse in children and adults. Some authors (Tesser \& Nelson, 1994; p. 321) argue that "an experience not talked about (such as a secretive sexual abuse episode) may not be recallable by the child" and that "[t]his is one possible reason for poor memory for some such incidents". Alpert, Brown, and Courtois (1998, p. 975) even stated that [t]he identified dynamics of sexual abuse and of perpetrator tendencies to deny and "not know" must be given consideration in understanding how a child might lose memory for or "forget" abuse". Other authors believe that impaired memory due to denial or threats would work against a full disclosure (Sjöberg \& Lindblad, 2002). However, our results suggest that it is not easy to impair children's memory by providing them with suggestive information. Obstacles to disclosure of abuse might have more to do with social phenomena than with memory erasure.

So, it is likely that different mechanisms are fundamental to children's commission and omission errors. While commission errors are predominantly linked to memory corruption (e.g., Lindsay et al., 2004; Loftus et al., 1989), omission errors seem to be caused by social pressure. More interestingly, omission errors appear to be related to far-reaching 
compliance. Remember that in Chapter 7, 13\% $(n=6)$ of the children still failed to mention the critical piece of clothing to their parents. So, children's compliant behavior seems to exert a long-lasting effect on their omission errors.

\section{Forensic significance}

This thesis has some imperative implications for the forensic area. To start, the present dissertation conclusively shows that the ecological validity of the DRM paradigm is limited in legal cases in which suggestive interviewing techniques are an issue. Expert witnesses should be aware that two false memory research lines exist. Furthermore, when they have to report about children's alleged statements of events, they should consult results of studies which share methodological similarities with the development of children's alleged statements.

The first false memory research line shows that when children's statements are the product of suggestive interrogations, younger children are more likely to come up with fictitious stories than older children and adults. The other research line shows that under some circumstances younger children are less likely to develop a false memory than older children and adults. These circumstances only occur when children have to process meaning-relevant information. In legal cases, expert witnesses should determine which research line should be used to explain children's memory reports. However, pointing to some high-profile cases (e.g., Wee Care Nursery School, McMartin Preschool, Oude Pekela, Outreau), the impression arises that most cases can best be accounted for by suggestionbased false memory research. Most importantly, expert witnesses should realize that in children, DRM- and suggestion-based false memories are unrelated to each other. The significance of these two types of false memories becomes clear when looking at the amount of interrogations in which children are involved. For example, in the Netherlands, approximately 1100 interrogations in which children are witness and/or victim of a horrendous event take place each year (J. van der Sleen, personal communication April 14, 2009). ${ }^{15}$ Obviously, people working in these settings must be aware of different types of false memories that can occur.

\footnotetext{
${ }^{15}$ See for more information http://www.kinterview.com
} 
Second, the current thesis shows that professionals working in the legal domain (e.g., interrogators, lawyers, researchers, expert witnesses) should not be misled by the content of children's statements. For instance, in the "Oude Pekela" case, Jonker and Jonker-Bakker (1991, p. 196) argued that "[i]t is important for child abuse professionals to be aware that the most bizarre stories may indicate the possibility of satanic rituals." This thesis clearly shows that the bizarreness and negative nature of children's stories can not be used to infer the authenticity of these stories. Furthermore, the amount of details of children's statements does not provide any indication about the authenticity of a memory report.

These implications are related to some specific antecedents that are associated with false memories. Therefore, in legal cases, attention should be drawn to these specific antecedents. To clarify, take a look at these two examples. They are excerpts from interviews from the "Wee Care Nursery School" trial. ${ }^{16}$

Interviewer: Tell me now, what did Kelly do to your hiney?

Child: I'll try to remember.

Interviewer: What did she put in your hiney?

Child: The fork.

Interviewer: Did (name) have to put his penis in her penis, too?

Child: Yes, at the same time.

Interviewer: At the same time? How did you do that?

Child: We chopped our penises off.

These statements refer to rather bizarre and implausible events. Some clinicians (e.g., Faller, 1996; Summit, 1992) argue that children do not invent fantastic stories and that bizarre aspects in statements are an indication of a true event. Chapter 2, however, shows that even bizarre and implausible false events are highly likely to be implanted into children's memory. Furthermore, they should be aware that providing young children with information implying that false events are plausible (i.e., prevalence information) is perilous for children's recollections. This could happen in interview settings, for example, when the interrogator tells children that other children also experienced these false events. Strikingly, such information was often provided in cases as the "McMartin Preschool" and the "Wee Care Nursery School" trials (Ceci \& Bruck, 1993; Garven et al., 2000).

\footnotetext{
${ }^{16}$ http://www.crimemagazine.com/daycaresidebar.htm
} 
Another issue of which professionals working in the legal domain should be aware is that children's memory is more likely to be distorted for negative events than neutral events (Chapter 5). As legal cases are predominantly characterized by negative events, expert witnesses should be cautious when children's statements are the consequence of suggestive questioning. Furthermore, they should be aware that children's knowledge about events could be an additional vulnerability factor for false memory development.

Legal professionals are often faced with the question how to determine whether children's statements are based on reality or fabrication. This thesis, however, shows that the RM criteria are inefficient in distinguishing children's true and false memories. One might wonder then how to deal with children's testimonies of traumatic events. The most obvious approach to handle such statements is to examine under which circumstances they were obtained. When such statements are elicited spontaneously, then research shows that children are highly accurate in describing their experiences (see Bidrose \& Goodman, 2000; Orbach \& Lamb, 1999). However, when evidence exists that suggestive interviewing techniques were present, then statements can be tainted.

A potential problem with spontaneous generated statements is that research shows that children are quite reluctant in disclosing horrendous events (e.g., GoodmanBrown, Edelstein, Goodman, Jones, \& Gordon, 2003; Sjöberg \& Lindblad, 2002). One intriguing speculation is that the limited disclosure of children's experiences is highly related to the phenomenon of omission errors. It could well be that part of this limited disclosure mirrors actual omission errors. As the results presented in the previous section show that children's omission errors can best be explained by social influences, it is a challenge for interrogators to make children's limited reports more elaborate by asking open nonsuggestive questions. Thus, people working in forensic arena should be aware that although, in general, children's memories are a treasure of the mind, the findings presented in this dissertation clearly show that these memories can easily be become a treachery of the mind. That is, this dissertation shows that children can easily be led into developing false memories for entire events. 


\section{Future research avenues}

Although the present thesis provides new insights into the area of children's false memories, it also suggests some new research opportunities. To address these opportunities, novel avenues should be constructed. Below, we will briefly sketch some possible research lines.

The present dissertation evidently demonstrates that younger children are more likely to include suggestive information into their memory than older children. However, when children are presented with meaning-related information, then younger children show lower false memory levels than older children. The most logical next step would be to identify which specific mechanisms account for this opposing result. A promising answer lies in the development of children's executive functions. Recent research provides some tentative evidence that poor maturation of executive functions co-occur with a heightened susceptibility for suggestion in children (e.g., Alexander et al., 2002; Melinder, Endestad, \& Magnussen, 2006; Robert \& Powell, 2005; Roebers \& Schneider, 2005). Specifically, executive functions such as inhibition seem to be related to children's suggestibility. However, the results are not unequivocal and therefore this field requires further investigation. One could hypothesize that children with inhibitory control deficiencies are more vulnerable to suggestion than children without these deficiencies.

Furthermore, other mechanisms that are related to maturation of the prefrontal cortex and executive functioning could bear relevance to children's false memories (e.g., Theory of Mind). Research shows that executive functions and processing of meaningrelated information are related to frontal lobe development (e.g., Brainerd et al., 2008; Dempster, 1993). Taken together, research that examines relationships between concepts such as executive functions (e.g., inhibition) and Theory of Mind on the one hand and false memories induced by suggestion and the DRM paradigm on the other, could be fruitful research enterprises.

A worthwhile research avenue would also be to improve the coding schemes of the RM criteria among researchers. As things stands, instruments as the RM framework cannot be used in individual cases because of the danger of false positives and negatives (see also Memon et al., in press). Recent research has already begun to use new standardized RM coding schemes (Memon et al., in press). Future studies should examine 
whether these schemes can be useful to detect statements that are the product of suggestion.

Another research line that could offer more productive knowledge about children's false memories concerns the relationship between children's psychopathology and false memory development. Virtually no studies have tackled this issue, yet it is safe to assume that children with atypical developments could be frequently involved in legal proceedings (e.g., Young, 2007). For example, research shows that children with Attention Deficit Hyperactivity Disorder (ADHD) are at high risk to develop antisocial behavior (Marshal \& Molina, 2006). Bruck, London, Landa, and Goodman (2007, p. 92) for instance stated that "[i]nterviewing children with developmental disabilities presents unique challenges for families and professionals who care for these children." As disorders as ADHD and autism seem to be related to deficits in source monitoring and processing meaning-related information (Bruck et al., 2007; Gudjonsson, Young, \& Bramham, 2007; Kamio \& Toichi, 2007), one predicts that children with these disorders will be more vulnerable to false memories. However, so far, the limited research in this field has not provided any concrete evidence for this prediction. In sum, theory-driven research which examines whether children with specific disorders are more or less susceptible to false memory formation could be of significant value for understanding and evaluating the accuracy of children's memory reports. 


\section{References}

Alexander, K.W., Goodman, G.S., Schaaf, J.M., Edelstein, R.S., Quas, J.A., \& Shaver, P.R. (2002). The role of attachment and cognitive inhibition in children's memory and suggestibility for a stressful event. Journal of Experimental Psychology, 83, 262-290.

Alonso-Quecuty, M.L., \& Hernández-Fernaud, E. (1997). Tócale otra vez Sam: repitiendo las mentiras [Play it again Sam: Retelling a lie]. Estudios de Psicología, 57, 29-37.

Anastasi, J.S., \& Rhodes, M.G. (2008). Examining differences in the levels of false memories in children using child-normed lists. Developmental Psychology, 44, 889-894.

Alpert, J.L., Brown, L.S., \& Courtois, C.A. (1998). Symptomatic clients and memories of childhood sexual abuse. Psychology, Public Policy, and Law, 4, 941-995.

Bernstein, D.M., Laney, C., Morris, E.K., \& Loftus, E.F. (2005). False memories about food can lead to food avoidance. Social Cognition, 23, 11-34.

Bidrose, S., \& Goodman, G. (2000). Testimony and evidence: A scientific case study of memory for child sexual abuse. Applied Cognitive Psychology, 14, 197-213.

Bjorklund, D.F. (2004). Children's thinking: Cognitive development and individual differences. Belmont, CA: Wadsworth.

Bjorklund, D.F., Bjorklund, B.R., Brown, R.D., \& Cassel, W.S. (1998). Children's susceptibility to repeated questions: How misinformation changes children's answers and their minds. Applied Developmental Science, 2, 99-111.

Blandon-Gitlin, I., Pezdek, K., Lindsay, D.S., \& Hagen, L. (2009). Criteria-Based Content Analysis of true and suggested accounts of events. Applied Cognitive Psychology, 23, 901-917.

Blandon-Gitlin, I., Pezdek, K., Rogers, R., \& Brodie, L. (2005). The effects of event familiarity on CriteriaBased Content Analysis ratings: An experimental study. Law and Human Behavior, 29, 187197.

Brainerd, C. J., \& Reyna, V.F. (1988). Memory loci of suggestibility development: Comment on Ceci, Ross, and Toglia. Journal of Experimental Psychology: General, 118, 197-200.

Brainerd, C.J., \& Reyna, V.F. (1998). Fuzzy-trace theory and children's false memories. Journal of Experimental Psychology, 71, 81-129.

Brainerd, C.J., \& Reyna, V.F. (2002). Fuzzy-trace theory and false memory. Current Directions in Psychological Science, 11, 164-169.

Brainerd, C.J., \& Reyna, V.F. (2005). The science of false memory. New York: Oxford University Press.

Brainerd, C.J., Forrest, T.J., Karibian, D., \& Reyna, V.F. (2006). Development of the false-memory illusion. Developmental Psychology, 42, 962-979.

Brainerd, C.J., Reyna, V.F., \& Ceci, S.J. (2008). Developmental reversals in false memory: A review of data and theory. Psychological Bulletin, 134, 343-382. 
Brainerd, C.J., Reyna, V.F., \& Forrest, T.J. (2002). Are young children susceptible to the false-memory illusion? Child Development, 73, 1363-1377.

Brainerd, C.J., Reyna, V.F., Wright, R., \& Mojardin, A.H. (2003). Recollection rejection: False-memory editing in children and adults. Psychological Review, 110, 762-784.

Brainerd, C.J., Stein, L.M., Silveira, R.A., Rohenkohl, G., \& Reyna, V.F. (2008). How does negative emotion cause false memories? Psychological Science, 19, 919-925.

Bruck, M., \& Ceci, S.J. (1999). The suggestibility of children's memory. Annual Review of Psychology, 50, 419-439.

Bruck, M., Ceci, S.J., \& Hembrooke, H. (2002). The nature of children's true and false narratives. Developmental Review, 22, 520-554.

Bruck, M., London, K., Landa, R., \& Goodman, J. (2007). Autobiographical memory and suggestibility with autism spectrum disorder. Development and Psychopathology, 19, 73-95.

Candel, I. (2006, May). False memories: The role of plausibility and valence. In R. McNally (Chair), Remembering, distorting, and forgetting trauma. Association of Psychological Science Annual Convention, New York.

Candel, I., Hayne, H., Strange, D., \& Prevoo, E. (2009). The effect of suggestion on children's recognition memory for seen and unseen details. Psychology, Crime, \& Law, 15, 29-39.

Candel, I., Merckelbach, H., Jelicic, M., Limpens, M., \& Widdershoven, H. (2004). Children's suggestibility for peripheral and central details. The Journal of Credibility Assessment and Witness Psychology, 5, 9-18.

Candel, I., Merckelbach, H., Loyen, S., \& Reyskens, H. (2005). “I hit the Shift-key and then the computer crashed": Children and false admissions. Personality and Individual Differences, 38, 13811387.

Candel, I., Merckelbach, H., \& Muris, P. (2000). Measuring interrogative suggestibility in children: Reliability and validity of the Bonn Test of Statement Suggestibility. Psychology, Crime, \& Law, 6, 61-70.

Carneiro, P., Albuquerque, P., Fernandez, A., \& Esteves, F. (2007). Analyzing false memories in children with associative lists specific for their age. Child Development, 78, 1171-1185.

Ceci, S.J., \& Bruck, M. (1993). Suggestibility of the child witness: A historical review and synthesis. Psychological Bulletin, 113, 403-439.

Ceci, S.J. \& Bruck, M. (1995). Jeopardy in the courtroom: A scientific analysis of children's testimony. Baltimore, MD: Port City Press.

Ceci, S.J., Huffman, M.L.C., Smith, E., \& Loftus, E.F. (1994a). Repeatedly thinking about a non-event: Source misattributions among preschoolers. Consciousness and Cognition, 3, 388-407.

Ceci, S.J., Loftus, E.F., Leichtman, M.D., \& Bruck, M. (1994b). The possible role of source misattributions in creation of false beliefs among preschoolers. International Journal of Clinical and Experimental Hypnosis, 42, 304-320. 
Ceci, S.J., Ross, D.F., \& Toglia, M.P. (1987). Suggestibility of children's memory: Psycholegal implications. Journal of Experimental Psychology: General, 116, 38-49.

Ceci, S.J., Toglia, M., \& Ross, D. (1988). On remembering. . .more or less. Journal of Experimental Psychology: General, 118, 250-262.

Clancy, S.A., McNally, R.J., Schacter, D.L., Lenzenweger, M., \& Pitman, R.K. (2002). Memory distortion in people reporting abduction by aliens. Journal of Abnormal Psychology, 111, 455-461.

Colwell, K., Hiscock, C.K., \& Memon, A. (2002). Interviewing techniques and the assessment of statement credibility. Applied Cognitive Psychology, 16, 287-300.

Corson, Y., \& Verrier, N. (2007). Emotions and false memories: Valence or arousal? Psychological Science, 18, 208-211.

Davis, D., \& Loftus, E.F. (2007). Internal and external sources of misinformation in adult witness memory. In M.P. Toglia, J.D. Read, D.F. Ross, \& R.C.L. Lindsay (Eds.), Handbook of eyewitness psychology (Vol. I). Memory for events. (pp. 195-237). Mahwah, NJ: Erlbaum.

Deese, J. (1959). On the prediction of occurrence of particular verbal intrusions in immediate recall. Journal of Experimental Psychology, 58, 17-22.

Dempster, F.N. (1993). Resistance to interference: Developmental changes in a basic processing mechanism. In M.L. Howe \& R. Pasnak (Eds.), Emerging themes in cognitive development. (pp. 3-27.) New York: Springer-Verlag.

DePrince, A.D., Allard, C.B., Oh, H., Freyd, J.J. (2002). What's in a name for memory errors? Implications and ethical issues arising from the use of the term "false memory" for errors in memory for details. Ethics \& Behavior, 14, 201-233.

Desjardins, T., \& Scoboria, A. (2007). "You and your best friend Suzy put Slime in Ms. Smollett's desk": Producing false memories with self-relevant details. Psychonomic Bulletin \& Review, 14, 1090-1095.

Elischberger, H.B. (2005). The effects of prior knowledge on children's memory and suggestibility. Journal of Experimental Child Psychology, 92, 247-275.

Endres, J. (1997). The suggestibility of the child witness: the role of individual differences and their assessment. Journal of Credibility Assessment and Witness Psychology, 1, 44-67.

Engelkamp, J. (1995). Visual imagery and enactment of actions in memory. British Journal of Psychology, $86,227-240$.

Esposito, N.J. (1975). Review of discrimination shift learning in young children. Psychological Bulletin, $82,432-455$.

Faller, K.C. (1996). Interviewing children who may have been abused: A historical perspective and overview of controversies. Child Maltreatment, 1, 83-95.

Farrar, M.J., \& Goodman, G.S. (1992). Developmental changes in event memory. Child Development, 63, 173-187.

Farwell, L.A., \& Donchin, E. (1991). The truth will out: Interrogative polygraphy (“lie detection”) with event-related brain potentials. Psychophysiology, 28, 531-547. 
Fivush, R. (1997). Event memory. In Cowan N. (ed.), The Development of Memory in Childhood (pp. 139162). Psychology Press: Hove.

Fivush, R. (1998). Children's recollections of traumatic and nontraumatic events. Development and Psychopathology, 10, 699-716.

Foley, M.A., Hughes, K., Librot, H., \& Paysnick, A. (2009). Imagery encoding effects on memory in the DRM paradigm: A test of competing predictions. Applied Cognitive Psychology, 23, 828-848.

Foley, M.A., Johnson, M.K., \& Sopasakis, M. (1989). Discriminating between memories: Evidence for children's spontaneous elaborations. Journal of Experimental Psychology, 48, 146-169.

Foley, M.A., Wozniak, K., \& Gillum, A. (2006). Imagination and false memory inductions: Investigating the role of process, content, and source of imagination. Applied Cognitive Psychology, 20, 1119-1141.

Freyd, J.J., \& Gleaves, D.H. (1996). "Remembering” words not presented in lists: Relevance to the current recovered/false memory controversy. Journal of Experimental Psychology: Learning, Memory, and Cognition, 22, 811-813.

Gabbert, F., Memon, A., \& Wright, D. B. (2006). Memory conformity: Can eyewitnesses influence each other's memories for an event? Applied Cognitive Psychology, 17, 533-543.

Gallo, D.A. (2006). Associative illusions of memory: False memory research in DRM and related tasks. New York: Psychology Press.

Garry, M., \& Gerrie, M. (2005). When photographs create false memories. Current Directions in Psychological Science, 14, 321-325.

Garry, M., \& Wade, K.A. (2005). Actually, a picture is worth less than 45 words: Narratives produce more false memories than photographs do. Psychonomic Bulletin \& Review, 12, 359-366.

Garven, S., Wood, J., \& Malpass, R. (2000). Allegations of wrongdoing: The effects of reinforcement on children's mundane and fantastic claims. Journal of Applied Psychology, 83, 38-49.

Garven, S., Wood, J., Malpass, R., \& Shaw III, J. (1998). More than suggestion: The effect of interviewing techniques from the McMartin Preschool case. Journal of Applied Psychology, 83, 347-359.

Geraerts, E., Arnold, M. M., Lindsay, D. S., Merckelbach, H., Jelicic, M., \& Hauer, B. (2006). Forgetting of prior remembering in people reporting recovered memories of childhood sexual abuse. Psychological Science, 17, 1002-1008.

Gentner, D., \& Collins, A. (1981). Studies of inference from lack of knowledge. Memory \& Cognition, 9 , 434-443.

Ghetti, S. (2003). Memory for nonoccurrences: The role of metacognition. Journal of Memory and Language, 48, 722-739.

Ghetti, S. (2008). Rejection of false events in childhood. Current Directions in Psychological Science, 17, 16-20.

Ghetti, S., \& Alexander, K.W. (2004). "If it happened, I would remember it": Strategic use of event memorability in the rejection of false autobiographical events. Child Development, 75, 542561. 
Ghetti, S., Qin, J., \& Goodman, G.S. (2002). False memories in children and adults: Age, distinctiveness, and subjective experience. Developmental Psychology, 38, 705-718.

Gobbo, C. (2002). Naturally occurring memory distortions and suggestion-dependent memory distortions: Two separate research lines? European Psychologist, 7, 31-38.

Goodman, G.S., Quas, J.A., \& Redlich, A.D. (1998). The ethics of conducting 'false memory' research with children: A reply to Hermann and Yodor. Applied Cognitive Psychology, 12, 207-217.

Goodman-Brown, T.B., Edelstein, R.S., Goodman, G.S., Jones, D.P.H., \& Gordon, D.S. (2003). Why children tell: A model of children's sexual abuse. Child Abuse \& Neglect, 27, 525-540.

Granhag, P.A., Strömwall, L.A., \& Landström, S. (2006). Children recalling an event repeatedly: Effects on RM and CBCA scores. Legal and Criminological Psychology, 11, 81-98.

Gudjonsson, G.H. (1984). A new scale for interrogative suggestibility. Personality and Individual Differences, 5, 303-314.

Gudjonsson, G.H. (1989). Compliance in an interrogation situation: A new scale. Personality and Individual Differences, 10, 535-540.

Gudjonsson, G.H. (1992). The psychology of interrogations, confessions, and testimony. Chichester, John Wiley \& Sons.

Gudjonsson, G.H., Young, S., \& Bramham, J. (2007). Interrogative suggestibility in adults diagnosed with attention-deficit hyperactivity disorder (ADHD). A potential vulnerability for police questioning. Personality and Individual Differences, 43, 737-745.

Hall, D.F., Loftus, E.F., \& Tousignant, J.P. (1984). Postevent information and changes in recollection for a natural event. In G.L. Wells \& E.F. Loftus (Eds.), Eyewitness testimony: Psychological perspectives. Cambridge: Cambridge University Press.

Hart, R., \& Schooler, J. (2006). Increasing belief in an invasive procedure that never happened: The role of plausibility and schematicity. Applied Cognitive Psychology, 20, 661-669.

Hege, C.G., \& Dodson, C.S. (2004). Why distinctive information reduces false memories: Evidence for both impoverished relational-encoding and distinctiveness heuristic accounts. Journal of Experimental Psychology: Learning, Memory, and Cognition, 30, 787-795.

Holliday, R.E., Reyna, V.F., \& Brainerd, C.J. (2008). Recall of details never experienced: Effects of age, repetition, and semantic cues. Cognitive Development, 23, 67-78.

Howe, M.L. (1998). When distinctiveness fails, false memories prevail. Journal of Experimental Child Psychology, 71, 170-177.

Howe, M.L. (2007). Children's emotional false memories. Psychological Science, 18, 856-860.

Howe, M.L. (2008). Visual distinctiveness and the development of children's false memories. Child Development, 79, 65-79.

Howe, M.L., Candel, I., Otgaar, H., Malone, C., \& Wimmer, M.C. The role of valence in children's and adults's immediate and long-term false memory illusions. Submitted for publication. 
Howe, M.L., Cicchetti, D., Toth, S.L., \& Cerrito, B.M. (2004). True and false memories in maltreated children. Child Development, 75, 1402-1417.

Howell, D.C. (2002). Statistical methods for psychology ( $5^{\text {th }}$ ed.). Boston: Thomson Learning.

Hudson, J.A., Fivush, R., \& Kuebli, J. (1992). Scripts and episodes: The development of event memory. Applied Cognitive Psychology, 6, 483-505.

Hyman, I.E., Husband, T.H., \& Billings, F.J. (1995). False memories of childhood experiences. Applied Cognitive Psychology, 9, 181-197.

Johnson, M.K. (1988). Reality monitoring. Journal of Experimental Psychology: General, 117, 390-394.

Johnson, M.K., Hashtroudi, S., \& Lindsay, D.S. (1993). Source monitoring. Psychological Bulletin, 114, 328.

Johnson, M.K., \& Raye, C.L. (1981). Reality monitoring. Psychological Review, 88, 67-85.

Jonker, F., \& Jonker-Bakker, P. (1991). Experiences with ritualist child sexual abuse: A case study from the Netherlands. Child Abuse \& Neglect, 15, 191-196.

Kamio, Y., \& Toichi, M. (2007). Memory illusion in high-functioning autism and asperger's disorder. Journal of Autism and Developmental Disorder, 37, 867-876.

Kensinger, A., \& Schacter, D.L. (2006). Processing emotional pictures and words: Effects of valence and arousal. Cognitive, Affective, \& Behavioral Neuroscience, 6, 110-126.

Kleider, H.M., \& Pezdek, K., Goldinger, S.D., \& Kirk, A. (2008). Schema-driven source misattribution errors: Remembering the expected from a witnessed event. Applied Cognitive Psychology, 22, 1-20.

Köhnken, G., Schimossek, E., Aschermann, E., \& Hofer, E. (1995). The cognitive interview and the assessment of the credibility of adults' statements. Journal of Applied Psychology, 80, 671684.

Koriat, A., Goldsmith, M., Schneider, W., \& Nakash-Dura, M. (2001). The credibility of children's testimony: Can children control the accuracy of their memory reports. Journal of Experimental Child Psychology, 79, 405-437.

Lampinen, J.M. \& Smith, V.L. (1995). The incredible (and sometimes incredulous) child witness: Child eyewitnesses' sensitivity to source credibility cues. Journal of Applied Psychology, 80, 621627.

Laney, M.A.., Loftus, E.F. (2005). Traumatic memories are not always accurate memories. Canadian Journal of Psychiatry, 50, 823-828.

Lindsay, S., Hagen, L., Read., J.D., Wade, K., \& Garry. M. (2004). True photographs and false memories. Psychological Science, 15, 149-154.

Lindsay, D.S., \& Johnson, M.K. (2000). False memories and the source monitoring framework: Reply to Reyna and Lloyd (1997). Learning and Individual Differences, 12, 145-161.

Lindsay, D.S., Johnson, M.K., \& Kwon, P. (1991). Developmental changes in memory source monitoring. Journal of Experimental Child Psychology, 52, 297-318. 
Lindsay, D.S., \& Read, J.D. (1995). "Memory work" and recovered memories of childhood sexual abuse: Scientific evidence and public, professional, and personal issues. Psychology, Public Policy, and the Law, 1, 846-908.

Loftus, E.F. (1993). The reality of repressed memories. American Psychologist, 48, 518-537.

Loftus, E.F. (1997). Creating false memories. Scientific American, 277, 70-75.

Loftus, E.F. (2003). Our changeable memories: Legal and practical implications. Nature Reviews:

Neuroscience, 4, 231-234.

Loftus, E.F. (2004). Memories of things unseen. Current Directions in Psychological Science, 13, 145-147.

Loftus, E.F. (2005). Planting misinformation in the human mind: A 30-year investigation of the malleability of memory. Learning \& Memory, 12, 361- 366.

Loftus, E.F., \& Bernstein, D.M. (2005). Rich false memories: The royal road to success. In A.J.F. Healy (Ed.), Experimental cognitive psychology and its implications. Decade of Behavior (pp. 101113). Washington, DC, US: American Psychological Association.

Loftus, E.F., Donders, K., Hoffman, H., \& Schooler, J.W. (1989). Creating new memories that are quickly accessed and confidently held. Memory \& Cognition, 17, 607-616.

Loftus, E.F., \& Hoffman, H.G. (1989). Misinformation and memories: The creation of new memories. Journal of Experimental Psychology: General, 118, 100-104.

Loftus, E. F., Miller, D. G. \& Burns, H. J. (1978). Semantic integration of verbal information into a visual memory. Human Learning and Memory, 4, 19-31.

Loftus, E.F., \& Pickrell, J.E. (1995). The formation of false memories. Psychiatric Annals, 25, 720-725.

Marshal, M.P., \& Moline, B.S.G. (2006). Antisocial behaviors moderate the deviant peer pathway to substance use in children with ADHD. Journal of Clinical Child and Adolescent Psychology, 35, 216-226.

Markus, H. (1977). Self-schemata and processing information about the self. Journal of Personality \& Social Psychology, 35, 63-78.

Masip, J., Sporer, S., Garrido, E., \& Herraro, C. (2005). The detection of deception with the reality monitoring approach. A review of the empirical evidence. Psychology, Crime, \& Law, 11, 99122.

Mazzoni, G. (2002a). Naturally occurring and suggestion-dependent memory distortions: The convergence of disparate research traditions. European Psychologist, 7, 31-38.

Mazzoni, G. (2002b). Reply to the commentaries on "Naturally occurring and suggestion-dependent memory distortions". European Psychologist, 7, 31-38.

Mazzoni, G. \& Kirsch, I. (2002). Autobiographical memories and beliefs: A preliminary metacognitive model. In T. Perfect, B. Schwartz (Eds.) Applied Metacognition (pp. 121-145). Cambridge, U.K., Cambridge University Press.

Mazzoni, G., Loftus, E., \& Kirsch, I. (2001). Changing beliefs about implausible autobiographical events: A little plausibility goes a long way. Journal of Experimental Psychology: Applied, 7, 51-59. 
Mazzoni, G., \& Memon, A. (2003). Imagination can create false autobiographical memories. Psychological Science, 14, 186-188.

McCloskey, M., \& Zaragoza, M. (1985). Misleading postevent information and memory for events: Arguments and evidence against memory impairment hypotheses. Journal of Experimental Psychology: General, 114, 1-16.

McNally, R.J., Lasko, N.B., Clancy, S.A., Macklin, M.L., Pitman, R.K., \& Orr, S.P. (2004).

Psychophysiological responding during script-driven imagery in people reporting abduction by space aliens. Psychological Science, 15, 493-497.

Meade, M., \& Roediger, H. (2002). Explorations in the social contagion of memory. Memory \& Cognition, 30, 995-1009.

Meijer, E.H., Smulders, F.T.Y., Merckelbach, H.L.G.J., \& Wolf, A.G. (2007). The P300 is sensitive to concealed face recognition. International Journal of Psychophysiology, 66, 231-237.

Melinder, A., Endestad, T., \& Magnussen, S. (2006). Relations between episodic memory, suggestibility, theory of mind, and cognitive inhibition in the preschool child. Scandinavian Journal of Psychology, 47, 485-495.

Memon, A. (2002). Commentaries and author's reply on "Naturally occurring and suggestion-dependent memory distortions". European Psychologist, 7, 31-38.

Memon, A., Fraser, J., Colwell, K., Odinot, G., \& Mastroberardino, S. (in press). Distinguishing truthful from invented accounts using reality monitoring criteria. Legal and Criminological Psychology.

Merckelbach, H., van Roermund, H., \& Candel, I. (2007). Effects of collaborative recall: Denying true information is as powerful as suggesting misinformation. Psychology, Crime, \& Law, 13, 573581.

Metzger, R.L., Warren, A.R., Shelton, J.T., Price, J., Reed, A.W., \& Williams, D. (2008). Do children “DRM” like adults? False memory production in children. Developmental Psychology, 44, 169-181.

Meyer, J., \& Jesilow, P. (1996). Obedience to authority: Possible effects on children's testimony. Psychology, Crime \& Law, 3, 81-95.

Nemeth, R.J., \& Belli, R.F. (2006). The influence of schematic knowledge on contradictory versus additive misinformation: False memory for typical and atypical items. Applied Cognitive Psychology, 20, 563-573.

Nourkova, V., Bernstein, D.M., \& Loftus, E.F. (2004). Altering traumatic memory. Cognition and Emotion, 18, 575-585.

Orbach, Y., \& Lamb, M.E. (1999). Assessing the accuracy of a child's account of sexual abuse: A case study. Child Abuse \& Neglect, 23, 91-98.

Ornstein, P.A., Merrit, K.A., Baker-Ward, L., Furtado, E., Gordon, B.N., \& Principe, G. (1998). Children's knowledge, expectation, and long-term retention. Applied Cognitive Psychology, 12, 387-405.

Ost, J., Foster, S., Costall, A., \& Bull, R. (2005). False reports of childhood events in appropriate interviews. Memory, 13, 700-710. 
Ost, J., Ghonouie, H., Cook, L., \& Vrij, A. (2008). The effects of confederate influence and confidence on the accuracy of crime judgments. Acta Psychologica, 128, 25-32.

Otgaar, H. (2009) Not all false memory paradigms are appropriate in court In L. Strömwall \& P.A. Granhag (Eds.), Memory: Reliability and personality (pp. 37-46). Göteborg: Göteborg University.

Otgaar, H., Meijer, E.H., Giesbrecht, G., Smeets, T., Candel, I., \& Merckelbach, H. (in revision). Children's suggestion-induced omission errors are not caused by memory erasure.

Otgaar, H., Candel, I., \& Merckelbach, H. (2008). Children's false memories: Easier to elicit for a negative than for a neutral event. Acta Psychologica, 128, 350-354.

Otgaar, H., Candel, I., Merckelbach, H. \& Wade, K.A. (2009). Abducted by a UFO: Prevalence information affects young children's false memories for an implausible event. Applied Cognitive Psychology, 23, 115-125.

Otgaar, H., Candel, I., Scoboria, A., \& Merckelbach, H. (in revision). Script knowledge affects the development of children's false memories.

Peters, M.J.V., Jelicic, M., \& Merckelbach, H. Inducing false memories: A Dutch version of the Deese/Roediger-McDermott paradigm. Submitted for publication.

Pezdek, K. (2007). It's just not good science. Consciousness and Cognition, 16, 29-30.

Pezdek, K., Blandon-Gitlin, I., Gabbay, P. (2006a). Imagination and memory: Does imaging implausible events lead to false autobiographical memories. Psychonomic Bulletin \& Review, 13, 764-769.

Pezdek, K., Blandon-Gitlin, I., Lam, S., Hart, R. E., \& Schooler, J.W. (2006b). Is knowing believing? The role of event plausibility and background knowledge in planting false beliefs about the personal past. Memory \& Cognition, 34, 1628-1635.

Pezdek, K., Finger, K., \& Hodge, D. (1997). Planting false childhood memories: The role of event plausibility. Psychological Science, 8, 437-441.

Pezdek, K., \& Hodge, D. (1999). Planting false childhood memories in children: The role of event plausibility. Child Development, 70, 887-895.

Pezdek, K., \& Lam, S. (2007). What research paradigms have cognitive psychologists used to study "False memory", and what are the implications of these choices? Consciousness and Cognition, 16, 2-17.

Pezdek, K., Morrow, A., Blandon-Gitlin, I., Goodman, G.S., Quas, J.A., Saywitz, K.J., Bidrose, S., Pipe, M., Rogers, M., \& Brodie, L. (2004). Detecting deception in children: Event familiarity affects Criteria-Based Content Analysis ratings. Journal of Applied Psychology, 89, 119-126.

Pezdek, K., \& Roe, C. (1995). The effect of memory trace strength on suggestibility. Journal of Experimental Child Psychology, 60, 116-128.

Pezdek, K., \& Roe, C. (1997). The suggestibility of children's memory for being touched: Planting, erasing, and changing memories. Law and Human Behavior, 12, 95-106. 
Plancher, G., Nicolas, S., \& Piolino, P. (2008). Influence of suggestion in the DRM paradigm: What state of consciousness is associated with false memory? Consciousness and Cognition, 17, 11141122.

Pollack, S.D., \& Kistler, D.J (2002). Early experience is associated with the development of categorical representations for facial expressions of emotion. Proceedings of the National Academy of Sciences, USA, 99, 9072-9076.

Poole, D.A., Lindsay, D.S., Memon, A., \& Bull, R. (1995). Psychotherapy and the recovery of memories of childhood sexual abuse: U.S. and British practitioners' opinions, practices, and experiences. Journal of Clinical and Consulting Psychology, 63, 426-437.

Porter, S., Bellhouse, S., McDougall, A., ten Brinke, L., \& Wilson, K. A prospective investigation of the vulnerability of positive and negative scenes to the misinformation effect. Submitted for publication.

Porter, S., Spencer, L., \& Birt, A. (2003). Blinded by emotion? Effect of emotionality of a scene on susceptibility to false memories. Canadian Journal of Behavioral Sciences, 35, 165-175.

Porter, S., Taylor, K., \& ten Brinke, L. (2008). Memory for media: An investigation of false memories for negatively- and positively-charged public events. Memory, 16, 658-666.

Porter, S., Yuille, J.C., \& Lehman, D.R. (1999). The nature of real, implanted, and fabricated memories for emotional childhood events: Implication for the recovered memory debate. Law and Human Behavior, 23, 517-537.

Powell, M.B., Roberts, K.P., Ceci, S.J., \& Hembrooke, H. (1999). The effects of repeated experience on children's suggestibility. Developmental Psychology, 35, 1462-1477.

Quas, J.A., Malloy, L.C, Melinder, A., Goodman, G.S., D’Mello, M., \& Schaaf, J. (2007). Developmental differences in the effects of repeated interviews and interviewer bias on young children's event memory and false reports. Developmental Psychology, 43, 823-837.

Quas, J.A., \& Schaaf, J.M. (2002). Children's memories of experienced and nonexperienced events following repeated interviews. Journal of Experimental Child Psychology, 83, 304-338.

Raskin, D.C., \& Esplin, P.W. (1991). Statement validity assessment: Interview procedures and content analysis of children's statements of sexual abuse. Behavioral Assessment, 12, 265-291.

Reyna, V., Holliday, R., \& Marche, T. (2002). Explaining the development of false memories. Developmental Review, 22, 436-489.

Reyna, V. F., \& Kiernan, B. (1994). The development of gist versus verbatim memory in sentence recognition: Effects of lexical familiarity, semantic content, encoding instructions, and retention interval. Developmental Psychology, 30, 178-191.

Reysen, M.B. (2007). The effects of social pressure on false memories. Memory \& Cognition, 35, 59-65.

Richardson, G., \& Kelly, T.P. (2004). A study in the relationship between interrogative suggestibility, compliance and social desirability in institutionalized adolescents. Personality and Individual Differences, 36, 485-494 
Rivers, S.E., Reyna, V.F., \& Mills, B. (2008). Risk taking under the influence: A fuzzy trace theory of emotion in adolescence. Developmental Review, 28, 107-144.

Roberts, K., \& Blades, M. (2000). Children's source monitoring. Mahwah, NJ: Lawrence Erlbaum Associates.

Roberts, K.P., \& Powell, M.B. (2005). The relation between inhibitory control and children's eyewitness memory. Applied Cognitive Psychology, 19, 1003-1018.

Roebers, C.M., \& Schneider, W. (2005). Individual differences and in young children's suggestibility: Relations to event memory, language abilities, working memory, and executive functioning. Cognitive Development, 20, 427-447.

Roediger, H.J., Balota, D.H., \& Watson, J.M. (2001). Spreading activation and arousal of false memories. In H.J. Roediger, J.S. Sairne, I. Neath, \& A.M. Surprenant (Eds.), The nature of remembering: Essays in honor of Robert G. Crowder (pp. 95-115). Washington, DC: American Psychological Association

Roediger, H. L., \& Gallo, D. A. (2005). Associative memory illusions. In R. F. Pohl (Ed.), Cognitive Illusions: A Handbook on Fallacies and Biases in Thinking, Judgment and Memory (pp. 309-326). New York: Psychology Press.

Roediger, H. L., \& McDermott, K. (1995). Creating false memories: remembering words not presented in a list. Journal of Experimental Psychology: Learning, Memory, and Cognition, 21, 803-814.

Roediger, H. L., \& McDermott, K. (1996). False perceptions of false memories. Journal of Experimental Psychology: Learning, Memory, and Cognition, 22, 814-816.

Rovee-Collier, C. (1995). Time windows in cognitive development. Developmental Psychology, 31, 147169.

Ruby, C.L., \& Brigham, J.C. (1997). The usefulness of the Criteria-Based Content Analysis Technique in distinguishing between truthful and fabricated allegations: A critical review. Psychology, Public Policy, and Law, 3, 705-737.

Salmon, K., \& Pipe, M. (1997). Props and children's event reports: The impact of a 1-year delay. Journal of Experimental Child Psychology, 65, 261-292.

Sawilowsky, S.S. (1990). Nonparametric tests of interaction in experimental design. Review of Educational Research, 60, 91-126.

Saywitz, K. J. (1990). The child as a witness: Experimental and clinical considerations. In A. M. LaGreca (Ed.), Through the eyes of the child: Obtaining self-reports from children and adolescents (pp. 329-367). Toronto, ON: Allyn and Bacon.

Schooler, J.W., Gerhard, D., \& Loftus, E.F. (1986). Qualities of the unreal. Journal of Experimental Psychology: Learning, Memory, and Cognition, 12, 171-181.

Schreiber, N., Bellah, L.D., Martinez, Y., McLaurin, K.A., Strok, R., Garven, S., \& Wood, J. (2006). Suggestive interviewing in the McMartin Preschool and Kelly Michaels daycare abuse cases: A case study. Social Influence, 1, 16-47. 
Scoboria, A., Mazzoni, G., Kirsch, I., \& Jimenez, S. (2006). The effects of prevalence and script information on plausibility, belief, and memory of autobiographical events. Applied Cognitive Psychology, 20, 1049-1064.

Scoboria, A., Mazzoni, G., Kirsch, I., \& Relyea, M. (2004). Plausibility and belief in autobiographical memory. Applied Cognitive Psychology, 18, 791-807.

Scullin, M.H., \& Ceci, S.J. (2001). A suggestibility scale for children. Personality and Individual Differences, 30, 843-856.

Sharman, S.J., \& Scoboria, A. (in press). Imagination equally influences false memories of high and low plausibility events. Applied Cognitive Psychology.

Sjöberg, R.L., \& Lindblad, F. (2002). Limited disclosure of sexual abuse in children whose experiences were documented by videotape. American Journal of Psychiatry, 159, 312-314.

Smeets, T., Merckelbach, H., Horselenberg, R., \& Jelicic, M. (2005). Trying to recollect past events: Confidence, beliefs, and memories. Clinical Psychology Review, 25, 917-934.

Snodgrass, J.G., \& Corwin, J. (1988). Pragmatics of measuring recognition memory: Applications to dementia and amnesia. Journal of Experimental Psychology: General, 117, 34-50.

Sporer, S.L. (1997). The less traveled road to truth: Verbal cues in detection deception in accounts of fabricated and self-experienced events. Applied Cognitive Psychology, 11, 373-397.

Sporer, S.L. (2004). Reality monitoring and deception of detection. In P.A. Granhag, \& L. Strömwall (Eds.), Deception detection in forensic contexts (pp. 64-102). Cambridge: Cambridge University Press.

Sporer, S.L., \& Sharman, S.J. (2006). Should I believe this? Reality monitoring of accounts of selfexperienced and invented recent and distant autobiographical events. Applied Cognitive Psychology, 20, 837-854.

Steller, M. (1989). Recent developments in statement analysis. In J.C. Yuille (Ed.), Credibility Assessment, (pp. 135-154). Dordrecht, the Netherlands: Kluwer Academic Publishers.

Strange, D., Hayne, H., \& Garry, M. (2008). A photo, a suggestion, a false memory. Applied Cognitive Psychology, 22, 587-603.

Strange, D., Sutherland, R., \& Garry, M. (2006). Event plausibility does not determine children's false memories. Memory, 14, 937-951.

Strömwall, L.A., Bengtsson, L., Leander, L., \& Granhag, P.A. (2004). Assessing children's statements: The impact of a repeated experience on CBCA and RM ratings. Applied Cognitive Psychology, 81, $653-668$

Strömwall, L.A., \& Granhag, P.A. (2005). Children's repeated lies and truths: Effects on adult's judgments and reality monitoring scores. Psychiatry, Psychology, and Law, 12, 345-356.

Sugrue, K., \& Hayne, H. (2006). False memories produced by children and adults in the DRM paradigm. Applied Cognitive Psychology, 20, 620-631. 
Summit, R. (1988). Hidden victims, hidden pain in societal avoidance of child sexual abuse. In G. E. Wyatt \& G. J. Powell (Eds.), Lasting effects of child sexual abuse (pp. 39-60). Beverly Hills, CA: Sage Publications.

Summit, R. (1992). Abuse of the child sexual abuse accommodation syndrome. Journal of Child Sexual Abuse, 1, 153-163.

Sutherland, R., \& Hayne, H. (2001). Age-related changes in the misinformation effect. Journal of Experimental Child Psychology, 79, 388-404.

Symons, C.S., \& Johnson, B.T. (1997). The self-reference effect in memory: A meta-analysis. Psychological Bulletin, 121, 371-394.

Talmi, D., \& Moscovitsch, M. (2004). Can semantic relatedness explain the enhancement of memory for emotional words? Memory \& Cognition, 32, 742-751.

Talmi, D., Luk, B., McGarry, L., \& Moscovitch, M. (2007). The contribution of relatedness and distinctiveness to emotionally-enhanced memory. Journal of Memory and Language, 56, 555-574

Tesser, A., \& Leone, C. (1977). Cognitive schemas and thought as determinants of attitude change. Journal of Experimental Social Psychology, 13, 340-356.

Tessler, M., \& Nelson, K. (1994). Making memories: The influence of joint encoding on later recall by young children. Consciousness and Cognition, 3, 307-326.

Thomas, A.K., \& Loftus, E.F. (2000). Creating bizarre false memories through imagination. Memory \& Cognition, 30, 423-431.

Undeutsch, U. (1989). The development of statement reality analysis. In J.C. Yuille (Ed.), Credibility Assessment, (pp. 101-121). Dordrecht, the Netherlands: Kluwer Academic Publishers.

Van Golde, C., Sharman, S.J., \& Candel, I. (in press). High prevalence information from different sources affects the development of false beliefs. Applied Cognitive Psychology.

Van Loon - Vervoorn, W.A., \& Bekkum van, I.J. (1991). Woordassociatie lexicon.

[Word association lexicon]. Amsterdam: Swets \& Zeitlinger.

Vrij, A. (2005). Criteria-based content analysis: A qualitative review of the first 37 studies. Psychology, Public Policy, and Law, 11, 3-41.

Vrij, A. (2008). Detecting lies and deceit: Pitfalls and opportunities. Chichester: Wiley.

Vrij, A., Akehurst, L., Soukara, S., \& Bull, R. (2004). Let me inform you how to tell a convincing story: CBCA and reality monitoring scores as a function of age, coaching, and deception. Canadian Journal of Behavioral Science, 24, 239-263.

Vrij. A., \& Mann, S. (2006). Criteria-based content analysis: An empirical test at its underlying process. Psychology, Crime, \& Law, 12, 337-349.

Vrij, A, Mann, S., Fisher, R., Leal, S., Milne, R., \& Bull, R. (2008). Increasing cognitive load to facilitate lie detection: The benefit of recalling an event in reverse order. Law and Human Behavior.

Vrij. A., Mann, S., Kirsten, S., \& Fisher, R.P. (2007). Cues to deception and ability to detect lies as a function of police interview styles. Law and Human Behavior, 31, 499-518. 
Wade, K.A., Garry, M., Read, J.D., \& Lindsay, S. (2002). A picture is worth a thousand lies: Using false photographs to create false childhood memories. Psychonomic Bulletin \& Review, 9, 597-603.

Wade, K., Sharman, S., Garry, M., Memon, A., Mazzoni, G., Merckelbach, H., \& Loftus. E. (2007). False claims about false memory research. Consciousness and Cognition, 16, 18-28.

Wessel, I., \& Moulds, M.L. (2008). Collective memory: A perspective from (experimental) clinical psychology. Memory, 16, 288-304.

Wilkinson, C., \& Hyman, I.E. (1998). Individual differences related to two types of memory errors: Word lists may not generalize to autobiographical memory. Applied Cognitive Psychology, 12, 2946.

Williams, S., Wright, D.B., \& Freeman, N.H. (2002). Inhibiting children's memory of an interactive event: The effectiveness of a cover-up. Applied Cognitive Psychology, 16, 651-664.

Wright, D.B.., \& Loftus, E.F. (1998). How misinformation alters memories. Journal of Experimental Child Psychology, 71, 155-164.

Wright, D.B., Loftus, E.F., \& Hall, M. (2001). Now you see it; Now you don't: Inhibiting recall and recognition of scenes. Applied Cognitive Psychology, 15, 471-482.

Young, S. (2007). Forensic aspects of ADHD. In M. Fitzgerald, M. Bellgrove, \& M. Gill (Eds.), Handbook of attention deficit hyperactive disorder. Chichester: Wiley.

Zajac, R., Gross, J., \& Hayne, H. (2003). Asked and answered: Questioning children in the courtroom. Psychiatry, Psychology and Law, 10, 199-209. 
Summaries 


\section{English}

Children's memory can easily be contaminated. That is, an impressive corpus of studies shows that suggestion can cause children to "recollect" entire non-experienced events. These memory errors are also called false memories. The objective of the present dissertation is to identify potential precursors contributing to children's false memory development. Some clinicians, however, argue that children's memories always refer to an experienced event, even when the event is extremely bizarre. As children are increasingly involved in legal proceedings in which their memories are of key interest, insight in these precursors is of great practical value.

Chapter 1 presents an overview of false memories paradigms, false memory theories, and of precursors that are likely to contribute to children's false memory creation. Additionally, in this chapter, the outline of this thesis is discussed and in doing so 6 research questions are emphasized, namely 1) Do different false memory paradigms reveal different results? 2) What is the role of event plausibility in the development of children's false memories? 3) What is the role of script knowledge in the development of children's false memories? 4) What is the role of valence in the development of children's false memories? 5) Can children's true and false memories be differentiated? and 6) What is the effect of misleading information on omissions and commissions in children's memory reports?

In Chapter 2, two different false memory paradigms (DRM vs. suggestion) are compared with each other. In two experiments, results showed that children's DRM illusions are not related to suggestion-based false memories. The findings reported in this chapter suggest that DRM findings are not useful in legal cases in which children's statements were the result of suggestive interviewing.

Chapter 3 describes a study that investigated how event plausibility affects the formation of children's false memories. Ninety-one 7-8-year old and 11-12 year-old children listened to narratives about a true event about their first school day and a fictitious event about an implausible (i.e., abducted by a UFO) or a plausible (i.e., almost choked on a candy) event. Furthermore, half of the children received a false newspaper article describing that the event frequently occurred (i.e., prevalence information). Then, during two interviews, children were asked to report everything they could remember about the events. Plausible and implausible events were equally likely to give rise to a false memory. Furthermore, 
younger children developed more false memories at the first interview when they were presented with a false newspaper article than younger children who did not receive the article. These findings show that children are easily led into falsely assenting to highly implausible events.

The studies described in Chapter 4 and 5 employed the same experimental procedure as Chapter 3. The main purpose of Chapter 4 was to examine whether script knowledge (i.e., knowledge about the sequences of events) affects children's false memory development. To this end, children were presented with a false event of which they had knowledge (i.e., script-present event; being stuck with your fingers in a mousetrap) or a false event of which their knowledge was limited (i.e., script-absent event; receiving a rectal enema). Moreover, half of the children received additional information about these events. Results showed that, at both interviews, false memories were more likely to emerge for the script-present than for the script-absent event. Moreover, extra information inhibited the development of children's images into false memories at the first interview. These results imply that having knowledge about an event increases the susceptibility for falsely remembering that event.

The study reported in Chapter 5 sought to examine the role of valence in children's false memory formation. In this study, 7-year old children listened to two true and one false narrative. The false narratives described either a neutral (i.e., moving to another classroom) or a negative (i.e., being accused of copying off) event. Also, half of the children were presented their class photograph during the interviews. At both interviews children were more likely to falsely remember the emotional negative event than the neutral event. As legal cases are predominantly about negative events, these findings have immense practical significance. The addition of a class photograph did not promote children's false memories.

Chapter 6 focuses on the distinction between children's true and false memories using the Reality Monitoring (RM) criteria. Transcripts of children's reports of genuine and fabricated events were analyzed by means of RM criteria. RM criteria, however, were unable to discriminate between children's true and false memories. Hence, the results indicate that the RM instrument is insufficient to be used in the legal arena when the task is to examine whether children's statements refer to an authentic or fictitious event.

Chapter 7 describes a study that examines children's propensity to develop commission and omission errors after repeated interviews. Children were asked to remove three pieces of clothing of a puppet. During three interviews, they had to report which 
pieces of clothing they removed. Following this, they were provided with false evidence stating that they removed four pieces of clothing (i.e., commission) or two pieces of clothing (i.e., omission). While commission errors were more readily triggered compared to omission errors, both types of errors significantly declined after three interviews. These findings illustrate the relative ease with which omission and commission errors can be elicited.

The General Discussion summarizes and discusses the above reported findings in light of recent false memory research. Furthermore, the legal implications are reported and ideas for future research enterprises are discussed. 


\section{Nederlands}

Het geheugen van kinderen is vrij eenvoudig te beïnvloeden. Een indrukwekkende hoeveelheid studies laat namelijk zien dat suggestieve interviewtechnieken ertoe kunnen leiden dat kinderen zich fictieve gebeurtenissen gaan "herinneren". Deze geheugenfouten worden ook wel pseudoherinneringen genoemd. Het doel van de huidige dissertatie is om antecedenten te identificeren die samenhangen met de ontwikkeling van pseudoherinneringen bij kinderen. Sommige clinici merken echter op dat herinneringen van kinderen altijd naar een authentieke gebeurtenis verwijzen, ook als het gaat om bizarre herinneringen. Aangezien kinderen steeds vaker betrokken zijn bij rechtszaken waarin hun herinneringen van cruciaal belang zijn, zou inzicht in deze antecedenten waardevol zijn.

Hoofdstuk 1 presenteert een overzicht over hoe pseudoherinneringen geïnduceerd kunnen worden, welke theorieën over pseudoherinneringen bestaan, en welke antecedenten waarschijnlijk samenhangen met de ontwikkeling van pseudoherinneringen bij kinderen. Bovendien wordt in dit hoofdstuk de inhoud van dit proefschrift uiteengezet aan de hand van 6 onderzoeksvragen, namelijk 1) Leiden verschillende paradigma's die pseudoherinneringen uitlokken tot verschillende resultaten? 2) Wat is de rol van de plausibiliteit van gebeurtenissen in de ontwikkeling van pseudoherinneringen bij kinderen? 3) Wat is de rol van script kennis in het totstandkomen van pseudoherinneringen bij kinderen? 4) Wat is de rol van valentie in de ontwikkeling van pseudoherinneringen bij kinderen? 5) Kunnen ware herinneringen en pseudoherinneringen van kinderen van elkaar worden onderscheiden? en 6) Wat is het effect van misleidende informatie op omissies en commissies in de verklaringen van kinderen?

In Hoofdstuk 2 worden twee verschillende paradigma's om pseudoherinneringen uit te lokken (DRM vs. suggestion) met elkaar vergeleken. In twee experimenten wordt aangetoond dat DRM illusies van kinderen niet samenhangen met pseudoherinneringen door suggestie. Deze bevindingen suggereren dat DRM resultaten onbruikbaar zijn in rechtszaken waarin verklaringen van kinderen tot stand zijn gekomen door suggestieve ondervragingen.

Hoofdstuk 3 beschrijft een studie waarin het effect van de plausibiliteit van gebeurtenissen op de ontwikkeling van pseudoherinneringen werd onderzocht. Eenennegentig 7-8-jaar en 11-12 jaar oude kinderen kregen ware en onware verhalen te 
horen over gebeurtenissen die ze hadden meegemaakt toen ze 4 jaar oud waren. Het ware verhaal beschreef een gebeurtenis over hun eerste schooldag, terwijl de onware verhalen over een implausibele (ontvoerd door een UFO) of plausible (bijna gestikt zijn in een snoepje) gebeurtenis gingen. Tevens kreeg de helft van de kinderen een fictief krantenartikel waarin werd beschreven dat de gebeurtenis die de kinderen zouden hebben meegemaakt frequent voorkwam (prevalentie informatie). Hierna moesten kinderen tijdens twee interviews alles vertellen wat ze nog konden herinneren over de gebeurtenissen. Plausibele en implausibele gebeurtenissen konden even gemakkelijk in het geheugen van kinderen worden geïmplanteerd. Bovendien ontwikkelden jonge kinderen meer pseudoherinneringen bij het eerste interview wanneer ze het fictieve krantenartikel hadden ontvangen dan jonge kinderen die het artikel niet hadden gezien. Deze resultaten laten zien dat kinderen zeer gemakkelijk pseudoherinneringen ontwikkelen aan zeer implausibele gebeurtenissen.

De studies beschreven in Hoofdstuk 4 en 5 gebruikten dezelfde experimentele procedure als die beschreven in Hoofdstuk 3. Het hoofddoel van Hoofdstuk 4 was te onderzoeken of script kennis (kennis over de volgorde van gebeurtenissen) invloed heeft op de vorming van pseudoherinneringen bij kinderen. Kinderen werden geconfronteerd met een fictieve gebeurtenis waar ze kennis over hadden (vastzitten met je vingers in een muizenval) of een fictieve gebeurtenis waarover hun kennis beperkt was (darmspoeling krijgen). Tevens ontving de helft van de kinderen extra informatie over de gebeurtenissen. De resultaten toonden aan dat tijdens beide interviews, pseudoherinneringen vaker voorkwamen voor de gebeurtenis waarover de kinderen kennis hadden dan voor de gebeurtenis waarover ze nauwelijks iets wisten. Bovendien hinderde de extra informatie de ontwikkeling van beelden naar pseudoherinneringen van kinderen bij het eerste interview. Deze bevindingen suggereren dat het hebben van kennis de vatbaarheid voor het ontwikkelen van pseudoherinneringen vergroot.

Hoofdstuk 5 beschrijft een studie die onderzocht welke rol valentie speelt in de ontwikkeling van pseudoherinneringen bij kinderen. In deze studie luisterden 7-jarigen naar twee ware en een onwaar verhaal. De onware verhalen beschreven een neutrale (naar een andere klas verhuizen) en een negatieve (beschuldigd worden van afkijken) gebeurtenis. Ook kreeg de helft van de kinderen de klassenfoto gepresenteerd tijdens de interviews. Tijdens beide interviews waren kinderen meer geneigd om de emotioneel negatieve gebeurtenis foutief te herinneren dan de neutrale gebeurtenis. Aangezien rechtszaken 
voornamelijk over negatieve gebeurtenissen gaan, zijn deze resultaten van bijzonder groot belang. Het presenteren van een klassenfoto had geen effect op de ontwikkeling van pseudoherinneringen.

Hoofdstuk 6 richt zich op het onderscheid tussen ware herinneringen en pseudoherinneringen van kinderen door gebruik te maken van de Reality Monitoring (RM) criteria. Transcripten van verklaringen van kinderen over ware en onware gebeurtenissen werden geanalyseerd met behulp van deze criteria. De RM criteria waren echter niet in staat om ware en onware herinneringen van kinderen van elkaar te onderscheiden. De resultaten impliceren daarom dat de RM methode inadequaat is om gebruikt te worden in rechtszaken waarin moet worden vastgesteld of verklaringen van kinderen verwijzen naar een authentieke of fictieve gebeurtenis.

In Hoofdstuk 7 wordt een studie besproken die de vatbaarheid van kinderen voor commissie en omissie fouten na herhaalde interviews onderzoekt. Kinderen werden geïnstrueerd om drie kledingstukken van een pop uit te doen. Hierna kregen ze vals bewijs dat ze vier kledingstukken of twee kledingstukken hadden uitgedaan. Tijdens drie interviews werden kinderen gevraagd welke kledingstukken ze hadden uitgedaan. Hoewel commissie fouten gemakkelijker uitgelokt konden worden dan omissie fouten, namen beide typen van fouten significant af na herhaalde interviews. Deze bevindingen illustreren het relatieve gemak waarmee omissie en commissie fouten uitgelokt kunnen worden.

Het laatste hoofdstuk geeft een samenvatting van de resultaten besproken in dit proefschrift en bespreekt de bovengenoemde bevindingen in het licht van recent onderzoek naar valse herinneringen. Verder staat dit hoofdstuk stil bij de implicaties voor de forensische praktijk en ideeën voor toekomstig onderzoek. 


\section{Dankwoord}

Alles wat je in je leven bereikt, komt mede door de hulp van anderen. Ook dit proefschrift heeft niet kunnen bestaan zonder de steun van verscheidene mensen. Deze verschillende bronnen van hulp hebben tot een eenheid geleid in dit proefschrift en daarom staat de Javaanse spreuk bhinneka tunggal ika (eenheid in verscheidenheid) centraal in dit dankwoord.

Allereerst wil ik Harald en Ingrid, mijn promotor en co-promotor, bedanken. Harald, jij bent een bron van inspiratie en ik bewonder de grote hoeveelheid kennis die jij beschikt over de vakliteratuur. Jouw kritische blik heeft mij veel geholpen tijdens mijn promotie. Ingrid, ik kon mij geen betere begeleiding wensen. Jij stond/staat altijd voor mij klaar en hebt mij op inhoudelijk vlak ontzettend veel geleerd. Ik wil je vooral bedanken voor de manier hoe jij mij hebt laten kijken naar de wetenschap. Jij liet mij terecht zien dat er ook belangrijkere zaken zijn dan wetenschap. Deze zienswijze zal ik nooit vergeten. Bedankt!

Mijn (ex)-collega's van de Forensic Psychology sectie: bedankt voor alle hulp die jullie mij hebben gegeven, bedankt voor alle leuke koffie-uurtjes die we hebben gehad en ook bedankt voor de leuke bijnaampjes die ik van jullie heb gekregen. Bedankt: Beatrijs, Bruno, Corine, David, Elke, Ewout, Hugo, Jill, Kim, Lieke, Linsey, Maartje, Manuela, Maarten, Marko, Robert, Saskia en Timo

Mijn kamergenootjes Saskia en Elke: wat een leuke tijd hebben wij altijd op onze kamer. We kunnen praten over de wetenschap, maar ook over zoveel zaken daarbuiten. Bedankt voor alle lieve steun!

Dit proefschrift was zeker niet tot stand gekomen zonder de hulp van diverse scholen en talloze studenten. Dus bedankt: Jasper, Lisanne, Ris, Maya, Gwenda, Bart, Anne, Cigdem, Esma, Laura, Bart, Celine, Yoanne, Floor, Inger, Moos, Johanna, Stefan en alle andere studenten die betrokken zijn geweest bij mijn proefschrift.

Danny en Maarten, mijn paranimfen: Bedankt dat jullie aan mijn zijde wilden staan. Jullie steun heb ik zeer gewaardeerd. Danny, mijn beste teman, onze vriendschap betekent voor mij ontzettend veel. Terima kasih! Maarten, bedankt dat jij mijn proefschrift nog een keer helemaal hebt doorgespit.

Aisa en Leander: Bedankt voor jullie ontwerpen van de omslag!

Mijn saudara in de Pencak Silat: bedankt voor alle inspiratie die ik elke seconde 
krijg van jullie.

Mijn ouders, zus, schoonbroer, Inaya, en de rest van mijn familie en schoonfamilie: familie is heel belangrijk en ik bedank jullie voor alle steun die jullie mij altijd geven. Tot slot, Nathalie: ik heb zoveel respect voor het oneindige begrip dat jij hebt voor mij. Bedankt dat je mij altijd op zo'n lieve manier steunt. 


\section{Curriculum vitae}

Henry Otgaar was born in Maastricht on April $9^{\text {th }}$ 1983. He received his VWO degree from Jeanne d'Arc College in 2001. In 2001 he also started his study Psychology at Maastricht University and graduated in 2005. From 2006 to 2009, he was a PhD-student at the Faculty of Psychology and Neuroscience of Maastricht University. He currently holds a position as a post doctoral researcher at the same department. 


\section{List of publications}

\section{International journal articles}

Howe, M., Candel, I., Otgaar, H., Malone, C., \& Wimmer, M.C. (in revision). The role of valence in children's and adult's false memory illusions.

Otgaar, H., \& Candel, I. (in press). Children's false memories: Different false memory paradigms reveal different results. Psychology, Crime \& Law.

Otgaar, H., Meijer, E.H., Giesbrecht, G., Smeets, T., Candel, I., \& Merckelbach, H. (in revision). Children's suggestion-induced omission errors are not caused by memory erasure.

Otgaar, H. \& Candel, I., Memon, A., \& Almerigogna, J. (in press). Differentiating between children's true and false memories using Reality Monitoring criteria. Psychology, Crime \& Law.

Otgaar, H., Candel, I., \& Merckelbach, H. (2008). Children's false memories: Easier to elicit for a negative than for a neutral event. Acta Psychologica, 128, 350-354.

Otgaar, H., Candel, I., Merckelbach, H., \& Wade, K.A. (2009). Abducted by a UFO: Prevalence information affects young children's false memories for an implausible event. Applied Cognitive Psychology, 23, 115-125.

Otgaar, H., Candel, I., Scoboria, A., \& Merckelbach, H. (in press). Script knowledge enhances the development of children's false memories. Acta Psychologica

Otgaar, H., Candel, I., Smeets, T., \& Merckelbach, H. (in press). "You didn't take Lucy's skirt off": The effect of misleading information on omissions and commissions in children's memory reports. Legal \& Criminological Psychology.

Otgaar, H., \& Smeets, T. (submitted for publication). The fallacy of adaptive memory: Survival processing increases both true and false recall in adults and children

Otgaar, H., Smeets, T., \& van Bergen, S. (in press). Picturing survival memories: Enhanced memory after fitness-relevant processing occurs for verbal and visual stimuli. Memory \& Cognition

Smeets, T., Otgaar, H., Candel, I., \& Wolf, O.T. (2008). True or false? Memory is differentially affected by stress-induced cortisol elevations and sympathetic activity at consolidation and retrieval. Psychoneuroendocrinology, 33, 1378-1386.

\section{National journal articles}

Candel, I., \& Otgaar, H. (2008). De (on)mogelijkheden van de getuige-deskundige in zedenzaken. Expertise en Recht, 3, 83-86.

Otgaar, H.P., \& Candel, I. (2007). Kinderen en valse herinneringen: de rol van valentie. Kind en Adolescent, 28, 236-247. 


\section{Book contribution and various}

Otgaar, H. (2009). Not all false memory paradigms are appropriate in court. In L. Strömwall \& P.A. Granhag (Eds.), Memory: Reliability and personality (pp. 37-46). Göteborg: Göteborg University.

Otgaar, H. \& Candel, I. (2007). Herinneringen kleuters Heerle wellicht vals. Dagblad De Limburger.

De Ruiter, C. \& Otgaar, H. (2009). Zo onderzoek je geen zedenzaken. NRC Handelsblad.

\section{Conference presentations}

Otgaar, H. \& Candel, I. (2007) Abducted by a UFO: The effect of prevalence information on children's false memories for an implausible event. The $7^{\text {th }}$ International Conference, The Society of Applied Research in Memory and Cognition, July-25-29, Lewiston, Maine.

Otgaar, H., Candel, I., Scoboria, A., \& Merckelbach, H. (2008). Script knowledge affects the development of children's false memories. The 18th International Conference, The European Association of Psychology and Law, July 2-5, Maastricht, The Netherlands.

Otgaar, H., Candel, I., Memon, A., \& Almerigogna, J. (2009). Differentiating between children's true and false memories using reality Monitoring criteria. Society for Research in Child Development, April 2-4, Denver, CO.

Otgaar, H., Candel, I., Smeets, T., \& Merckelbach, H. (2009). Erasing children's memory. Society for Research in Child Development, April 2-4, Denver, CO.

Otgaar, H., Meijer, E.H., Giesbrecht, G., Smeets, T., Candel, I., \& Merckelbach, H. (2009). Erasing children's memories: A reaction time analysis of children's suggestion-induced omission errors. The $8^{\text {th }}$ International Conference, The Society of Applied Research in Memory and Cognition, July-25-30, Kyoto, Japan. 